\title{
BREAKING THE CULTURE OF SILENCE IN CHECKMATING HIV/AIDS AS A TEACHER-RESEARCHER
}

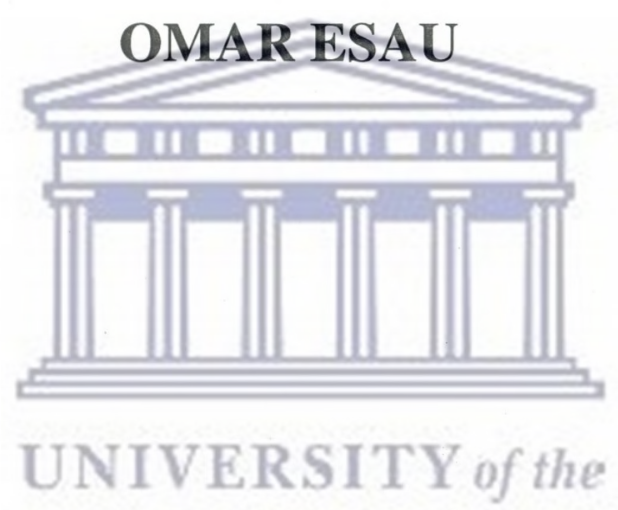

Submitted in fulfilment of the requirements for the Degree of Doctor of Philosophy, Faculty of Education, University of the Western Cape, Bellville.

SUPERVISOR: PROFESSOR D.A. MEERKOTTER

NOVEMBER

2007 


\section{ACKNOWLEDGEMENTS}

I wish to express my sincere thanks to the following people:

My dearest mother who constantly encouraged me to keep on working.

My family, especially Yoemna and Mishka, who gave me "time-off" and provided invaluable assistance and supported me throughout this research process.

Prof Dirk Meerkotter, my promoter, who offered much time and guidance in a kind and patient manner, constructive criticism and encouragement throughout the writing of this thesis.

The Principal, Staff, Parents and Students of Muhammadeyah Primary School for their support and innumerable contributions. In particular, the students without whom this study would not have been possible.

The field workers; Aneesa Adams, Desiree Joseph, Ruwayda Jappie, Athon Willenberg and Rashaad Schroeder, who supported and assisted me with the gathering and capturing of the data.

My friends who have always encouraged me to keep on working.

The Western Cape Education Department for granting permission for the research to be conducted.

The University of the Western Cape, especially the Education Faculty, the Postgraduate Enrolment and Throughout Project (PET) and the Librarians for their support and assistance.

The financial assistance of the National Research Foundation (NRF) of South Africa towards this research is hereby acknowledged. Opinions expressed and conclusions arrived at, are those of the author and are not necessarily to be attributed to the National Research Foundation of South Africa. 


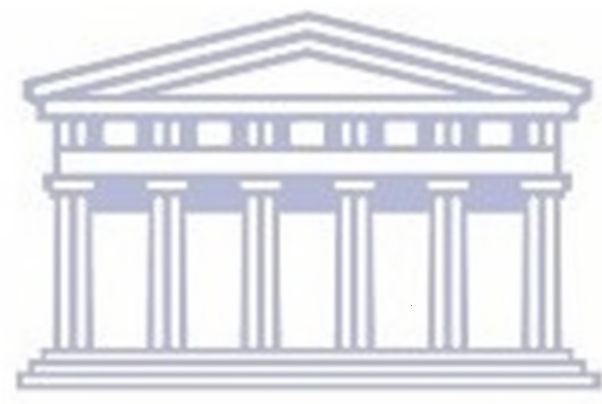

UNIVERSITY of the

WESTERN CAPE

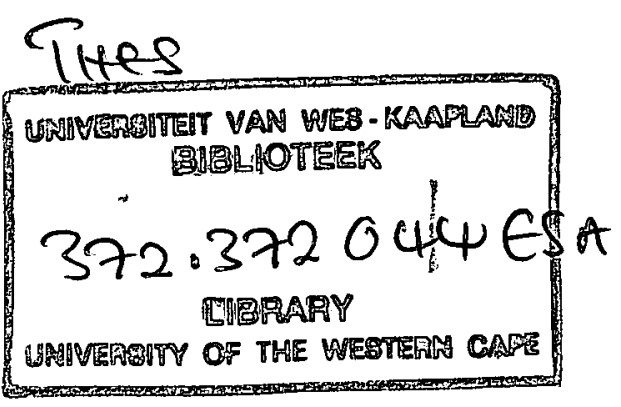




\section{DECLARATION}

I declare that Breaking the Culture of Silence in Checkmating HIV/AIDS as a

Teacher-Researcher is my own work that has not been submitted before for any degree or examination in any other university, and that all the sources I have used or quoted have been indicated and acknowledged by complete references.

Full Name: Omar Esau

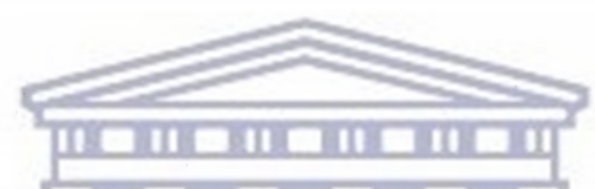

Date: November 2007

Signed:
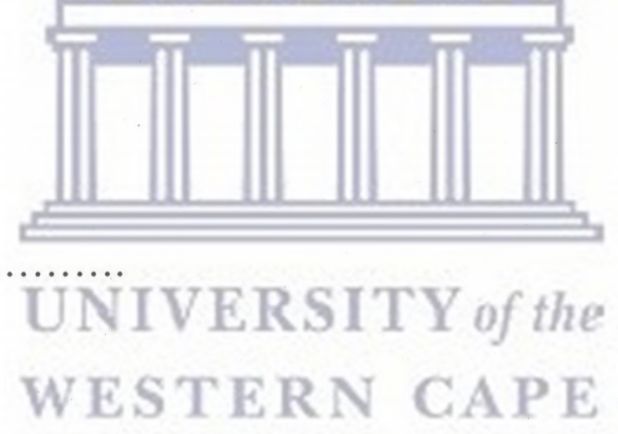


\section{ABSTRACT}

\section{Breaking the Culture of Silence in Checkmating HIV/AIDS as a Teacher- Researcher}

This study is about the author, a primary school teacher, who as a teacher-researcher wanted to improve the awareness of HIV/AIDS that has become a major challenge globally and has been on the increase over the past two-and-a-half decades, especially so, in sub-Saharan Africa. This is in spite of an "overflow" of HIV/AIDS information. The thesis documents two action research projects. Both of them are based on an emancipatory action research methodology.

It has long been recognised that the HIV/AIDS pandemic requires more than medical attention and that the way in which teachers deal with HIV/AIDS education, especially at primary school level, becomes critical. A fundamental assumption of this study is that teachers play a eritical role and are often the main adults, other than family members, with whom young people interact on a daily basis. Teachers can and must play a vital role in the development of valuable behavioural guidelines about reproductive health amongst the youth. This study views teachers, and more so primary school teachers, as important role players in the struggle to come to terms with HIV/AIDS.

In reflecting about the HIV/AIDS pandemic, I realised that my classroom practice was characterised by a "culture of silence" when it came to discussing sex and matters concerning sexuality. The study sets out to enhance behavioural change in the way learners think about sex and sexuality and includes a continuous process of selfreflection, self-awareness, planning and appropriate action. 
In Chapter One, I have tried to locate what I would regard as the problem in my teaching. I became increasingly convinced that my classroom practices might well be contributing to a lack of interweaving HIV/AIDS education into curriculum activity, while at the same time, promoting a "culture of silence" when it comes to issues of sex and sexuality. I arrived at this particular point as a result of reflectively looking at my own teaching career, as well as my own historical and schooling background which I felt has impacted on the way I teach. In this chapter I also give a brief historical background of the school where I teach and where I conducted my research. Towards the end of the chapter, I emphasise that teachers, including myself, need to redefine their role so as to empower students by creating the opportunity for their "voices" to be heard. I also explain concepts used in this written account such as "culture of silence" and "transformative intellectuals".
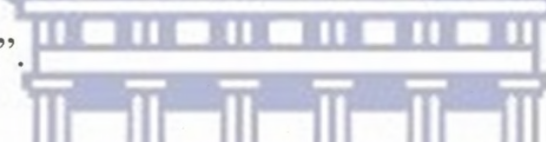

In Chapter Two, I address the HIV and AIDS pandemic debate in more detail. I look at the impact of HIV/AIDS on education and how the implementation of an outcomes based curriculum (C2005) takes up the HIV/AIDS challenge. In addition to this, I attempt to unpack the Western Cape Education Department's plans and policy concerning HIV/AIDS, after which I focus on breaking the HIV/AIDS "culture of silence". Before I conclude the chapter, I critically engage with the idea of the teacher as a researcher and critical change agent in an HIV/AIDS challenged society.

In Chapter Three I provide a brief historical background of the development of action research. I point out how Lewin (1948) and Stenhouse's (1975) idea of action research was later taken up further and given a more critical perspective by writers such as Elliott (1985), Hopkins (1985), Walker (1985), Carr \& Kemmis (1986), Grundy (1987), Winter (1989), McKernan (2000), Meerkotter (2002) and McNiff \& Whitehead (2006). I start 
with the defining (with due regard for the pitfalls of definitions) of action research and then focus on the nature and practices of an emancipatory action research approach. In this chapter I also elaborate on the reasons why I have decided on emancipatory action research as the main approach for this investigation.

Chapter Four focuses on my first action research project where I set out to hear my students" "voice". And to contribute to the development of their voice to empower them with regard to sex and sexuality issues, a voice reflecting their increasing understanding of the seriousness of the HIV/AIDS pandemic and most of all a “critical voice" as purported by Freire $(1972 ; 1980)$, Giroux $(1988 ; 1991)$ and McLaren (1991; 2006).

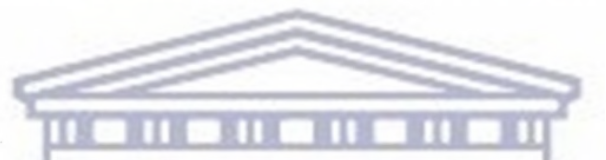

My second action research project "Checkmating HIV/AIDS", which is described in detail in Chapter Five, is a continuation of the first action research project where I tried to break down the "culture of silence" concerning HIV/AIDS and sex and sexuality in my classroom. On reflecting about the first project, I realized that awareness alone was not going to be enough to take up the HIV/AIDS prevention challenge. Infusing awareness with action was my next step, and sport, being a rallying point on our country's Transformation and Nation Building agenda became the ideal educational tool for this process. For successful prevention, individuals must be able to make decisions to protect themselves. In the second project I focus specifically on one code of sport, namely chess. In this second project, I set out to discuss the potential of using this code of sport to take up the HIV/AIDS challenge. 
Chapter Six is the concluding chapter. The question posed is: Can we ever win the battle against HIV/AIDS? Is it possible to change the way we think about sex and matters concerning sexuality? Thereafter the concept of change is interrogated and "clarified" in the context of my study. This is followed by looking at the two projects, and I specifically focus on whether these projects had been liberatory or transformative. I then address the issue concerning teachers as "transformative intellectuals" and teacher researchers and conclude by proposing emancipatory action research as a "vehicle" for change.

Too often the response to the pandemic produces plans that list endless interventions. I strongly recommend that further research relating to the role of sport in education, with specific reference to HIV/AIDS, be prioritised. The argument being that sport, recreation and play are increasingly elements of development programmes around the world, contributing to the well-being, health and education of children and young people. If chess can contribute to checkmating HIV/AIDS and basketball to dunking HIV/AIDS then a big code such as soccer can definitely contribute to "dribbling" and "tackling" the HIV/AIDS pandemic. Especially, in view of the fact, that South Africa is hosting and showcasing the soccer world cup of 2010. 


\section{TABLE OF CONTENTS}

Acknowledgements

Declaration

ii

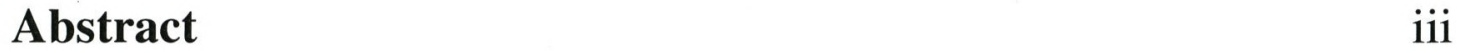

Table of Contents vii

$\begin{array}{ll}\text { Appendices } & \text { xiii }\end{array}$

Acronyms

$\begin{array}{ll}\text { Preamble } & \text { xvi }\end{array}$

\section{CHAPTER ONE}

Detecting the Problem

1.1 Introduction

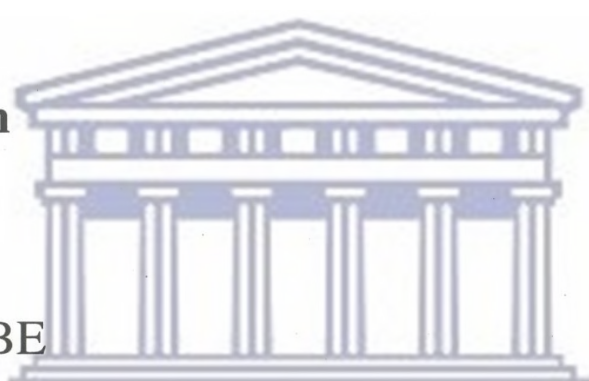

1.2 From CNE to $\mathrm{OBE}$

1.3 Aims of this Research IVERSITY of the

1.4 Rationale for the StudyS T ERN CAPE

1.5 Placing the Project in Context

1.6 Reasons For Engaging in Action Research 20

1.7 Unpacking Terminology 23

1.7.1 Culture of Silence 23

1.7.2 Adopting the Culture of Silence 26

1.7.3 Education and the Culture of Silence 28

1.7.4 The Culture of Silence in the Classroom 30

1.7.5 Resisting the Culture of Silence 32 
1.7.6 Breaking the Culture of Silence in the Classroom

1.7.7 Breaking the Culture of Silence about Sexuality and Aids

1.7.8 Transformative Intellectuals

1.8 Chapter Outline

\section{CHAPTER TWO}

\section{Addressing the HIV/AIDS Challenge}

2.1 Introduction

2.2 HIV/AIDS

2.3 The Impact of HIV/AIDS on Edueation

2.3.1 Supply and Quality

2.3.2 Aids Orphans

2.3.3 Young People at Risk IVERSITY of the

2.5 How does the implementation of C2005 meet the HIV/ AIDS Challenge?

2.6 The Western Cape Education Department's Plans and Policy Concerning HIV/AIDS

2.7 Breaking the HIV/AIDS Culture of Silence in the Classroom 62

2.7.1 Spiritual and /or Religious Constraints

2.7.2 Ambivalence of Culture 66

2.7.3 Demystifying Sex 68

2.8 The Teacher Researcher and Critical Theory 70 


\section{CHAPTER THREE}

\section{Towards An Emancipatory Action Research Approach}

3.1 Introduction

3.2 The Development of Action Research

3.3 What is Action Research?

3.4 Three Modes in which Action Research may be carried out 86

3.5 How then does Emancipatory Action Research operate? $\quad 89$

3.5.1 The Planning Stage (Phase One) 90

3.5.2 The Acting Stage (Phase Two) 92

3.5.3 The Observation Stage (Phase Three) m 93

3.5.4 The Reflecting Stage (Phase Four) $\square$

3.6 Why I Chose Action Research? 94

3.7 Resources Used In This ResearchITY of the 98

3.7.1 Literature Reviews ESTERN CAPE 98

3.7.2 Participant Observer 99

$\begin{array}{lll}3.7 .3 & \text { Interviews } & 99\end{array}$

3.7.4 Focus Groups 101

$\begin{array}{ll}\text { 3.7.5 Questionnaires } & 104\end{array}$

$\begin{array}{ll}3.7 .6 & \text { Field Notes } \\ & 104\end{array}$

$\begin{array}{lll} & \text { 3.7.7 Student Diaries } & 105\end{array}$

$\begin{array}{lll}3.7 .8 \text { Survey } & 105\end{array}$

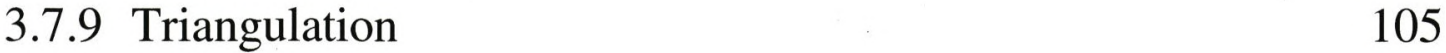




\section{CHAPTER FOUR}

My First Project: Taking up the HIV/AIDS Challenge

4.1 Becoming Aware

4.2 Taking up The Challenge

4.3 Deciding on My Topic

4.4 Constraints

$4.5 \quad$ Negotiations

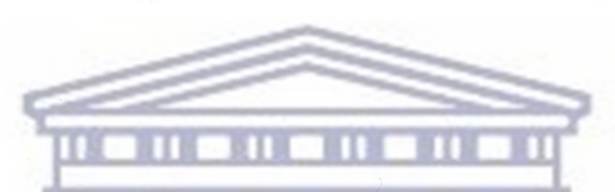

4.6 My Data Collection

4.6.1 Field Notes

4.6.2 Student Diaries UNIVERSITY of the

4.6.3 Interviews

4.6.4 Questionnaires

4.6.5 Triangulation

4.7 Planning My Classroom Action Research

4.8 Carrying Out My Plan

4.8.1 Activity One

4.8.2 Activity Two

4.8.3 Activity Three 
4.9 Reflecting on My Project

\section{CHAPTER FIVE}

\section{My Second Project: Checkmating HIV/AIDS}

5.1 Theory in Action - "Getting the Nation to Play!"

5.2 Establishing a Case for Classroom Chess

5.3 Integrating Sport as a Strategy to Prevent HIV/AIDS

5.4 Towards a Second Action Research Project

$5.5 \quad$ Negotiations

5.6 Collecting of Data

5.6.1 Field Notes

5.6.2 Student Diaries WESTERN CAPE

5.6.3 Interviews

5.6.4 Focus Group Activity

5.6.5 Questionnaires

5.7 Planning for Project Two 150

5.8 Carrying out My Plan

5.8.1 Activity One: Linking Chess Play with LO and HIV/AIDS 
5.8.3 Activity Three: Consolidation and Strengthening of Playing Skills

5.8.4 Activity Four: Each One, Teach One

5.8.5 Activity Five: Demonstration Game \& Simultaneous

5.8.6 Activity Six: Graduation Day

5.9 Reflecting on Project Two

\section{CHAPTER SIX}

\section{Conclusion}

6.1 Reflecting on Work Accomplished 175

6.2 From Classroom Practice to Community Interaction 177

6.3 Emancipatory Action and Understanding Change 178

6.4 Further Research 183

6.5 Concluding Remarks! WESTERN CAPE 


\section{Appendices}

Appendix 1

Approval letter from the Governing body to do Research at School

Appendix 2

Application letter to do the Research Project at School

Appendix 3

Conditional letter from the Head of Education

Appendix 4

Approval letter from the Department of Education to do the Research Project at School

Appendix 5

Survey Questionnaire of Grade 6 Learners: Muhammadeyah Primary School: February 2005.

Appendix 6

Unstructured Interview Concerning HIV/AIDS

Appendix 7

HIV and AIDS Education

Appendix 8

Project: Checkmating HIV/AIDS! 
Appendix 9

HIV/AIDS Action Plan For Muhammadeyah Primary

Appendix 10

223

Written Consent of Participants who participated in the Project

Appendix 11

224

Unstructured Interview - Checkmating HIV/AIDS

Appendix 12

Muhammadeyah Primary School's HIV/AIDS Policy

Appendix 13

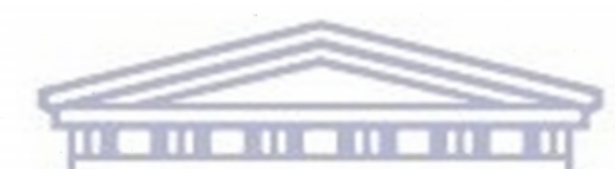

Newspaper Clippings \& Photos of Checkmating HIV/AIDS Project

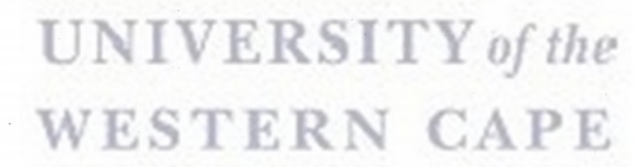




\section{Acronyms}

$\begin{array}{ll}\text { AIDS } & \text { Acquired Immune Deficiency Syndrome } \\ \text { ANC } & \text { African National Congress } \\ \text { ART } & \text { Antiretroviral Therapy } \\ \text { CNE } & \text { Christian National Education } \\ \text { COSATU } & \text { Congress of South African Trade Unions } \\ \text { C2005 } & \text { Curriculum 2005 } \\ \text { DA } & \text { Democratic Alliance } \\ \text { DoE } & \text { Department of Education } \\ \text { DoH } & \text { Department of Health } \\ \text { DoSD } & \text { Department of Social Development } \\ \text { DP } & \text { Democratic Party } \\ \text { DSR } & \text { Department of Sport and Recreation } \\ \text { DTI } & \text { Department of Trade and Industry } \\ \text { EFA } & \text { Education For All } \\ \text { ECD } & \text { Early Childhood Development } \\ \text { EU } & \text { European Union } \\ \text { FET } & \text { Further Education and Training } \\ \text { GDP } & \text { Gross Domestic Product } \\ \text { GNP } & \text { Gross National Product } \\ \text { GEAR } & \text { Growth, Employment and Redistribution } \\ \text { GET } & \text { General Education and Training } \\ \text { GNU } & \text { Government of National Unity } \\ \text { HAART } & \text { Highly Active Anti-Retroviral Therapy } \\ \text { HIV } & \text { Human Immunodeficiency Virus }{ }^{\circ} \\ \text { HSRC } & \text { Human Sciences Research Council P E } \\ \text { NP } & \text { National Party } \\ \text { NQF } & \text { National Qualifications Framework } \\ \text { OBE } & \text { Outcomes Based Education } \\ \text { PAC } & \text { Pan African Congress } \\ \text { PEI } & \text { President's Education Initiative } \\ \text { RDP } & \text { Reconstruction and Development Programme } \\ \text { RNCS } & \text { Revised National Curriculum Statement } \\ \text { SADC } & \text { Southern African Development Community } \\ \text { SADTU } & \text { South African Democratic Teacher's Union } \\ \text { SAHRC } & \text { South African Human Rights Commission } \\ \text { SAQA } & \text { South African Qualifications Authority } \\ \text { SETA } & \text { Sectoral Education and Training Authorities } \\ \text { TAC } & \text { Treatment Action Campaign } \\ \text { UNAIDS } & \text { United Nations Programme on HIV/AIDS } \\ \text { UNDP } & \text { United Nations Development Programme } \\ \text { UNICEF } & \text { United Nations Children's Fund } \\ & \end{array}$




\section{Preamble}

This thesis is the articulation of my living educational theory as a teacher-researcher, which evolved through undertaking research in the area of HIV/AIDS education and sport. It is a narrative account in which I offer descriptions of and explanations for my practice, as I continue to transform my educational contexts into a celebration for new forms of practice in the area of HIV/AIDS education with possible implications for policy formation.

In all research, the aim is to make an original contribution to knowledge in a specific field, and to demonstrate the capacity for criticalengagement. My claim to knowledge has to do with how I used spert as an educational tool to mitigate the impact of the HIV/AIDS pandemic, and that I have engaged critically in my own learning as a teacher-researcher, and with the literatures that has contributed to that learning.

\section{UNIVERSITY of the}

If the claim to knowledge is to be taken seriously, it has to be shown to be legitimate and that my claims are based on appropriate forms of evidence, thus representing more than a personal opinion. By establishing the validity of my claims, I also hope to feel better qualified to address the possible significance of my research. I believe that my research is significant in terms of demonstrating the potential of new forms of practice, as well as new forms of theory. I explain these issues below.

I begin with my evidence base. 


\section{The evidence base of my claims to knowledge}

My practice encompasses a range of contexts and participants. I have worked with children, teachers, parents and other stakeholders in education. Most importantly, I have worked with myself. I am claiming that I have included all participants in my research, in relation to developing new insights and new practices. I have contributed to their education, in the sense that I have enabled others, including myself, to become aware of their own capacity to think originally and to engage critically. I have learned to exercise that capacity for the transformation of their lives and circumstances, in terms of developing their agency to transform existing structures and norms into forms that can contribute to HIV/AIDS awareness, as well as their well-being. This is encapsulated in comments such as this from one of the students:

These chess pieces will always remind me to be sensitive towards AIDS patients. Whenever, I get myself involved with anything, I will first think, then analyse and then make my move (Chapter 5).

This comment is especially appropriate when it comes to producing evidence to test the validity of my claims that $\mathrm{f}$ have encouraged growth, and also encouraged others to see the potentials in their own capacity for encouraging their personal as well as the growth of others. I can point to the comprehensive evidence base of my research to show that this happened. I analyse this evidence base in terms of how I have contributed to education - my own education, the education of others, and the education of social formations. I then proceed to show how I have tested my claims, grounded in my evidence base, that I have made such contributions, in order to test the methodological rigour (Winter, 1989) of my research. By demonstrating this kind of methodological rigour, I hope to convince the reader that my research practices are legitimate, and that it, assisted me to generate a form of theory that enables me to engage in meaningful educational practices as a teacher-researcher. Below, I attempt 
to explain, how I have contributed to education, and how I have contributed to theory, and the potential significance thereof for both domains.

\section{How I have contributed to education}

In the following paragraphs I describe how, I have contributed to my own education, the education of others, and new forms of educational practice in the area of HIV/AIDS education, with potential transfer to other disciplines and educational situations, and with possible implications for policy development and implementation.

\section{Contributing to my own education}

I have contributed to my own education in the sense that I have learned from interrogating my practice, and through testing its validity against the critical feedback of others such as students, colleagues and parents.

My evidence base for these claims which I have contributed to my own education resides in personal documents, such as my field notes and my correspondence with my supervisor.

As recorded in Chapter 5, I wrote: "After some deep reflection and intense introspection of my own life and the things that formed and shaped my framework of thinking, I came up with the idea of teaching the students a game that made a difference in my life - chess."

Teaching my learners something I had a passion for, strengthened my confidence as a teacher, my own self-awareness and my self-esteem. Correspondence with my supervisor also reflected this growth. Following a long period of despondency and indecision in my research writing, the following note from my supervisor led me to 
believe that I was in fact learning, growing and doing 'good work'.

Impressive! Your research is highly relevant and original ... You have taken your classroom activity into the community to empower others...

Evidence of personal growth can also be found in my printed documents, such as this thesis and my Masters in Education dissertation and conference papers I delivered in 2006. My learning has been born out of the struggle of having to make sense of ongoing problematic situations from within. I am claiming here to have done that, and to know more about my situation and myself than I did before I began my formal research programme. My new learning is in the form of the realisation that I am a theorist who engages in practice and a practitioner who is able to theorise about my practice. As I generate my theory of practice, I am aware that it is embedded in an epistemology which continues to be drawn from my practice that locates learning in dialogical, holistic and inclusive ways of knowing.

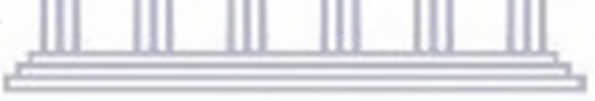

\section{Contributing to the education of othersR SITY of the}

I am claiming that I have contributed to the education of others through my research. The others in question are my students, my workplace colleagues, and parents.

\section{Contributing to the education of my students}

As a teacher with over twenty years experience, I have seen how 'uniform schools' and 'core curriculum' and an over-emphasis on basic linguistic and numeracy can close down learning opportunities for people. I began to try to create learning situations for my class, generally in the form of projects, such as 'Checkmating HIV/AIDS!', and frequently using technology to assist us, such that the children's 
different learning strengths and styles could be nurtured. I have contributed to the education of my students in the sense that they have not only learned to play chess, but to apply the lessons that they derived from the game in their daily lives. What they have experienced in their classroom interactions may well travel to how they treat the threats of social ills in other situations. One of the students remarked as follows:

Making the right move in your everyday life can have far reaching consequences. The nature of the game (chess) is a thinking game and in everyday life we need to think. If we want to prepare or take up any challenge in life be it AIDS or "TIK" then we need to sharpen our thinking skills (30 August 2006).

\section{Contributing to the education of colleagues}

I can also show that I have contributed to the education of workplace colleagues by referring to an extract of a speech made by my school principal at the assembly:

Encouraging deep and logical thinking about our actions are crucial for decision making. In our country where HIV/AIDS is a major threat we need to pull out all stops to take up the AIDS challenge. Checkmating HIV/AIDS is an interesting way to get learners to think. In order to make the right move in our liyes we need to think ... and playing chess does just that. Allow me to compliment Mr Esau and his team for bringing this innovative project to our school. Students must want to come to school and this project according to Mr Karbelkar and others, captured their attention ( $\mathrm{Mr}$ Ebrahim Ismail, principal of Muhammadeyah Primary, transcript of speech, 21 September 2006).

Amongst other colleagues that I claim to have influenced are Ms Aneesa Adams and

Mr Karbelkar-Pheiffer. Ms Aneesa Adams commented in her diary:

I went around the class to observe if the first group of learners actually knew what that they were doing and I must say I was very impressed with what I saw (31 August 2006).

Mr Karbelkar-Pheiffer commented:

I am very much impressed with the student coaches. Learners are enjoying themselves. I am thrilled with the enthusiasm (31 August 2006). 
I have demonstrated to my colleagues that learning could be both challenging and fun. Linking sport and education in the classroom could make education more relevant and exciting for the students. I believe I have also pioneered the use of peer tutoring which linked chess with HIV/AIDS.

I have many letters from colleagues, expressing their appreciation of what they have learned with me.

\section{Contributing to the education of parents}

In addition to have influenced the professional learning of colleagues, I believe that I have contributed to the education of parents. Importantly, the parents of children communicated to me that they had learned how to value their children and themselves more. There was more involvement and a greater interest shown by parents to have their children involved in playing chess. One parent who was connected to the local Rotary Club invited the President of the organisation to attend one of our classroom lessons. When the students left, I spoke to Ms Jackie James, President of the Wynberg Rotary Club "branch", who made the following comments:

We are interested in long term development of people and chess appears to be a sound investment. I would like you to present Checkmating HIV/AIDS at our next Rotary executive meeting that is held on Thursday evenings normally the first week of every month, at Constantia Nek (29 August 2006).

From the above visit it becomes obvious that my educational influence stretched much further than my classroom and the school. 


\section{Contributing to the education of the greater society}

My classroom project "Checkmating HIV/AIDS!" was also acknowledged by the poverty-stricken Vrygrond community as they tried to address the HIV/AIDS challenge. Nick Barnett from the Weekend Argus wrote the following:

Vrygrond Library last Saturday hosted its first chess tournament. As part of a community effort to encourage young people to advance their talents, Chess SA development officer Omar Esau coached the enthusiastic players and also taught them the rules of the game.... Chess WP is promoting chess as an activity under the slogan "Checkmating HIV/AIDS" in order to encourage young people to think about their next move both on and off the chessboard, and the consequences of making choices in life (2 December 2006).

A week later I was approached by Ms Ruth Saunders, the Cape Peninsula University of Technology sports administrator, to organise a similar project in the Langa community. In addition to this the Goodwood Prison's supervisor contacted me to facilitate the "Checkmating HIV/AIDS" project amongst the prisoners. At a meeting held with the Department of Sports and Recreation of the Western Cape, I was requested to organise a "Checkmating HIV/AIDS" workshop for August 2007 with 240 sport officials. This, I would like to believe, could serve as evidence that my small project that began in my classroom, had been more successful than I could, realistically, have imagined. Taking all of the above into consideration provides me with a feeling of hope that my action in the two action research projects had, after all, not been in vain and that it had already begun to have an impact beyond the walls of the classroom. In retrospect, I am reminded by Robinson (1993:5) that:

One small step for one teacher may indeed be one great leap for emancipatory practice, depending on how that small step is harnessed, supported and shared.

My research has demonstrated, what could happen when a teacher retains a sense of mission and commitment to education. Having built up a knowledge base, I believe 
that my research has much to contribute to new policy initiatives in the area of HIV/AIDS education. As a teacher-researcher within the South African context, I would argue that teachers should be recognised as lifelong researchers who can contribute to the well-being of society and the current policy framework for continuing professional teacher development. Teachers as researchers should be in the centre of policy debates about the continuing transformation of their profession and their society.

\section{The potential significance of my research}

Emancipatory action research, though not a magical cure for HIV/AIDS and for all the ills of education, can become a powerful force supporting the transformation of our society from defeatism to one of hope and possibility. My optimism comes from my personal experience. I have experienced the power of inquiry in my school and other schools where I have worked, with fellow educators and in my own classroom.

\section{UNIVERSITY of the}

This action research process has been an empowering experience. It has indeed been relevant to my students as well as to me at a personal level. Relevance is in this case almost guaranteed because the focus of each research project is determined by the researchers, who are also the primary consumers of the findings. Seeing students grow is probably the greatest joy educators could experience. I agree, with Sagor (2000), that, when teachers have convincing evidence that their work has made a real difference in their students' lives, the countless hours and endless efforts of teaching seem worthwhile. 
I also recommend that further research relating to sport and HIV/AIDS as prevention measures in South Africa to be undertaken. Currently, sport and the playing of sport, have been given much media coverage, which provides, an ideal opportunity for critical researchers to contribute meaningfully. I am, however, of the view that the sporting fraternity as much as the educational sector in the South African context need some form of intervention to become more active in the addressing of HIV/AIDS related challenges. Sport, which is highly technical and organised in accordance with strict rules, necessitates critical and reflective interventions to stimulate much needed creativity, so as to enhance alternatives that the sporting world can offer to humanity. If the Chess Federation in South Africa is checkmating HIV/AIDS and Basketball South Africa is dunking HIV/AIDS, then Bafana-Bafana and the South African Soccer Federation can most definitely 'tackle' the HIV/AIDS pandemic, more so, now that South Africa is hosting the FIFA 2010 soccer world cup.

Sport, wellness and HIV/AIDS education need to be woven into the curriculum throughout the educational system. In this hi-tech age of fast cars and fast foods, schools need to become centres for the enhancement of sport and wellness programmes that would cater for the student in her entirety. This holistic integration cannot be over-emphasised as the physical wellness condition as well as the creative and innovative mindset of the postmodern human being is currently being challenged to a larger extent by environmental and wellness matters than ever before.

HIV/AIDS will remain a problem for a long time to come. Addressing the "culture of silence" and the continuous "checking" of HIV/AIDS by teacher-researchers will be a phase that contemporary society will have to sustain to take on challenges such as the prevention of HIV infection in a meaningful way. In taking up the HIV/AIDS 
challenge, I believe that emancipatory action research does provide the teacher in the classroom with a viable option that she cannot afford to ignore. However small the intervention, it is essential to believe that one's ongoing intellectual engagement will ultimately make a difference and that today's response will have an impact on tomorrow's outcome.

This is an exciting time to be a teacher-researcher. I, and most probably other practitioners like me, know that the practical knowledge that we have gathered during our years of teaching and research is of critical importance to build and shape societies. I believe that my thesis is a practical contribution towards the vast pool of teacher knowledge. In addition I am invigorated by the idea that other practitioners might learn from my experiences and transform these in such a way that they become of use to them. This, investigation undoubtedly provided me the opportunity to describe my journey as a critical teacher with an emancipatory action research agenda. 


\section{CHAPTER ONE}

\section{DETECTING THE PROBLEM}

\subsection{INTRODUCTION}

Chapter One describes the contemporary education challenges in South Africa with specific reference to the HIV/AIDS pandemic. The rationale and basis for an investigation into a primary school classroom is explained and reasons for presenting the work within an action research paradigm are made clear. The chapter concludes with an explanation of certain key concepts used in this study.

The impact of HIV/AIDS remains a major health threat and continues to have a devastating impact on the socio-political and economic well-being of the global population. Nowhere has the impact been more devastating than in sub-Saharan Africa. During 2003 an estimated 2,2 million people died of AIDS in sub-Saharan Africa (UNAIDS, 2004). According to Holden (2004:5),

\section{UNIVERSITY of the}

...[m]ore than 90 percent of HIV-positive people live in developing nations, and sub-Saharan Africa alone is thought to account for about two thirds of the global total of cases. The worst affected region in the world, Southern Africa, is home to about two per cent of the world's population - but thirty per cent of all the people in the world who are living with HIV/AIDS live in Southern Africa.

It is clear that the response to HIV/AIDS cannot be sectoral but should be multisectoral. Despite the growing volumes of South African literature on the biomedical aspects of HIV/AIDS, it appears that little is known about the meaning, impact and consequences of the pandemic on the education system. In researching HIV/AIDS education it is clear that the study of sex and sexuality issues becomes integral to comprehend the spreading of HIV/AIDS. This research is a critical inquiry into my 
own practice as a teacher. In reflecting on my own teaching practice, I realised that my classroom practice was characterised by passivity and a lack of participation by the students when it came to discussing topics with regard to sex and sexuality. In fact, I was contributing to what Freire (1972:10) terms the "culture of silence". (Towards the end of Chapter One I provide an account of my understanding of the concept, "culture of silence":) In promoting HIV/AIDS education, I wanted to break this silence. I wanted to "give" my students a "voice". Sexuality education and awareness of HIV/AIDS are thus integral parts of the focus of this project. My research intends to serve both as an intervention concerning HIV/AIDS and sexuality education in a particular setting.

According to Wolfensohn, president of the World Bank $(2000: \mathrm{xv})$, IICI II II

AIDS is turning back the clock on development. In too many countries the gains in life expectancy won are being wiped out. In too many countries more teachers are dying each week than can be trained. We will mainstream AIDS in all World Bank work.

In South Africa where teachers face the constraints of implementing a revised outcomes-based education curriculum the challenges facing HIV/AIDS education have become more complex. The Department of Education in its Strategic Plan against HIV/AIDS (2002b:3) advocates its first strategic goal as “... dealing urgently and purposefully with the HIV/AIDS pandemic by utilizing the education and training system." The immediate challenge that confronted the strategic plan of the department was whether teachers were adequately prepared and trained in Curriculum 2005 and HIV/AIDS education in particular to address the challenge on hand. It was found that educators needed more in-service training to deal with life skills education, and that many of the trained educators had resigned or were redeployed and had to be replaced (Vally, 2001:50). 


\subsection{FROM CNE TO OBE}

When Sibusiso Bhengu became Minister of Education in 1994, he inherited a complex and an outdated system of education which was based on the previous government's apartheid policies. High levels of adult illiteracy, dysfunctional schools and universities, discredited curricula and illegitimate structures of governance were the most immediate challenges. The school curriculum was seen as reinforcing racial injustice and inequality and its transformation a necessity for the promotion of "unity and the common citizenship and destiny of all South Africans irrespective of race, class, gender or ethnic background" (ANC, 1994:68).

Prior to 1994, the South African education system was organised along racial lines based on the Christian National Education (CNE) ideology of no mixing of languages, cultures, religions and races. It was within this context of CNE policy that Fundamental Pedagogics emerged.According to many, Fundamental Pedagogics was an instrument to justify the Soüth African Government's position regarding apartheid and education. In the words of Enslin (1984:146),

Fundamental Pedagogics is an ideology rather than a science, because the practice of Fundamental Pedagogics is determined by the interests which it serves.

Post 1994 saw the implementation of Curriculum 2005 based on an outcomes-based education approach. Curriculum 2005 has its roots and precedents in the struggles of social movements around education and curriculum in the pre-apartheid period, but it is also a 'mutation' of those struggles born in a context of social compromise (Motala \& Vally, 2002:180; see also Cross, Mngadi \& Rouhani, 2002). Negotiations between the then Apartheid Government and civil society in the National Education and 
Training Forum in 1993 was followed by a process of curriculum "cleansing" immediately after Bhengu took office. According to Chisholm (2003:268), when C2005 was introduced in 1997, it was premised on three critical elements: the introduction of eight new learning areas suffused with values of democracy, nonracialism and non-sexism; outcomes-based education $(\mathrm{OBE})$ and the provision of a foundation in general education up to and including the $9^{\text {th }}$ Grade (see Kraak, 2002; Hindle, 1996 on 1994/95 curriculum revision processes; Seleti, 1997).

Outcomes-based education as a philosophy has been differently interpreted by different writers in the context of the unfolding debate over outcomes-based education. There are few educationists in South-Africa who have not taken a stance either for or against outcomes-based education. Writers such as Mohamed (1998), Malcolm (1999) and Odora-Hoppers (2002) have defended OBE, while others such as Kraak (2001) have been moderately critical, and yet others such as Jansen (1997; 1998; 1999, 2001a and 2001b), Jansen \& Christie (1999), Muller (1998; n.d., circa 2001), Muller \& Taylor (1995) and Unterhalter (1998b) have questioned its foundations.

The critical and developmental outcomes provide the "symbolic glue" holding together the different versions and revisions of C2005 (see DoE, 2002a). The critical outcomes envisage learners who will be able to:

- Identify and solve problems and make decisions based on critical and creative thinking.

- Work effectively with others as members of a team, group, organisation and community.

- Organise and manage themselves and their activities responsibly and 
effectively.

- Collect, analyse, organise and critically evaluate information.

- Communicate effectively using visual, symbolic and/or language skills in various modes.

- Use science and technology effectively and critically showing responsibility towards the environment and the health of others.

- Demonstrate an understanding of the world as a set of related systems by recognising that problem-solving contexts do not exist in isolation.

The developmental outcomes envisage learners who are able to:

- Reflect on and explore a variety of strategies to learn more effectively.

- Participate as responsible citizens in the life of local, national and global communities.

- Be culturally and aesthetically sensitive across a range of social contexts.

- Explore education and career opportunities.

- Develop entrepreneurial opportunities.

These critical and developmental outcomes mentioned above formed the basis for the further development of specific outcomes for each phase and learning area in C2005. These came to be known as the 66 specific outcomes. It was intended that teachers would use these outcomes to organise learning and resources in such a way that the emphasis would fall on the process of learning. Teachers would facilitate learning according to the pace and interests of each learner. Learners' participation in classroom processes rather than passive absorption and memorisation of predetermined 'facts' became a driving force behind the new approach. 
The structure and organisation of the curriculum became increasingly determined by the introduction of features which would allow integration across learning areas. The emphasis now fell less on subject content and values and more on the use of curriculum design tools such as 'phase organisers', 'programme organisers', 'range statements', 'performance indicators', 'expected levels of performance' and 'assessment criteria' (Chisholm, 2003). From early on, critics raised questions about this dimension of the curriculum for being unnecessarily complex and jargonised (Greenstein, 1998; Jansen, 1999).

The principles on which C2005 was based represented a dramatic departure from those which underpinned apartheid education. They included commitments to humanresource development, learner-centredness, relevance, integration, differentiation, redress and learner support, nation-building and hon-discrimination, creative and critical thinking, flexibility, progression, credibility and quality assurance (cited in Lubisi, Wedekind, Parker \& Gultig, 1997). Around these a degree of synergy and common purpose began to be built.

The assumptions about teachers and classrooms as well as the conception of curriculum design that informed the new model rapidly began to create difficulties. At the same time as critics such as Jansen found their critical views on "why OBE will fail" taken up with remarkable speed across the country, evidence was beginning to emerge that not only schools and teachers, but also informed commentators such as those in Education Policy Units, were struggling with the appropriateness and complex terminology involved in mastering the new curriculum (Greenstein, 1998; Jansen, 1999). A complex new terminology - the design tools for a curriculum which essentially left the content of curriculum design and development to teachers - began 
to be associated with, and to characterise the new curriculum. Teachers also experienced difficulties in operationalising new modes of assessment and this even became evident at the school where I teach.

In 1999, three things happened which were to have a decisive effect on the curriculum: the first was the appointment of Professor Kader Asmal as Minister of Education, the second was the connection made between South Africa's poor learner achievements and school curricula and the third was increasing Department-based evidence that implementation was not going as planned (Chisholm, 2003:274).

In his 'Call to Action' on 27 July 1999, Asmal gave OBE a specific content. He said:

We recognise the damage done over the decades by an approach to education that was essentially authoritarian and allowed little or no room for the development of critical capacity or the power of independent thought and inquiry. OBE is an approach that embraces the capacity of learners to think for themselves, to learn from the environment, and respond to wise guidance by teachers who value creativity and self-motivated learning (Asmal, 1999).

But he also distanced himself as a follower of the version of $\mathrm{OBE}$, which had become practice:

The Department resists over-zealous attempts from any quarter to convert OBE into a new orthodoxy with scriptural authority. There will be no mystification of an approach to learning and teaching that is essentially liberatory and creative (Asmal, 1999).

At the same time as this shift was occurring in official thinking, research findings were mounting that South Africa's learner achievement remained exceptionally poor despite curriculum changes. Research conducted in schools for the President's Education Initiative (PEI), under the auspices of the DoE, was widely publicised. The message of the PEI Report (Taylor \& Vinjevold, 1999) was that C2005 was not improving the capacity for learner achievement, but further damaging it. 
Research conducted both within the DoE and by academics in different parts of the country was also showing that policy, the curriculum framework, and aspects of implementation were facing severe difficulties (see Fleisch, 2002; Jansen, 1999; Khumalo, Papo, Mabitla \& Jansen, 1999; Marnewieck \& Spreen, 1999; Proudfoot Consulting, 1999; Vinjevold \& Roberts, 1999).

A Sunday Times (2001) spot survey of 20 well-functioning schools in all nine provinces found that teachers all had common problems. These include:

- Training done too late or too early;

- Training conducted like a "crash course" over three to five days;

- Trainers sometimes not knowing enough to give practical examples or demonstrate outcomes-based lessons; 10 m 10 m

- Teachers having nowhere to go if they have questions;

- Teachers not knowing how to assess pupils' progress;

- Schools receiving textbooks tate, receiving too few of them or receiving none at all; and

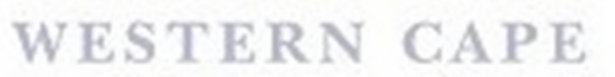

- Major practical problems like dealing with group work in classes of up to 60 pupils.

After considerable deliberation with the DoE, the Minister appointed a committee to review C2005 in February 2000. Between October 2000 and October 2002, ministerial Project Committees were established to revise the curriculum for Grades R-9 and then, when this was completed in April 2002, to design a curriculum for Grades 10-12. A study team was also established to make recommendations on the implementation of the National Qualifications Framework (NQF). The NQF provided the basis for the vision of a core national curriculum which would integrate academic 
and vocational skills (Chisholm, 2003). Forged in the 1990-1994 period by business and Cosatu, and taken up by the ANC, the new curriculum took legislative force through the National Education Policy Act (No 27 of 1996). The Review Committee proposed the introduction of a Revised National Curriculum Statement for Grades R-9 that would be implemented in 2004 and for Grades 10-12 in 2006.

The goals and values of education, as manifested in C2005 and the Revised National Curriculum Statement, have changed dramatically within the space of fewer than ten years. As a consolidated, simplified and strengthened version of C2005, the Revised National Curriculum Statement, for better or worse, represents democratic South Africa's first national curriculum for schools. It is a product of history and the myriad struggles at multiple levels that have shaped South African education and curriculum (Chisholm, 2003:285).

It is within this educational context that teachers find themselves with the additional challenge of the HIV/AIDS pandemic. It is within this social context that this study finds its place.

\subsection{THE AIMS OF THIS RESEARCH}
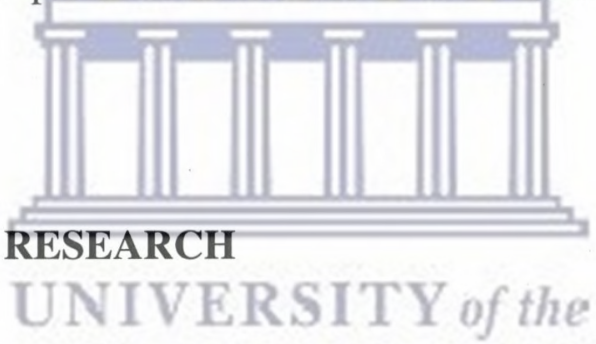

A fundamental assumption of this study is that teachersplay a critical role and are often the main adults, other than family members, with whom young people interact on a daily basis. Teachers can and must play a vital role in providing valuable behavioural guidelines about reproductive health to the youth. This study views teachers and more so primary school teachers as important role players in the struggle to come to terms with HIV and AIDS and to deal meaningfully with the effect that the disease has on the lives of infected as well as affected in schools specifically, and in the South African society, generally.

This study also sets out to enhance behavioural change through the way learners think about sex and sexuality. There appears to be a "culture of silence" when it comes to 
talking about sex and sexuality in our classrooms. For this behavioural change to take place continuous processes of self-reflection, self-awareness, planning and appropriate action are essential. This action research study therefore also aims to investigate how a meaningful HIV/AIDS education plan and action could develop the necessary behavioural changes to take place amongst grade 7 learners.

This study also aims to promote a cross-curricular approach to HIV/AIDS education in schools. HIV/AIDS education does not stop in the Life Orientation lessons but needs to be more comprehensive and integrated. To come to terms with the HIV/AIDS pandemic schools might have to incorporate learning activities about HIV/AIDS into other learning areas such as Mathematics, Social Science, Language Studies, Art and School-Based Extra-Mural activities. In this study, I attempt to assess the way in which the new Revised National Curriculum (RNCS), with its outcomesbased approach, complements HIV/AIDS education in the South African primary school.

\section{UNIVERSITY of the

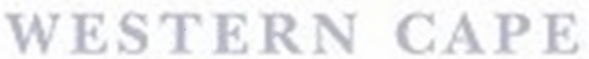

This study, in addition, sets out to promote sport in school as a "vehicle" to take up the HIV/AIDS challenge. Whilst I utilise the playing of chess as an educational tool to raise the awareness of the learners with regard to HIV/AIDS in this thesis, I remain optimistic that other codes of sport such as soccer, swimming and tennis, would generate creative ways to make communities aware of the HIV/AIDS pandemic and too change behaviour amongst learners to lessen the risk of becoming infected. 


\subsection{RATIONALE FOR THE STUDY}

The slogan witnessed on the T-shirts of AIDS activist and Treatment Action Campaign (TAC) leader Zackie Achmat and others, namely "I AM HIV POSITIVE" is applicable to all members of the South African society. Even though they might not all be infected by the HIV virus, all are affected. I have been a primary school teacher for the past twenty years and strongly contend that addressing the HIV/AIDS pandemic should be high on the agenda of all teachers as they interact with young people on a daily basis. In August 2003 I attended a South African Teachers Union (SADTU) provincial workshop at Salt River Community House in Cape Town where a visiting lecturer from Wits University, Salim Vally, addressed the audience on the impact of globalisation on education. During the tea break at about $11 \mathrm{am}$ that Saturday morning I quickly attended a TAC meeting that was held in the adjoining hall. The meeting was tense and the spokesperson, Mr Zinzele had a tone of urgency in his voice. While we were actively engaged in debating the future of our lives as educators in a "global village", our comrades next doof were literally debating their "funerals". Towards the end of November 2003 when I Pttended another TAC follow up meeting I was informed that the chairperson of the August 2003 meeting had passed on because of AIDS. This reality had a definite impact on the way I started to think about HIV/AIDS.

My involvement with HIV/AIDS was enhanced when I became part of an HIV/AIDS research team at the University of the Western Cape. Initially I wanted to research "the effects of outcomes based education and curriculum change in the New South Africa", but the impact of the HIV and AIDS pandemic on the future of our lives in sub-Saharan Africa encouraged me to research HIV/AIDS related issues in the education sector. In my MEd. mini-thesis, which I completed in 1994, I addressed the 
culture of silence prevalent in my classroom practice in order to enable my learners to act against the Apartheid regime and dictatorial educational practices in school. Now, a decade later in a post apartheid scenario we are faced with yet another challenge. This time round we need to empower our learners against the onslaught of the HIV/AIDS pandemic. With teachers facing the constraints of implementing outcomes-based education, the challenges facing teachers with regard to the disastrous effect of HIV/AIDS on schools and their communities have become increasingly complex. As an action researcher I was entering an educational journey of discovery and as a grade 7 classroom teacher, I felt well placed to depict, in a qualitative way, the impact of the implementation of outcomes-based education in our school and the ways the curriculum was addressing the HIV/AIDS challenge.

At a HIV/AIDS conference that I attended in Cape Town, the Second African Conference on Social Aspects of HIV/AIDS Research (9-12 May 2004), one of the outcomes of the conference was to encourage qualitative research into the effects of HIV/AIDS in schools. I believe teachers have the opportunity to research their classroom practice and can contribute to the much needed qualitative research in education. As a primary school teacher-researcher I set out to examine the taken-forgranted assumptions about primary school education and the constraints under which classroom practice proceeds. Sharing viewpoints and responses with my grade 7 coeducators went a long way in also strengthening the educators' response concerning the HIV/AIDS pandemic (see Chapter Four p.113). 
It has long been recognised that HIV/AIDS is a disease that requires more than just medical care (Arendse, 2002), and the way teachers deal with HIV/AIDS education especially at primary school level, therefore becomes critical. This study provided me with more insight and gave me a better understanding of the way primary school learners, educators and parents perceived the HIV/AIDS pandemic. I believe primary schools are amongst the first sites of defence as children remain the most vulnerable group in any given community. Research (loveLife, 2002) indicates that in order to prevent the spread of HIV/AIDS it is crucial to reach children before they become sexually active. Prevention of HIV/AIDS is fundamentally dependent on sexual behaviour, which is influenced by the environment in which teenagers find themselves, and the lifestyle choices they make. The best hope of curtailing the pandemic is to have a meaningful primary school program and this could be motivated in the fact that approximately $40 \%$ of South Africans are under 15 years of age (loveLife, 2002). The increasing incidence of sexual abuse also stresses the urgency to work with children from a veryyoung age.

\section{WESTERN CAPE}

In my view primary school teachers have the "space" to engage with learners more holistically as they are not as affected by public certification and the way in which this certification influences the practices and understandings of secondary school teaching and learning. The "primary" in primary education signifies the primary introduction to the cultural tools of society. In other words, primary school teachers are often in the role of significant other in the process of the internalization of the tools of society, particularly the psychological tool of language (Vygotsky, 1978). Primary school educators are the carriers of the social knowledge that is the basis of the schooling process. At the primary level of internalization, where children are 
encountering for the first time a new element in their social world, they are in a dependent relationship to the significant other (teacher). A teacher who reflects on this process and its outcomes can contribute most fruitfully to our understanding of how people come to know. An intention of this study, then, is to locate a meaning of teaching and learning such that it contributes to a developing theory of cognition. At the same time this 'new' understanding will seek to contribute to a developing theory and practice of pedagogy, that is, a critical pedagogy.

In reflecting about my own teaching practice, I realised that whenever I spoke about sex and sexuality in my classroom there appeared to be a lack of response and active participation by the students. I seemed to be-doing all the talking and it appeared to me that the students were schooled in a tradition, which views any talking about sex and sexuality issues, as a taboo. This type of classroom practice where the "voices" of the students were virtually absent was in fact contributing to what Freire, as far back as in 1972 termed the "culture of silence". In my attempts to "give" the students a "voice" I wanted to break this silence. How then could I possibly go about "giving" the students a "voice" to talk about sex and matters concerning sexuality?

In order to make my pedagogical activity more liberatory and participatory it became important that I tried to understand the context of my workplace. This, I believed, would assist me in understanding the school and the students much better. It therefore became necessary for me to delve into the history of the school where I taught at and planned to do my research. It is for this reason that I saw the need to go into the historical background of the school. 


\subsection{PLACING THE PROJECT IN CONTEXT}

Muhammadeyah is a primary school under the jurisdiction of the Western Cape Education Department and it is located in the Wynberg residential area in the Southern Suburbs of Cape Town. The school initially started out as a Muslim missionary school in 1929 and is now a public school in line with the rules and regulations of the South African Schools Act (1996). The reasons for the establishment of this primary school are clearly outlined by the school's former principal, Rashaad Jedaar (1992:1):

Muhammadeyah was born out of a need in the Muslim community at the Cape, and Wynberg in particular, for a school with an educational curriculum that would provide its children with the traditional "religious" education in addition to the tools to participate actively and creatively in the socio-economic life of the country. An education that would inculcate the values of Istam.

The school opened its doors for the first time in 1929 with an enrolment of eleven pupils ranging from pre-school to standard three. Amongst the first pupils was the eldest son of the first principal, Mogamat Saleh Berdien, Abduraquieb Berdien (20/08/1998) who had the followìing to say:

I attended this school in 1930 when I was 7 years old. At that time there were only 5 classrooms from Sub A to Std 3 and all classes were Afrikaans. I was also involved in a protest against Apartheid at Constantia station which is now Wittebome Station. In $1933 \mathrm{Mr}$ Saleh Berdien discovered that about 70 boys were not circumsized and called on Mr. Amien Majiet (Blaakers) to do the circumsitions. After the circumsitions, he transported the boys home by horse and cart.

During my interview with Mr Abduraquieb Berdien it became obvious that the school was absolutely involved in the activities and the tradition of its immediate community. The first principal, Mogamat Saleh Berdien, had to struggle to maintain departmental standards in his two roomed school. He was faced from the outset with 
an educational dilemma. This is emphasised by Jedaar (1992: 4):

Since the inception of the school, the first principal was torn between two ideological pressures: departmental demand for cognitive skills and the community's Culturo-Religious needs. In virtually every school report he was reprimanded for his bias towards Arabic and reminded of his academic function as principal.

Mogamat Saleh Berdien took ill in 1943 and handed over the reins to his successor, Ishmael Solomon.

Under the leadership of the new principal, Ishmael Solomon (1943-1979), the school underwent tremendous growth. He found himself in a multiplicity of roles: of teacher, of caretaker, builder and social worker. As a young committed teacher he had the stamina and the motivation to undertake the task with such vigour, that in his very first inspection report (July, 1946) the inspector commented thus: "the new principal devotes himself whole-heartedly to the culture-religious interests of the school."

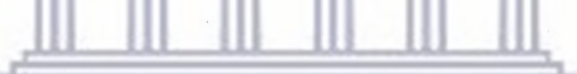

According to Mrs Ayesha Hendricks, who attended the school from 1965 to 1972, Mr Solomon was a very strict but fair principal. He used the cane as a form of corporal punishment on a regular basis. According to Widaad Kenny's Grandmother (10/10/1998), they went to school barefeet and received free soup, cod liver oil as well as jam and bread. They had to write on a black slate board. By 1979, the enrolment had reached 600 and the school was upgraded to a P1 (a large primary) school. At the end of that year, and coinciding with the school's $50^{\text {th }}$ anniversary, $\mathrm{Mr}$ Ishmael Solomon retired and handed over the principalship to his deputy, Mr Rashard Jedaar.

Mr. Rashard Jedaar (1980-1994) took up the task as principal with much zeal and enthusiasm and consolidated much of the ambitions of his predecessors. The school's 
roll increased to the 800 mark and more classrooms were built out of necessity. In his quest for efficiency he became the first principal to employ a full time secretary at the school. He introduced the school to the "computer age". He encouraged all his teachers to become computer literate and to further their studies in all facets of education. It would also be worthwhile to mention that it was under his guidance and supervision that the school undertook an educational tour (Umrah) to the holy cities of Mecca and Medina in Saudi Arabia in 1988. Mr Rashard Jedaar retired in 1994 and handed the responsibilities of the school to the new principal Mr Sedick Gamiet.

Mr Sedick Gamiet (1994-1996) was the head of the school for a short period until December 1996. During his short reign he established the Muhammadeyah Preschool that is presently housed at the Vigilance Centre in Bega Road in Wynberg. He also initiated the building of the Salaah (prayer) hall and improved the school grounds by demolishing the old toilets and replacing them with new ones. It was during his career as principal that we witnessed the South African education sector undergoing UNIVERSITY of the tremendous change. On paper the Apartheid era was drawing to a close and this led to large scale retrechments in Government sectors. Muhammadeyah was forced to decrease the roll of its staff and also lost the services of its principal who retired.

The new principal who took up his post in January 1997 is Mr Ebrahim Ismail and he continues to head the school today. He is also an ex-pupil of Muhammadeyah (Sub A in 1959) and has already proven over the years to be a hardworking and dedicated teacher.

In 1997, with an enrolment of 866 pupils, 26 classrooms and a staff of 28 , Muhammadeyah was amongst the biggest state-aided Muslim schools in the Western 
Cape. This staff establishment was short lived as the school felt the pinch of the Government's retrenchment and redeployment policy in education. Being essentially a Muslim Mission School, it has great support amongst the Muslim community in both its immediate area as well as the surrounding suburbs. The school enjoys a long lineage of family ties going as far back as 1929 when it was established.

A major shortcoming of this school, however, is the lack of space and the continuous need for funds. The school has no sport fields, assembly hall or change room facilities available for learners during physical education periods and classes are crowded with an average of 40 learners per class. This physical set-up at our school was not to deter the new principal who took up the cudgels almost immediately. In 1999 we witnessed Muhammadeyah Primary undertake another educational journey to Mecca, Medina, Jerusalem and Egypt under the auspices of Mr Ebrahim Ismail. This Umrah (visit to Mecca and Medina) trip once again reinforced the community spirit within the school. This community spirit also made fundraising easier than at other previously disadvantaged schools. The office block was revamped with a new hi-tech telephone and inter-com system. The old library was customized and upgraded to a new secretarial and reception room. The year 2000 also saw Muhammadeyah acquiring its own computer lab. This room with all its latest technological computer equipment assisted with the much needed computer literacy skills for the school.

The school, which was initially Afrikaans-medium, has now been changed into an English-medium school. As a Muslim school, it offers a third language Arabic and Islamic Studies in its curriculum. Presently, the school is in great demand and if this is going to be the trend for the future then this school needs to upgrade its existing facilities. Recently the Governing Body purchased the house adjacent to the school in 
its quest to acquire more land. Although the school has a Muslim base, it attracts learners from other cultural backgrounds as well. Given the support it gets from the community, there appears to be a need for community schools like Muhammadeyah in South Africa.

This is an historical overview of the school where I teach and where I planned and undertook my research as teacher-researcher.

Amongst the challenges the school faced was the HIV/AIDS pandemic. This was further highlighted at a staff development meeting held on 16 September 2004. According to the principal Mr Ebrahim Ismail, "The impact of HIV/AIDS on society shall most definitely sooner rather than later affect our education system and our school and our immediate community. The drafting of an HIV/AIDS policy and strategy for the school becomes an essential document."

Whilst HIV/AIDS was identified amongst the challenges that our school was facing, I believed and was strongly convinced that other schools were experiencing similar and even more complex challenges from the pandemic. My intention was to address the HIV/AIDS challenge at the school and to improve and change the way we take up the issues of sex and sexuality. As the school was essentially a Muslim based school I was also cautioned by Fataar (2003: 23),

Sex education can be regarded as a hard marker in these (Muslim) schools as it is 'over determined' by a position that advocates sex within marriage. Sex is only referred to in the context of marriage. Speaking about condoms is taboo as it is perceived as implying sexual license and permissiveness. 


\subsection{REASONS FOR ENGAGING IN ACTION RESEARCH}

As an action researcher and a grade 7 teacher in a particular context I was convinced that my project concerning HIV/AIDS could assist and serve as some contribution towards the contemporary challenges the school faced, and that it would also be a definite interactive learning process for the learners, educators, parents and me. According to McKernan (2000:5),

Action research is a reflective process whereby in a given problem area, where one wishes to improve practice or personal understanding, inquiry is carried out by the practitioner - first, to clearly define the problem; secondly, to specify a plan of action - including the testing of hypotheses by application of action to the problem. Evaluation is then undertaken to monitor and establish the effectiveness of the action taken. Finally, participants reflect upon, explain developments, and communicate these results to the community of action researchers.

Thus action research is a systematic self-reflective scientific inquiry by practitioners to improve practice. This method of research suited my requirements. As a teacher wanting to reflect critically about the HIV/AIDS crisis I felt almost compelled to engage in a research process whereby $\mathrm{I}$ could understand/and therefore change my own teaching practice.

This gives me, as a teacher, responsibility for the research process and requires me to understand the process as a teacher-researcher. As a teacher-researcher, I need to investigate my own practice to extend my personal understanding of my practice through systematic selfreflection to extend my professional base (Walker, 1988:150).

Effecting behavioural change is a distinct and much more complex task than effecting physical change. Behavioural change requires a strategic pathway. The question here is, Is it possible for action research projects to contribute to behavioural change? According to the literature on critical theory and the critical theoretical approach to action research, it is. In fact, according to Kemmis \& McTaggart (1982), Carr \& 
Kemmis (1986) and McNiff (2006), who draw on Habermas (1972), behavioural change is amongst the main purposes of action research.

Some of my reasons for getting involved with action research have already been expressed and details of action research as a methodology will be discussed in Chapter Three. I am in pursuit of personal practical knowledge as opposed to "scientific" single knowledge in the traditional sense. Through action research I hope to heighten my awareness and improve my understanding of my practice in the educational situation as a consequence of observation and reflection (Beattie, 1989:8).

In my research process I was motivated to move-away from what Davids (1990:34) calls a classroom practice characterised by a product-orientedness towards a process-oriented approach which has, at its roots, a democratic teacher-pupil interaction mode of classroom practice. This |"process-oriented" approach to classroom practice becomes meaningful once teachers question "the what" and "the how" of teaching instead of just accepting and then depositing pre-packaged curriculum content into the memories of students. I feel strongly that emancipatory action research offers that much needed democratic vigour to assist teachers in their daily practices. McNiff (1988:5-6) notes:

Action Research is not just teaching. It is being aware and critical of that teaching, and using this self-critical awareness to be open to a process of change and improvement of practice. It encourages teachers to become adventurous and critical in their thinking, to develop theories and rationales for their practice, and to give reasoned justification for their public claims to professional knowledge. It is this systematic inquiry made public which distinguishes the activity as research. 
It was precisely because I needed to be self-critical and self-reflective of my teaching practice that I chose to engage in action research. According to McNiff (2002:5), selfreflection is a major component in action research:

The idea of self-reflection is central. In traditional forms of research empirical research - researchers do research on other people. In action research, researchers do research on themselves. Empirical researchers enquire into other people's lives. Action researchers enquire into their own. Action research is an enquiry conducted by the self into the self .

In being self-critical and self-reflective, I might possibly move beyond reliance upon the development and refinement of traditional practice and improve or change my teaching practice in such a way that it opens up the possibility for democratic teacherstudent interaction. This view is also held by Grundy (1987: 191) when she says,

The exciting implication which action research has for teachers is that of opening up the possibility for practitioners to exercise a greater degree of autonomy and responsibility with regard to their own work experiences for the students with whom they work.

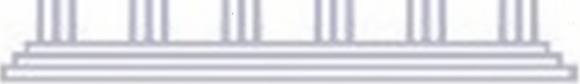

I am aware that action research is a continuous process and that it can provide teachers with a powerful tool to improve their classroom practice as well as possibly affect changes in the wider society. If I take account of the constraints placed upon teachers within the present schooling system it becomes difficult to assess the potential action research can have in transforming the oppressive material conditions in which most South Africans live. I would, however, agree with Walker (1989:62) that to "dismiss action research would be to dismiss the contribution which teachers can make towards the shaping of a pedagogy which creates the space for democratic and reflective classroom practices". 


\subsection{UNPACKING TERMINOLOGY}

While the way in which I use the pedagogical terminology in this thesis is explained in some detail in the next chapter, I thought that it might be helpful to the reader if I provided some clarification of the two main educational concepts, before proceeding. The two concepts which I focus on below, are, the "culture of silence" in South African classrooms and my understanding thereof, and second, the notion of teachers as researchers and "transformative intellectuals".

\subsubsection{Culture of Silence}

A key development in postmodern/ poststructuratist and feminist research has been the introduction of issues of silencing and voice into research on schools and schooling (McLaren 2006; McNiff 2002; 2006; 2007). Globalisation, a feature of the postmodern era, in its many manifestations including a "culture of silence" has presented challenges and opportunities for activists working for social change (Fisher 2000; Fullan 2001; $2003 ; 2005)$.

\section{UNIVERSITY of the}

Freire and Shor (1987:123) describe the phrase "culture of silence" as "passive tolerance of domination". According to McLaren (1989:171) the term culture signifies the particular ways in which a social group lives and makes sense of its "given" circumstances and conditions of life. Once a social group is curbed and prevented from expressing its dreams, desires and that which makes sense to them, it could then be assumed that it is caught up in a "culture of silence". This is also expounded in the works of Paulo Freire, as pointed out by McLaren (1989:195) who states that,

Freire's theories grow out of a "culture of silence", where people are victimised and submerged in "semi-intransitiveness", they ... engaged in a struggle against oppressive and dehumanising structures." 
The "culture of silence" can be described as having several dimensions. These dimensions, which include passivity and aggression, are reflected in the classroom, according to Freire and Shor (1987:122). Below, I briefly focus on the way students express these dimensions of the "culture of silence" in the classroom. In fact, allow me to reflect on my own schooling experience.

I recall many students sitting passively in the classroom waiting for the teacher to give them instructions. During my primary school years I had been exposed to a significant number of teachers who mostly emphasised rote learning and memorisation. Our poetry lessons were boring as our teacher talked continuously and we were non-participants in those teacher dominated lessons.

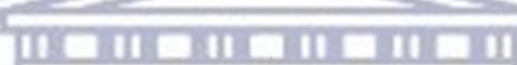

Another dimension of the "culture of silence" prevalent in the classroom is aggression. According to Freire and Shor (1987:122) this aggression on the part of the students seems "inevitable":

Aggression is inevitable because passivity is not a natural condition of childhood or adulthood. There is a 'symbolic/violence' in school and society which imposes silence on students. It is symbolic because it is in the very order of things... an environment of rules, curriculum, tests, punishments, requirements, correction, remediation, and standard English, which establish the authorities as the ones in charge. This environment is symbolically violent because it is based in manipulation and subordination. The student(s) often use aggression to resist the authoritarian teacher and the school.

Another form of aggression which I became accustomed to at school was the physical beatings that the teachers employed. As students we sometimes became victims of an aggressive teacher who made considerable use of corporal punishment. When teachers are not able to control their students by keeping them obedient, they make use of force 
(corporal punishment), and this is paralleled by the State's use of force (repressive state apparatus) when its hegemony breaks down (Althusser, 1972:226).

Being a product of the South African apartheid society and its strict authoritarian schooling system, I think, I still bear the scars of the "culture of silence". I sometimes fall foul of being an authoritarian teacher, who is not much different than the teachers who taught me when I was at school. I certainly support the notion that teachers' own experiences as pupils at school tend to influence their teaching practices. This is also strengthened by Walker (1989:15) who states:

...teacher behaviour is learnt during one's own school days and that this school experience is more significant than pre-service training in shaping how one teaches.

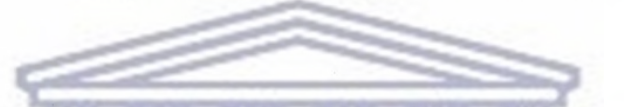

By not allowing my students to be creative and innovative enough in my classroom practice I have muted, to some extent, the "voices" of my students and have become nothing more than an authoritarian and transmission teacher. This, as I have mentioned earlier, worried me as I became more concerned about the way, I was teaching. I had to question the process, whereby I was silencing the "voices" of the students, by reflecting and attempting to change my teaching practice.

In my attempt to address the "culture of silence" in my classroom, I was partially motivated by the words expressed by McLaren (1989:235) when he reflected on his teaching career. He says: "My teaching would have been more effective if I had been able to engage in a critical analysis of these aspects of everyday life that resonated with and affirmed the dreams, desires, and histories of the students."

I suggest, with Freire (1972; 1982), Giroux (1981; 1988; 1992), Wieder (2003) and McNiff $(2006 ; 2007)$, that we must take the experiences and voices of students 
themselves as a starting point. We must confirm and legitimate the knowledge and experiences through which students give meaning to their everyday lives.

\subsubsection{Adopting the Culture of Silence}

The impact of the "culture of silence" on the indigenous people is aptly described by Da Costa (1994:ix):

The marginalisation of the colonised people within the socio-political systems imposed upon them has been one of the most destructive weapons of control to have been used by the European countries in most parts of the colonial and semi-colonial worlds during the last few centuries. Such marginalisation has involved far more than simply excluding the colonised peoples from the major decision-making processes in the countries concerned, or pushing them aside to the margins of society. There has been another devastating aspect, and that has been the silencing of the voices of the colonised. The significance of their contribution to world civitisation and the course of history has been largely ignored and substantially reduced. $\mathrm{m}$ m

It seems that the idea of a "culture of silence" had its roots in the colonization of the so called "Third World" countries by the European colonial powers. This relationship becomes more complex as the colonised country becomes a more advanced one. Freire UNIVERSITY of the

(1972:11), as far back as 1972, being exposed to the reality of oppression, came to realize that, their (the oppressed) ignorance and lethargy were the direct product of the whole situation of economic, social, and political domination - and of the - paternalism of which they were victims. Rather than being encouraged and equipped to know and respond to the concrete realities of their world, they were kept "submerged" in a situation in which such critical awareness and response were practically impossible. And it became clear to him that the whole educational system was one of the major instruments for the maintenance of this culture of silence

From the above extract from Freire's "Pedogogy of the Oppressed", it would appear that the "culture of silence" acts on the dominated classes and is used by the ruling class to 
ensure the pacification of the oppressed masses. The "culture of silence" involves the cultural subjugation of the indigenous society. This might perhaps lead to them rejecting their own view of reality and the acceptance of the view of the metropolitan society.

The indigenous society, according to Fataar (1992:28), is thus

... forced to discard its own world view at the expense of internalising the 'new' world view. The 'new' world view involves accepting the dominant economic, social and political institutions, the values and traditions of the colonial power.

This uncritical, unreflective and almost blind acceptance of the dominant view of reality is one of the most striking features of the "culture of silence". The oppressed now wants to imitate, copy and aspire to become like the oppressor. Compliance with the dominant view of society is a basic feature of the "culture of silence" and is rooted in the perception of the oppressed of what it is to be human. One of Freire's claims (Behardien, 1989:17), "...is that the success of colonisation of the Third World can be traced to the successful imposition of the culture of silence on the colonial society."

\section{UNIVERSITY of the}

It appears that a "culture of/silence" pervades not only colonial societies but also metropolitan societies. It would be safe to say that in many countries and given societies we find oppressors and oppressed, dominators and dominated. This is what I gathered from the words of Freire (1972:14) who states:

... our advanced technological society is rapidly making objects of most of us and subtly programming us into conformity to the logic of its system. To the degree that this happens, we are also becoming submerged in a new culture of silence.

This viewpoint is further elaborated on by Jonathan (2001: 29):

For the process of schooling reform is compromised whilst the scapegoating of schools for social and political ills makes them targets for policy fashions inappropriately designed to remedy extra-educational problems. And social as well as schooling reform is frustrated while each citizen looks to education for escape from their condition rather than for 
its transformation, delegating to private educational effort what can only be effectively achieved through open political negotiation.

\subsubsection{Education and the Culture of Silence}

Central to the development of a "culture of silence" is the field of education. This point is emphasised by Da Costa \& Meerkotter (1994:18):

The cultural colonization of the African, Asian, Afro-Asian and Latin American peoples has been most devastating and glaring in the field of education. Thus the content of education from the primary school to the tertiary level is geared to develop in their recipients the perception that middle class Euro-American cultural norms are the only valid and worthwhile ones.

It therefore becomes clear that education is amongst the major instruments for the maintenance of the "culture of silence". Education as we have witnessed in the history of politics in South Africa, is also the major instrument in breaking down the "culture of silence". The dominant class attempts to use education to reproduce the attitudes, values and skills necessary for the subjugation of the dominafed.lesouth Africa is a good example of how a state attempted to make use of the education system in order to produce obedient, docile and compliant students who would later become industrious and servile workers, who, in turn, would internalise and accept their oppression as natural, normal and inevitable.

The implementation of Bantu Education in 1953 was a scheme to entrench a "culture of silence" amongst the indigenous population of South Africa. There was no attempt to disguise the fact that Bantu Education was purposely intended to prepare the African child to fit into an inferior, subordinate role in South African society. Maseko (1993:12) 
states:

The Bantu Education Act of 1953 began the formal politicisation of black education, replacing the country's 4500 African mission schools with a system designed to exclude the black population from the mainstream of political, social and economic life.

Today, as we move into a new era in the history of South Africa, the notorious words of the former prime minister, Hendrik Verwoerd (1954:col 3586) have not been forgotten. He said,

I just want to remind honorary members that if the Native in South Africa today in any kind of school in existence is being taught to expect that he will live his adult life under a policy of equal rights, he is making a big mistake.

Verwoerd (1953:3576) also said quite explicitly that Bantu education would teach Africans from childhood that equality with Europeans is not for them. I want to agree with Manie (1992:3) when he says:

... Bantu education, coupled, of course, with a high level of political repression, was fairly successful in enabling the State, for a while at least, to establish an educational system which provided Capital with the labour requirements (sufficient numbers of unskilled and semi-skilled workers) to sustain the great boom of the 1960s. ... In order to ensure the hegemony of the Statè, teachers at "African"A schools played a very important role by "socialising politically" the vast numbers of "African" students.

Often without being aware of it, some teachers became instruments of the state, resulting in them unwittingly producing the kind of compliant, docile labour force needed to sustain the "culture of silence". This of course, does not happen without it being contested.

Today there are major changes in the state of South Africa's schools, but there are also deep continuities with the past. Education by its very nature is slow to change and it is so embedded in the tensions, stresses and strains of the society itself that there is a 
continuous contradiction between its intentions and outcomes. According to Chisholm (2005: 203):

It is no accident that the poorest provinces with the poorest schools are those that incorporate former homelands: the current state of schools in these provinces is closely intertwined with the twists and turns of a history more than two centuries old.

\subsubsection{The Culture of Silence in the Classroom}

It is usually behind close doors, in their classrooms that teachers either impose or resist the "culture of silence". By using authoritarian teaching methods, the teacher continues marginalising the voice of the oppressed thus inextricably sustaining the culture of silence. Freire (1972:61) refers to these teachers as "bank-clerk teachers who do not realize that they are serving only to dehumanize."

Freire (1972:59) describes the "banking method" as follows:

(a) the teacher teaches and the students are taught;

(b) the teacher knows everything and the students know nothing;

(c) the teacher thinks and the students are thought about;

(d) the teacher talks and the students listen - meekly;

(e) the teacher disciplines and the students are disciplined;

(f) the teacher chooses and enforces his (sic) choice, and the students comply;

(g) the teacher acts and the students have the illusion of acting through the action of the teacher;

(h) the teacher chooses the program content, and the students (who were not consulted) adapt to it.

(i) the teacher confuses the authority of knowledge with his own professional authority, which he sets in opposition to the freedom of the students; 
(j) the teacher is the subject of the learning process while the pupils are mere objects.

It appears as if Freire is oversimplifying a very complicated relationship in the classroom. However, for the purposes of clarity as to what the "banking method" is all about and how the system of schooling can impose a "culture of silence", I want to accept Freire's "banking method" concept for the purposes of this thesis. Later in my study when I discuss my projects, I refer to the "banking method".

I would like to conclude that the system of schooling is sometimes built on the undemocratic principles of unilateral decision-making, denying consultation with students and rejecting community involvement. This denial that others might also have legitimate educational contributions to make, arises from political dominance by a few and the belief in the notion of expert knowledge, which is based on the idea that education must be left in the hands of educationists who are the ultimate arbiters in deciding what is good for the people to know. Such beliefs make possible the WESTERN CAPE

maintenance of undemocratic practices, unequal social relations, and facilitate social engineering. Thus, could it be that the teacher using authoritarian teaching practices together with the mystification of knowledge in his or her classroom forms an integral part of the State's plan to create a dependent and docile society? Even if the State's plan might have changed over the last ten years, the challenges facing teacher development remain the same. The State's plan as I have already mentioned has, however, constantly been contested and resisted. 


\subsubsection{Resisting the Culture of Silence}

For the state to sustain its "culture of silence" it has to make use of anti-dialogical action and hegemony. McLaren (1989:173) describes hegemony as follows: "Hegemony is a struggle in which the powerful wins the consent of those who are oppressed, with the oppressed unknowingly participating in their own oppression”.

However, the process of imposing this "culture of silence" is not without flaws and was not always passively received. This is also pointed out by Aronowitz \& Giroux (1987:148):

As important as this position is on the relationship among power, culture and schooling, it also suffers from some serious theoretical flaws, the most important of which is its failure to address how oppositional culture gets produced rather than merely reproduced. Moreover, underlying this one-sided treatment of culture is the false notion that students are merely passive in the face of oppressive school practices.

In South Africa the idea of pacifying and oppressing students was in fact continually resisted. We only have to look at student turmoils of 1976,1980 and 1985 to see how the education system particularly in South Africa has been rejected. I therefore, believe that the "culture of silence" is not all that pervasive, that absolute, that capable of curbing independent thought. The oppressed do have specific ways of articulating the world even more so as the intensity of domination increases. For masses to resist the "culture of silence" Freire (1972:167) suggests the theory of dialogical action and its characteristics which includes co-operation, unity, organization and cultural synthesis. In encouraging dialogue as an alternative, Freire (1972:168) states:

Dialogue does not impose, does not manipulate, does not domesticate, does not "sloganize". This does not mean, however, that the theory of dialogical action leads no where, nor does it mean that the dialogical man (sic) does not have a clear idea of what he wants or of the objectives to which he is committed. 
Freire refers to the dialogical approach as the essential aspect in his methodology of "liberation education" (1972:67). Dialogue becomes the crucial factor precisely because it rejects that reality must be a pre-interpreted domain. Interpretation and understanding emerge from discussion, from debates and from critiques about the way people see their society. Thus, education becomes a creative process in which the learners and the educators re-examine their society and themselves. There are many teachers who claim that they are progressive in the struggle for liberation and chant all the freedom slogans at mass meetings and gatherings, but behind closed doors, in their classrooms they tend to keep dialogue at a minimum. This viewpoint is also expressed by Meerkotter

Towards the end of 1991, however, it was accepted (by the National Education Co-ordinating Committee) that it was not simply at the level of education governance that change was required, but that oppression in the classroom also needed to be addressed. Many activist teachers realised that democratic rhetoric emanating from political platforms would not automatically result in the transformation of authoritarian schools. Some politically conscious teachers, for example, were often autocratic in their own classrooms.

\section{UNIVERSITY of the}

Thus it appears that our authoritarian ways at our schools leave most of our students "voiceless" and in the process the "culture of silence" is perpetuated. We can therefore ask ourselves, can this "culture of silence" ever be broken down? The recurring answer is "yes". The task of progressive teachers is to confront the above teacher dominated perception of teaching. We need to devise ways to minimise teacher talk and maximise student "voice". A recommended place to begin could be with individual teachers trying to make sense of their own teaching. At this point it would be useful to quote McNiff (1988:3) who states:

... the greatest revolutions start with individuals and this teaching revolution must start with individual teachers in their own classrooms who are attempting to make sense of their own practice. 


\subsubsection{Breaking the Culture of Silence in the Classroom}

Breaking down the "culture of silence" at our school is indeed a huge task although not impossible. Despite the constraints and the onslaughts there remains what Giroux (1988: 221) terms "hope and possibility". I would like to agree with him and contend that teachers have the space, autonomy (not withstanding certain constraints), even the moral obligation, to struggle collectively (networking) in order to create those ideological and material conditions that will enable them to empower students to ultimately break down their "culture of silence". They (teachers) must believe that their actions will and can make a difference.

On this Giroux (1992:106) gives sound advice when he says that,

Educators need to encourage students by example to find ways to get involved to make a difference, to think in global terms, and to act from specific contexts. Educators must therefore develop a public language that actively abandons those forms of pedagogical practice that prevent our students from becoming aware of and offended by the structures of oppression at work in both institutional and everyday life.

UNIVESITY of the

Taking all this into consideration gives me a feeling of hope that my action as a teacherresearcher who attempts to democratise and encourage dialogue in my little primary school classroom can make a difference. It could, however, be classified as a start or a small attempt towards empowering my students.

In trying to break down the "culture of silence" that pervades our schools, Freire (1982:50) suggests that teachers become "critical activists". Through the utilization of problem-posing methods students should no longer remain docile listeners but become actively and critically involved in dialogical action with the teacher. Nowadays I am worried when the word student has been replaced by a more technical word - learner. The student for me has the connotation of being studious and critically engaged in 
learning whereas the learner has a more docile meaning. It appears that the new learners of the 2000's are not more politically conscious than the students of the 1970's, 1980's and the early 1990's.

In our attempt to break down the "culture of silence", teachers should start questioning the technicist and mechanical approach to teaching. They should start questioning what they teach, how they teach, who controls existing knowledge at schools and for which purpose that control is exercised.

\subsubsection{Breaking the Culture of Silence about Sexuality and AIDS}

Sex education and AIDS education are inextricably linked. As mentioned earlier (p. 19, see Fataar, 2003) speaking about sex and sexuality issues in some religious schools could be classified as taboo. Although we find commercial sex being rife as seen on television and in the local newspapers it appeared that a silence pervaded in my classroom when the topic of sex and sexuality was being addressed.

\section{UNIVERSITY of the}

While the biological process of sexual maturation occurs naturally in all people, and hence within all societies, the manner in which it is managed (for example what is regarded as acceptable and unacceptable behaviour around it) differs quite considerably. Despite these differences what almost all societies have in common, from the urban middle class in Australia to isolated communities in the Amazon, there is a culture of silence around the process of sexual maturation. In all societies, most aspects of human sexuality are regarded as 'private', even taboo, with very strict codes about when, who and how it can be talked about (http://www.sn.apc.org/fred/quest/cycle-silence.htm. 2007/03/14). 
As was the case in countries in the West a little more than a generation ago, traditional values dictate that unmarried couples simply do not have sexual relationships, particularly young women who should be virgins when they marry. But traditional values, while filling as important a role in South Africa as they do in any culture, can be as fragile as fairy tales when confronted with the fast-changing facts of modern life.

Young people do have sex in South Africa and I can almost make this statement with confidence. This statement was supported by one of the parents when she told me at a teacher-parent meeting in February 2005 (see Chapter Four) "You only know the children as far as you can see them". A 'culture of silence' does not encourage the production or availability of accessible-and appropriate information around the issue of sex and sexuality. The group which feels this absence most strongly are young people who are on the threshold of adulthood and in need of understanding, advice and direction as they actively experience the process of sexual maturation. What perpetuates this silence further is the absence of appropriate and guided information thus meaning that misinformation and myths about sex andsexuality and HIV/AIDS are allowed to flourish. In the following chapter (Chapter Two) I address the HIV and AIDS debate in more detail.

My research suggests that the best starting point to any effective intervention is to 'break the silence' which currently exists around sexuality. One of the most effective means of responsibly breaking down the existing silence around sexuality and HIV/AIDS is ensuring that the education system - beginning with primary schools - engages effectively and sensitively with this work. The starting point in schools needs also to be 
the development of a process which ensures that all children receive accessible, accurate and appropriate information about sex and sexuality matters.

My research incorporated two emancipatory action research projects that I undertook at the school where I teach. These projects, as I mentioned earlier, were attempts to get my students more involved in taking up the HIV/AIDS challenge in society and also to change their behaviour towards sex and sexuality matters. As a teacher-researcher it most certainly also changed my views concerning sexuality and HIV and AIDS.

\subsubsection{Transformative Intellectuals}

Central in my argument in this dissertation is the idea that teachers should become teacher-researchers as well Tas what Giroux (1988:125) calls "transformative intellectuals".

Giroux (1988:125) mentions various reasons for this:

First, it provides a theoretical basis for examining teacher work as a form of intellectual labour, as opposed to defining it in purely instrumental or technical terms. Second, it clarifies the kinds of ideological and practical conditions necessary for teachers to function as intellectuals. Third, it helps to make clear the role teachers play in producing and legitimating various political, economic and social interests through the pedagogics they endorse and utilize.

Teachers as transformative intellectuals should start questioning the "purely instrumental" approach to teaching. They should be careful of not falling into the trap of carrying out hegemonic practices by slavishly promoting the dominant ideology and thus undermining the cultural capital of the students who they teach and are indulged with.

Thus teachers as "transformative intellectuals" must see teaching as a political act. This 
is also emphasised by Giroux (1988:127):

Central to the category of transformative intellectual is the necessity of making the pedagogical more political and the political more pedagogical. Making the pedagogical more political means inserting schooling directly into the political sphere by arguing that schooling represents both a struggle to define meaning and a struggle over power relations ... Making the political more pedagogical means utilizing forms of pedagogy that embody political interests that are emancipatory in nature; that is, using forms of pedagogy that treat students as critical agents ... and make the case for struggling for a qualitatively better world for all people.

To ensure that a more meaningful contribution towards the building of a future South Africa takes place, teachers should strive to become "transformative intellectuals" or what Freire (1982) calls "critical activists". This view is also held by other authors such as Datnow \& Castellano (2000), Elmore (1996) and Hargreaves (1994) who see teachers as critical change agents who need to be involved closely in change initiatives. Fullan (1991: 90) states that "educational change depends on what teachers think and do. It's as simple or as complex as that."

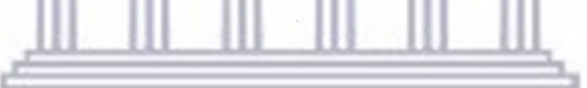

Wood \& Bennett (2000:1) note that in an "era of radical reform, there are potential tensions between changes that are imposed externally through government policy and changes in professional knowledge and praetice that are generated by teachers."

But playing an active role in the broader educational struggle, like fighting against unjust teacher retrenchments, participating in national marches and stay-aways should not impress on us the idea that our classroom practice would automatically become democratic or liberatory once a new government comes into power. New policies and new curriculum will not turn things around like a magic wand, since teacher activity in the classroom has a great role to play. Robinson (1993:3) refers to this as "political romanticism". 
In breaking down this "political romanticism" teachers should not ignore the importance of improving their own teaching practice in their quest for liberation. To assist teacher-researchers Robinson (1993:5) suggests networking.

Most important to this (democratic struggle) is to build a network of teacher educators committed to emancipatory action, so that ideas and experiences can be shared, and resources pooled. To this end I continue to hold on to a picture of groups of teachers, at the same or different schools, actively engaged in debate about the kinds of values, knowledge and skills they would hope to promote in society through their teaching, and sharing ideas about how they would like to get there.

Elliott in his attempt to assist teacher-researchers against the constraints they face also encourages networking. He (1991:67) suggests the following:

A small band of isolated teacher-researchers can tap into a reflective counter culture in the form of an action-research network which transcends school boundaries and is linked to a teacher education institution. Membership of such a network can provide the kind of cultural resources which strengthen the capacity of aspiring teacher researchers to resist the time pressures operating on them from inside their schools.

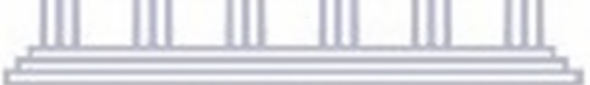

Despite the constraints and the onslaughts that teacher-researchers and transformative UNIVERSITY of the

intellectuals face there remains, what Giroux (1988) terms "hope and possibility" and I want to agree with him. I believe teachers have the space and opportunity to struggle collectively in order to create those ideological and material conditions that will enable them to empower students to ultimately break down their "culture of silence". They (teachers) must believe that their actions will and can make a difference. This is emphasised by McLaren (1989:167) who says that "schooling must be tied to a struggle for a qualitatively better life for all through the construction of a society based on non-exploitative relations and social justice."

Taking all this into contention gives a feeling of hope that my action in my two action research projects (see Chapter Four \& Chapter Five) could, however, be classified as a 
start or a small attempt towards liberating my teaching practice. On this Robinson (1993:5) comments: "One small step for one teacher may indeed be one great leap for emancipatory practice, depending on how that small step is harnessed, supported and shared."

Thus, I would like to believe that my two action research cycles being dialogical processes made me, I think, more self-reflective and more critical. Freire and Shor, (1987:44) comment as follows on this:

Even if teachers have political space to deviate, to express some radicalism, we must believe that we too will be educated in the process, and not arrange the pedagogy so that transformation goes one way.

\section{Th: 11 in}

There is no question that teachers are living in a time (more so since September 11, 2001) when they must stretch the boundaries of critical educational principles, in order to infuse social and institutional with its revolutionary potential. It is a moment when emancipatory theories must be put into action, in an effort to counter a misguided national rhetoric that would render teachers, students, parents and communities voiceless and devoid of social agency. Thus as transformative intellectuals, I want to suggest with Darder (2007) that critical ideas and practices in the interest of democratic schooling must be central to our efforts to confront the powerlessness and uncertainty that is so much the reality in many public schools today.

\subsection{CHAPTER OUTLINE}

In Chapter One, I have tried to locate what I would regard as the problem in my teaching that is: A lack of interweaving HIV/AIDS education into curriculum activity and also promoting a "culture of silence" when it comes to issues of sex and sexuality. I have done this by critically looking at my own teaching career as well as my own historical and schooling background which have impacted on my teaching. In this chapter I also 
give a brief historical background of the school where I teach and where the research was carried out. Towards the end of the chapter, I point out that we as teachers need to redefine our role so as to empower our students by giving them a "voice". I also explain concepts used in this written account.

In the following chapter (Chapter Two) the HIV and AIDS pandemic debate is addressed in more detail. I look at the impact of HIV/AIDS on education and how the implementation of C2005 takes up the HIV/AIDS challenge. An attempt is also made to unpack the Western Cape Education Department's plans and policy concerning HIV/AIDS.

In Chapter Three a brief historical background of the development of action research is given. I point out how Lewin (1940) and Stenhouse's (1975) idea of action research was later taken up further and given a more critical perspective by writers such as Elliott (1981), Hopkins (1985), Walker (1985), Carr \& Kemmis (1986), Grundy (1987), Winter (1989), McKernan (1991; 2000) and McNiff (2000; 2003; 2006; 2007). I define (with due regard for the pitfalls of definitions) action research. I next try to give an idea how emancipatory action research ought to be viewed and discuss why I chose it as the research approach of this thesis.

Chapter Four focuses on my first action research cycle where I made an attempt to break down the "culture of silence" that I felt existed in my classroom. Apart from sketching the various incidents and events in the cycle, I discuss some of the different aspects of action research, namely the importance of negotiations, consultations and ethics, the various phases and the data collecting techniques. I conclude the chapter by critically reflecting on the various happenings during the cycle. 
In Chapter Five I give an account of my second action research project "Checkmating HIV/AIDS". This project is a continuation of the first action research project where I tried to break down the "culture of silence" concerning HIV/AIDS and sex and sexuality in my classroom. On reflecting about project one, I realised that awareness alone was not going to be enough to take up the HIV/AIDS prevention challenge. In this project I focus specifically on one code of sport - CHESS and set out to discuss the potential of using this code of sport to take up the HIV/AIDS challenge. The chapter concludes by reflecting on what I have learnt during the cycle.

Chapter Six is the concluding chapter. The question - Can we ever win the battle against HIV/AIDS is posed? Is it possible to change the way we think about sex and matters concerning sexuality? Thereafter the concept of change is clarified. This is followed by looking at the two projects, and I specifically focus on whether these projects had been liberatory or transformative. I then address the issue concerning teachers as "transformative intellectuals" and teacher researchers and conclude by proposing emancipatory action research as a "vehicle" for change and make recommendations for further research. 


\section{CHAPTER TWO}

\section{ADDRESSING THE HIV/AIDS CHALLENGE}

\subsection{INTRODUCTION}

In Chapter One, I emphasized that the HIV/AIDS pandemic is amongst the most contemporary challenges in sub-Saharan Africa and more specifically in South Africa. I started the chapter by sketching the historical background of the South African educational scenario. The rationale and basis for an investigation into a primary school classroom was explained and I put forward reasons for presenting my work within an action research paradigm of which a more detailed explanation will be provided in Chapter Three. I concluded the chapter by attempting to unpack my understanding of certain key concepts, "culture of silence" and "teachers as transformative intellectuals", used in this study

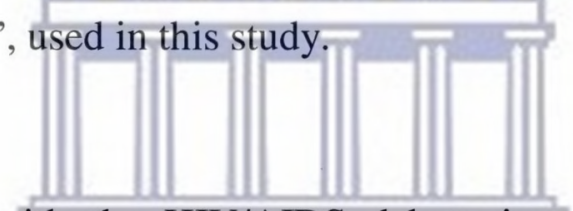

In this chapter I engage with the HIV/AIDS debate in more detail. As already mentioned earlier, the emphasis of this research is not biomedical. I have, therefore, decided to elaborate more on the meaning of, the impact on, and the consequences of the pandemic for education. The views that I hold about HIV/AIDS not only being a 'clinical-medical' problem, but an all encompassing one with education playing a vital role, were strengthened and reinforced when I came across the readings of writers such as Chisholm (2005), Quinlan \& Willan (2005), Richter, Dawes \& Smith (2004) and Holden (2004). Other authors that influenced my thinking were Shisana \& Simbayi (2002), Johnson \& Dorrington (2002), Coombe \& Kelly (2001), Foster \& Williamson (2001), Hubley (2000) and Fawole, Asuzu, Oduntan \& Brieger (1999). 
In my quest to elaborate on the challenges that the pandemic is highlighting in South African Education, I focus on the following aspects in this chapter. First, I give an overview of HIV/AIDS with specific reference to its impact on education. Second, I set out to focus on the formulation of the HIV/AIDS policy and, third, how the implementation of C2005, now renamed as the Revised National Curriculum Statement (RNCS) meets the HIV/AIDS challenge. Following on the above, I unpack the Western Cape Education Department plans and policy concerning HIV/AIDS, and then I focus on breaking the HIV/AIDS culture of silence. Before I conclude the chapter, I critically engage with the idea of the teacher as a researcher and critical change agent in an HIV/AIDS challenged society.

\subsection{HIV/AIDS}

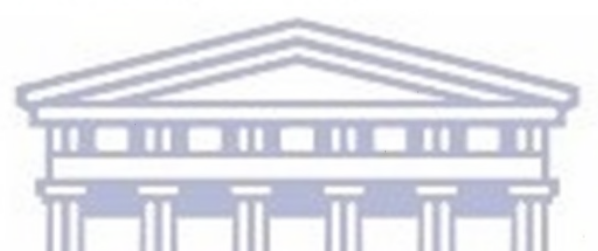

HIV/AIDS continues on its path of destruction. Taking up the challenge means confronting the disease on all fronts, noting that education has a particularly important role to play in this regard. For any educational institution to maintain quality education there is a need to comprehend to what extent it is being affected by the disease, or rather pandemic, as it has already become to be known.

HIV/AIDS is unequivocally the most devastating disease we have ever faced and it will get worse before it gets better (UNAIDS, 2004). The HIV/AIDS pandemic is complex, consisting of a number of smaller and constantly changing epidemics which affect individuals, communities and nations in a multiplicity of ways (Doyal, Naidoo \& Wilton, 1994). AIDS (Acquired Immune Deficiency Syndrome) emerged in the 1980s as the most terrifying epidemic of modern times (Jackson, 2002). According to UNDPI \& UNAIDS (2001), since the epidemic began, more than 60 million people 
have been infected with the virus. Sub-Saharan Africa continues to bear the brunt of HIV and AIDS, with close to $70 \%$ of the global total of HIV positive people (UNAIDS, 1999). In 2005 alone, a total of 3.1 million people died of HIV/AIDS related causes (UNAIDS, 2005). HIV/AIDS is noted to be the leading cause of death in Sub-Saharan Africa (UNAIDS, 2001). Botswana, Lesotho, Mozambique, South Africa, Swaziland and Zimbabwe comprise 1.3 percent of the world's population and account for 23.3 percent of the total HIV/AIDS burden globally. Similarly, 12.1 percent of the Sub-Saharan Africa population reside in these countries, yet they account for 32.5 percent of the people living with HIV/AIDS on the sub-continent (Martin, 2003). AIDS is clearly one if not the key obstacle to achieving sustainable development on the sub-Saharan region (Shisana, 2004).
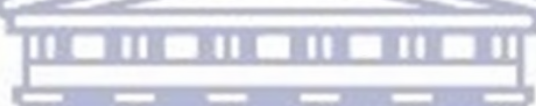

According to Di Caelers (Cape Argus, 19 October 2005) the newly released 2004 National HIV and Syphilis Antenatal Sero-Prevalence Survey, show that “...KwaZulu Natal tops the list of all nine provinees at $40,7 \%$, followed by Gauteng at $33,1 \%$ and Mpumalanga at 30,8\%. Although the Western Cape reflects the lowest HIV prevalence at $15,4 \%$, this percentage has virtually doubled since $2001 . "$

In his 2006 welcome message, Willy Madisha, the president of the largest teachers union in South Africa (SADTU) re-committed the union to combat the scourge of HIV and AIDS. He emphasized the recent ELRC-commissioned study by the Human Sciences Research Council that revealed statistics that 4,000 educators died of Aids in 2004 and that currently between 10,000 and 20,000 educators require anti-retroviral treatment to save their lives. These statistics are enough to make one aware that the pandemic has already impacted on South Africa's education system significantly. 


\subsection{THE IMPACT OF HIV/AIDS ON EDUCATION}

Despite growing volumes of South African literature on the biomedical aspects of HIV/AIDS, much is still to be understood about the educational meaning, impact and consequences of the pandemic. There are few researchers involved in studying the impact of HIV/AIDS on education in South Africa, more is needed. Abt Associates (November 1999), one of the many emerging HIV/AIDS research organisations, are still to reveal their research findings. Various writers agree that HIV/AIDS impacts upon education in different ways. I agree with Kelly (2000d:1) who conceptualised HIV/AIDS as having the potential to affect education through the following: reduction in demand, supply and availability of resources; adjustments in response to the special needs of a rapidly increasing number of orphans; adaptations to new interventions, both within schools and between schools and communities; curriculum

modification, altered roles to be adopted by the educators in the system; the ways in which the schools and the education system as a whole are organised; the planning and the management of the system; and donor support for education.

\subsubsection{Supply and Quality}

HIV/AIDS will most definitely have an adverse impact on both the supply and the quality of education. AIDS “... clearly threatens the Education For All (EFA) goal of ensuring everyone's fundamental right to education" Khathide (2000:7). This particular assault on education is also reiterated by Kelly (2000b) who states that “... an estimated 860,000 children in sub-Saharan Africa lost teachers to AIDS in 1999." "In the Central African Republic 85 percent of teachers who died between 1996 and 1998 were HIV-positive, and on average died 10 years before they were due to retire" 
(UNAIDS 2000a). "In Zambia 1,300 teachers died in the first 10 months of 1998, compared with 680 teachers in 1996" (Kelly, 1999). HIV-positive teachers are estimated at more than 30 percent in parts of Malawi and Uganda (Coombe, 2000b), 20 percent in Zambia (Kelly, 2000a) and 12 percent in South Africa (Coombe, 2000a).

With the increase in HIV/AIDS cases amongst teachers, the disruption of class activity will affect the quality of education, particularly due to teacher absenteeism. Infected teachers will increasingly be absent from school due to the progressive nature of the disease. According to a World Bank (1999) analysis, an infected teacher or education officer is likely to tose 6 months of professional time before developing

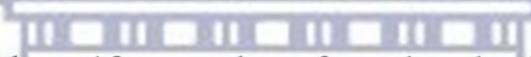

full-blown AIDS and a further 12 months after developing the disease. Teacher absenteeism will also increase as they need to see to their sick family members or attend regular funerals. Teacher absenteeism and non-performance will increase as a result of the psychological effects of the pandemic. The supply of teachers to promote education in the rural areas will also probably be negatively affected. According to (Kelly, 2000a), "AIDS-affected teachers prefer to be close to hospitals and clinics in urban areas as opposed to rural areas where there is a lack of hospitals and clinics."

\subsubsection{AIDS Orphans}

The increase in orphans may well represent one of the largest impacts of the AIDS pandemic. According to the World Bank (2002:16),

AIDS orphans are estimated to number 35 million by 2010. Projections for 1990-2010 for 15 African countries show uniformly significant increases resulting from parents' AIDS mortality. Projections indicate that in 2010, 79 to 94 percent of orphans will be the result of AIDS mortality, compared with 61 to 84 percent in 2000 . 
Orphans are among the most vulnerable children in our society. They often suffer the trauma of seeing their parents die of AIDS, often become "orphaned" several times over as new guardians also become infected, fall victim to malnutrition and starvation, as well as the risk of becoming street children. The impact of orphaning on school enrolment is unclear and will probably differ from locality to locality. Estimates of orphan numbers also depend on the definition of an orphan, the time frame and other underlying assumptions. According to Smart (2003:11),

If we define an orphan as a child under the age of 18 whose mother has died, it is estimated that there were over 885000 orphans in South Africa in July 2002, 38\% of whom were orphaned by HIV/AIDS. HIV/AIDS accounted for $73 \%$ of all new orphans in 2002, and $81 \%$ in KwaZulu-Natal.

\section{II II II II II}

Although there is considerable confusion when faced with current and future statistics on orphan-hood from varying sources, this should not detract one's attention from the main issue, namely regardless of which sources are in use, the impact of HIV/AIDS is grave and will become worse in years to come.

$$
\text { UNIVERSITY of the }
$$

\subsubsection{Young people at Risk}

In many of the affected countries, young people represent the most rapidly growing component of new HIV/AIDS infections, with girls outnumbering boys by a substantial factor. According to the Commonwealth Secretariat (2002:38),

Every minute, six people under the age of 25 become HIV positive. Half of all new HIV infections are in young people aged 15-24. In eight African countries, AIDS is expected to claim the lives of at least a third of today's 15 year olds. In Botswana, according to the Human Rights Watch website, a 15 year old boy now has an 85 percent chance of dying of AIDS. 
The reasons given for this vulnerability include factors relating to poverty, lack of information, lack of socio-economic empowerment, and lack of availability of protective methods. In most countries it appears that there is an absence of adolescent sexual and health services. Young people are then left to their own devices and often rely on incomplete or inaccurate information circulating in peer groups. According to (UNICEF, 2002:42),

Many young women and men tend to ignore risks, falsely believing that a stable relationship is protection enough. In a number of countries where AIDS is epidemic, nearly half of sexually active girls between the ages of 15-19 believe they face no risk of contracting the disease.

Young people also face the risk of having unplanned sexual relations as they may be coerced or they may also become vietims of sexual abuse and exploitation, thus making them especially vulnerable to HIV infection.

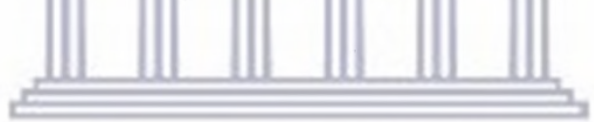

Where sexual and reproductive health services exist, young people find it hard to use these, because of lack of money, inconvenient opening times, shame and embarrassment, concerns about privacy and confidentiality, laws that prevent unmarried girls and boys using contraception or require parental consent, as well as negative and judgemental attitudes of service providers.

It is reported by UNDPI \& UNAIDS (2001:46) that,

Marginalised young people (including street children, refugees and migrants) may also be at particular risk because of stigma, their exposure to unprotected sex (in exchange for food, protection or money and the use of illegal drugs). Injecting drug use is rising in young people in some countries, increasing the risk of HIV transmission through sharing contaminated needles and syringes. 
Reflecting on the above, it becomes clear that HIV/AIDS can no longer be considered as a medical problem only. What is needed is a multi-sectoral response to HIV/AIDS as recommended by the Commonwealth Secretariat as far back as 2002, who indicates that:

... [a] multi-sectoral response means involving all sectors of society governments, business, civil society organisations, communities and people living with HIV/AIDS - at all levels - pan Commonwealth, national and community - in addressing the causes and impact of the HIV/AIDS epidemic. Such a response requires action to engender political will, leadership and co-ordination, and to develop and sustain new partnerships and ways of working, and to strengthen the capacity of all sectors to make an effective contribution (2002:51).

If one considers the integrated plan needed to take up the HIV/AIDS challenge, then it seems as if education might potentially be the single most powerful institution to employ against HIV transmission. It offers a window of hope unlike any other for escaping the grip of HIV/AIDS (World Bank, 2002:Xv). If one considers the South African scenario, then it means a radical transformation of the education system for it to be able to cope with the impact of HIV/AIDS.

\section{WESTERN CAPE}

\subsection{TOWARDS AN HIV/AIDS POLICY IN SOUTH AFRICA}

The South African Constitution, 1996, and Bill of Rights emphatically declare that one cannot discriminate against anyone unfairly whether it involves race, colour, creed or sex. This Equality Clause states that "Everyone is equal before the law and has the right to equal protection and benefit of the law." Human rights lawyers and people living with HIV or AIDS say that HIV must be treated as a disability under the Bill of Rights and this is also substantiated by Fine, et al. way back in 1997, because: 
- People with HIV have a medical condition that may affect their day-to-day activities, even when they do not look or feel ill. This is a disability.

- People with HIV or people who are thought to have HIV, often face discrimination that makes it more difficult for them to live and work together with other people. They are handicapped by obstacles put up by society because of fear and prejudice about their condition (Fine, Heywood \& Strode, 1997:39).

The above view is supported by foreign law, e.g. in countries such as the USA, Canada and Australia, and international law, e.g. United Nations Conventions. Although HIV is not mentioned in the South African constitution, HIV has now been recognised by the constitutional court as a prohibited ground of discrimination. This was emphasised in the constitutional court in the Hoffmann v South African Airways case (2000). It thus becomes clear that in formulating policy for the HIV/AIDS pandemic, whether nationally; or locally, human rights standards should be used as a constant guide. A learner or teăcher or prospective learners or teachers with HIV shall not be treated differently from those with comparable life-threatening conditions. HIV status shall not be a criterion for refusing to promote, train and develop a learner or teacher or an assistant teacher.

Despite the noble intentions one cannot escape the harsh realities of the politics of HIV/AIDS policy in South Africa. The mid-1990s saw the government moving away from its proclaimed 'people-centred approach', espoused in the Reconstruction and Development Programme (RDP) policy, to a 'top-down approach', espoused in the Growth, Employment and Redistribution (Gear) policy. This, as viewed by the TAC, 
has also been reflected in the National AIDS policy as expressed by President Thabo Mbeki's and the Minister of Health, Manto Tshabalala-Msimang, who refuse to prioritise the HIV/AIDS agenda. In denying the other causes of HIV/AIDS or at least it appears so, the President on the one hand, saw poverty as the real cause of AIDS and on the other hand, the Minister of Health prescribes good nutrition as an alternative to Antiretroviral Therapy (ART).

The multi-sectoral approach to combating the HIV/AIDS pandemic is found lacking and this is emphasised once again by the TAC in the objection to the Department of Health being the sole arbiter of policy and strategy. As a 'presidential-lead project', meaning that it had preferential access to funds, one-would have expected a coordinating unit consisting of all the different government departments being responsible for HIV/AIDS intervention. This view is also held by Nattras (2003b:44) who points out that the provincial governments also located HIV/AIDS programmes in their respective health ministries, thereby recasting AIDS as a health rather than a social problem, and limiting the potential for a multi-sectơral, co-ordinated response.

The disjunction intimated in these assessments is that the national plan since 1994 had the hallmarks of an integrated methodology, but there was no requirement that the DoH transform itself to accommodate the plan. This critique leads us to reconsider the government's revised strategic plan, the National HIV/AIDS Strategy 2000-2005. The multi-sector programmes and broad-based interventions give the appearance of an integrated approach. What is missing, however, is the substantive transformation of 
the Department's procedures and activities. According to Quinlan \& Willan

(2005:237),

... [t]his is an underlying reason for the conflict between civic organisations such as the $\mathrm{TAC}$ and the government. Institutional transformation is part of the social contract of any organisation that proclaims an integrated approach. In moving away from fulfilling that contract (which had been espoused in the early-to-mid 1990s' formulation of HIV/AIDS policy), the DoH made itself vulnerable to challenges from civil society, and the courts inevitably became the means.

Related to the above disjunctions is the emerging tension between the $\mathrm{DoH}$ and the DoSD (Department of Social Development). Both departments were expressing their concerns over their budgets and it appears that there is an open contest over health and welfare's ideologies in government planning. This was also revealed in the report by the Taylor Committee of Inquiry (2002) who hightighted the need for South Africa to define an approach to social spending.

\subsection{HOW DOES THE IMPLEMENTATION OF C2005 MEET THE HIV/AIDS CHALLENGE?}

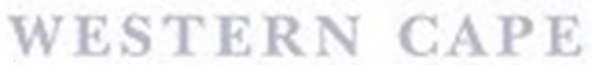

One can only but agree with Chisholm (2004) that much has changed for South Africa's schools in this post-apartheid era in which HIV/AIDS has emerged as the deadly, unspoken and silent scourge of liberation, casting its shadow over every statement, initiative and intervention.

The main initiative since 1994 has been the introduction of outcomes-based education and Curriculum 2005 (C2005) in 1997. At the heart of Curriculum 2005 is a set of values linked to social justice, human rights, equity and development, as well as a learner-centred approach to teaching and learning. As mentioned in Chapter One (see 
page 8), in 2000 this curriculum was reviewed and revised and is presently being implemented through the Revised National Curriculum Statements for Schools from 1994.

I have made reference earlier (see p.51) to the bureaucratic inertia in the case of South Africa, the 'denialist' approach of the President and the dominant position of the Ministry of Health in public sector campaigns against the pandemic. This tension between commitment to integration and co-ordination when it comes to mainstreaming HIV/AIDS, restricts the country's efforts to contain the pandemic. It is within this context that the DoE seeks to contain the pandemic at school and it is within this context that teachers need to implement their classroom practice.

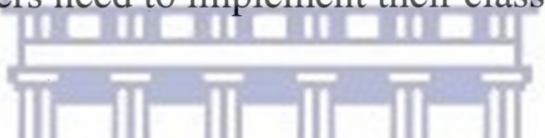

The Department of Education (2002:3) in its Strategic Plan against HIV/AIDS advocates its first strategic goal as $"$. dealing urgently and purposefully with the HIV/AIDS pandemic by utilizing the education and training system." The immediate challenge that confronts the strategic plan of the Department is whether teachers are adequately prepared and trained in Curriculum 2005 and HIV/AIDS education to address the challenge on hand. It was found that educators need more in-service training to deal with life skills, and that many of the trained educators had resigned or were redeployed and had to be replaced (Vally, 2001:50).

The lack of trained personnel and adequate resources to combat the HIV/AIDS pandemic is also experienced in other parts of the African continent. According to a review by James-Traore, Finger, Ruland \& Savariaud (2004), while the HIV/AIDS 
crisis has resulted in new attention to sexuality education in schools, Africa's educational systems are struggling to adopt meaningful education initiatives. It is by now well-known that inadequate funding and poor infrastructure plaque education systems throughout sub-Saharan Africa. Teachers overwhelmingly report a shortage of teaching materials, and available materials are often outdated. In many sub-Saharan African countries there is also a shortage of experienced teachers.

In South Africa, where teachers face the constraints of implementing a revised outcomes-based education curriculum, the challenges facing HIV/AIDS educational programmes have become more defined. Despite the complexity of curriculum change and the onslaught of the HIV/AIDS pandemic, the ex-Minister of Education, Kader Asmal, remained optimistic and strongly felt that teachers have a contribution to make. According to Asmal (2002:42) "Educators are not social workers. Nevertheless, they can work with others to provide care and support for those affected by HIV/AIDS, creating a culture of caring in schools, ensuring a secure environment."

In response to the high prevalence of HIV/AIDS in South Africa, particularly among youth, the DoE developed a national policy in HIV/AIDS for students and teachers in public schools. The policy seeks to promote effective prevention and care within the public education system and focuses on providing accurate information on: the nature of risk factors concerning HIV infection and AIDS; precautionary measures; and the obligation resting on school communities to avoid discrimination against infected persons (DoE, 2000). 
The guidelines (DoE, 2000) also offer educators basic facts about HIV/AIDS and key messages about preventing HIV infection. Educators are urged to teach children about HIV/AIDS. Further, educators are instructed on how to prevent disease transmission in schools, how to manage accidents and injuries and how to care for people with HIV/AIDS. The guidelines advise educators to build an enabling environment and culture of non-discrimination for those students and teachers living with HIV/AIDS. The guidelines encourage schools to develop their own policies on HIV/AIDS in order to give effect to these national guidelines.

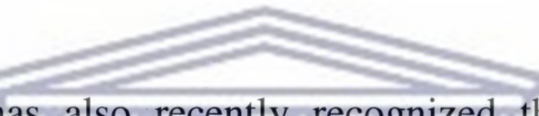

The education department has atso recently recognized the problem of teachers sexually abusing female students in its warning against sexual misconduct in new school guidelines on HIV/AIDS issues. According to Jewkes (2001:2), the guidelines note the prevalence of the problem and call on teachers to refrain from sex with students because of the dangers of HIV transmission and because "...having sex with learners betrays the trust of the community." The HIV/AIDS guidelines (DoE, 2000) set out and explain that sexual relations between teachers and students are highly illegal:
\end{abstract}

- Educators must not have sexual relations with learners. It is against the law, even if the learner consents. Such action transgresses the code of conduct for educators, who are in a position of trust.

- Strict disciplinary action will be taken against any educator who has sex with a learner. 
- Sex that is demanded by an educator without consent is rape, which is a serious crime, and the educator will be charged. If an educator has sex with a girl or boy who is under 16 years, he or she will be charged with statutory rape and may face a penalty of life imprisonment.

- If you are aware of a colleague who is having sexual relations with a learner you must report them to the principal or higher educational authorities, and if the boy or girl is under 16 , to the police. If you do not do so, you may be charged with being an accessory to rape.

Currently, policy coordination is lacking and communication gaps are common between the national and provincial education departments and schools. For instance, the Minister of Education's guidelines on HIV/AIDS for the school system have been met with resistance at the local level in some areas. Individual schools fail to implement policies, while relevant polieies have yet to be implemented consistently across government departments. IOne provincial education department official expressed her concern over the breakdown in control over schools as follows:

As much as we develop policy, nothing will happen if schools aren't held accountable. Individual school principals must be held accountable. By the time a policy gets to the school nobody is accountable. We need them to access information and policies meant to deal with school problems and we must be able to hold schools accountable for certain things that happen at school (Sunday Times 23.09.2000).

This view was substantiated by the local subject advisor and HIV/AIDS co-ordinator in the Wynberg area where I teach and conducted this research. He expressed the problem of theory and practice. C2005 speaks about tackling the HIV/AIDS problem, 
but there is no real budget available for the implementation of HIV/AIDS education at schools. Teacher apathy is pointed out as another challenge, as well as a lack of resources.

To address social and health issues, the curriculum in contemporary South African schools includes a learning area known as Life Orientation, which could address HIV/AIDS. According to the Revised National Curriculum Statement Grades R-9 Schools Policy (2002:26), "Life Orientation specifically equips learners for meaningful and successful living in a rapidly changing and transforming society." According to the provincial coordinator for the HIV/AIDS Life Skills Programme Peter Fenton (2004:2), “...schools can usually onty accommodate about 10 to 30 hours of HIV/AIDS life skills at primary school levet and 10 to 15 hours at secondary school level within the space of a year." Clearly, that's not enough if championing the HIV/AIDS cause is going to mean changing attitudes and behavioural patterns of learners. Fenton (2004) also cautions educators against $\mathrm{HIV}$ fatigue where pupils just don't want to hear about it, any more.

In an educational situation, especially with younger learners, some subjects or learning areas fail to impart information to the students simply because the students are not interested and do not pay attention. I am of the opinion that this is unlikely to be the case with HIV/AIDS education; the simple fact that HIV/AIDS education involves the discussion of sex - a topic of fascination for young people who are discovering their own sexualities - is likely to ensure at least initial attention. This attention will wane, however, if the information is not imparted in a lesson interesting 
enough to maintain students' concentration. It is not only important to have HIV/AIDS education, but to provide HIV/AIDS education in a meaningful way. In addition to providing information, an engaging class-based lesson where a learner is amongst his/her peers can help to shape attitudes, reduce prejudice and alter behaviour.

\subsection{THE WESTERN CAPE EDUCATION DEPARTMENT'S PLANS AND POLICY CONCERNING HIV/AIDS}

The WCED has committed itself to dealing with the AIDS emergency (2003, http://www.hrd.wcape.school.za) in two ways. Firstly, to use its position as the primary transmitter of knowledge, skills and values to the youth of our society, to raise HIV awareness, to disseminate information about HIV and its transmission, and to help change the attitudes of young people to inhibit the spread of the epidemic. They intend doing this primarily within the curriculum, but also through extracurricular activity, and through the role modelling of teachers and other authorities. The second way is to ensure that students and teachers who have been infected by HIV are not discriminated against, and to ensure, too, that they are able to live meaningful lives for as long as possible.

The WCED policy concerning HIV/AIDS is well reflected in the White Paper of Special Needs Education Bulletin (July, 2000). Emphasis is placed on developing an inclusive education and training system taking into account the incidence and the impact of the spread of HIV/AIDS and other infectious diseases. The Department of Education intends to develop and introduce appropriate and timely programmes, 
which include special measures, such as the strengthening of information systems, establishing a system to identify orphans, co-ordinating support and care programmes for such learners, putting in place referral procedures for educators, and developing teaching guidelines on how to support orphans and other children in distress. In this regard, the Ministry intends working closely with provincial departments of education and the Departments of Social Development, Health and Public Service Administration.

It is stated in the WCED HIV/AIDS Life Skills Programme (2004:12), that ... [b]oth Tirisano and the National Curriculum (C2005 and RNCS) mandate that information about HIV/AIDS and (age-appropriate) sexuality education must be integrated into the curriculum, at all levels. Thus, there are specific components in the Life Skills (Foundation Phase) and Life Orientation learning areas (Intermediate Phase, Senior Phase and FET band), that deal with reproductive health and sexuality education - not as an add-on or optional subject, but as a mandatory part of the curriculum. Approximately $1 / 2$ hour per week (taken on average over the year) of HIV/AIDS and sexuality life skills education, per class is mandatory. The teaching of HIV/AIDS and sexuality education must therefore be timetabled and is to be mainstreamed.

In terms of the provincial education policy for HIV/AIDS, based on the national policy each school should have its own HIVIAIDS policy, an HIV/AIDS Coordinator, and, if possible, establish a 'Health Advisory Committee'. Like all provinces the Western Cape commemorates World Aids Day annually on 1 December.

The Western Cape Education Department in conjunction with the Department of Poverty Alleviation introduced a pilot project from March 2006 - November 2006, whereby they allocated teaching assistants to 160 primary schools across the province in an attempt to improve numeracy and literacy skills among foundation phase learners. Although the teaching assistants provided the much needed care and support for poverty-stricken Grade 1-3 learners, they have also been placed in a unique 
position to assist in research, monitoring and evaluating the impact of HIV/AIDS on our overcrowded schools.

The ideal would be to supply all schools with teacher assistants but the reality is government does not have a big enough budget or as mentioned earlier (see p.53), a co-ordinated integrated system whereby all departments pool their resources. In spite of the lack of personnel and resources, the Western Cape Education Department encourages HIV/AIDS education, but needs teachers to become creative in their respective classrooms to challenge the effects of the HIV/AIDS pandemic.

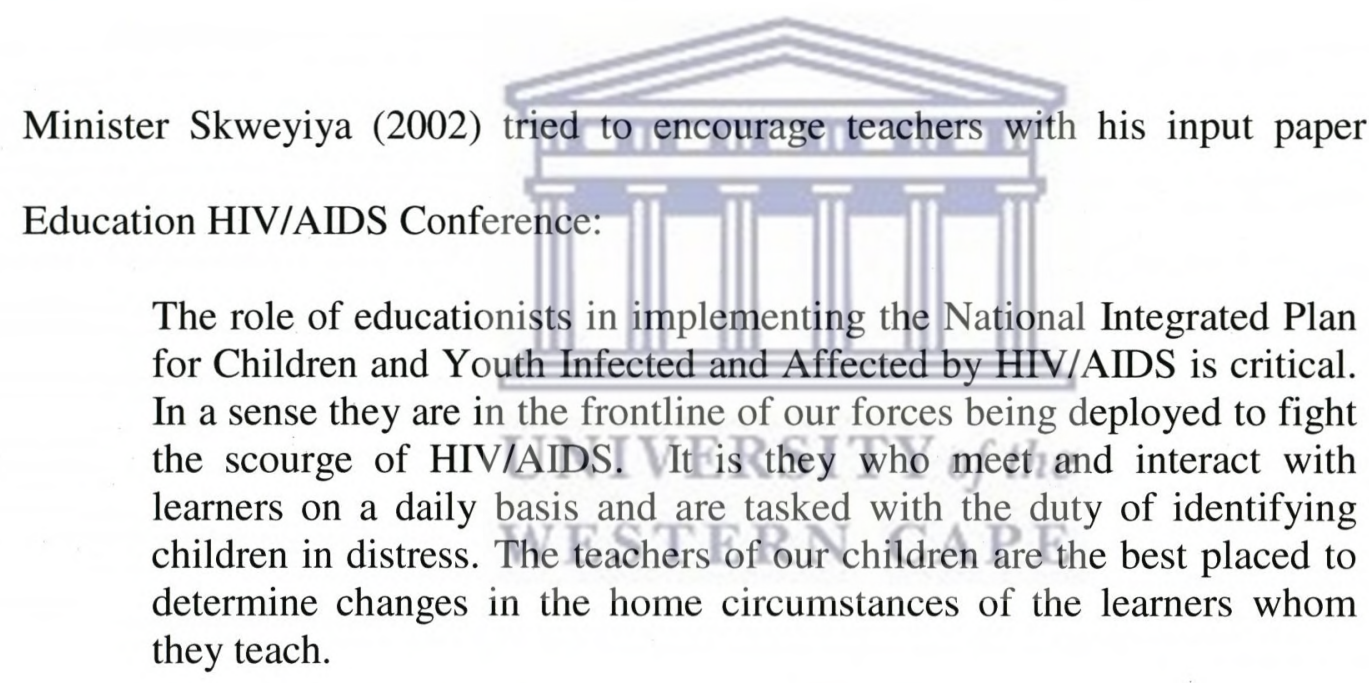

The question that arises is, Are all teachers creative enough or stimulated enough to tackle the HIV/AIDS challenge? It is assumed that teachers play a critical role and are often the main adults, other than family members, with whom students interact on a daily basis. 


\subsection{BREAKING THE HIV/AIDS CULTURE OF SILENCE IN THE CLASSROOM}

It is normally behind close doors, in their classrooms that teachers either impose or resist the "culture of silence". There are many different ways of contracting HIV and there are various ways of preventing HIV/AIDS. There are many different groups of people exposed to HIV/AIDS and there are many ways in which people living with HIV/AIDS are discriminated against. The Whys, How's and Who's change from one cultural context to another.

On the basis of the Mexico Declaration of 1982, culture is broadly understood within

UNESCO to include:

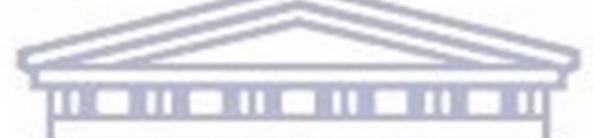

... ways of life, traditions and beliefs, representations of health and disease, perceptions of life and death, sexual norms and practices, power and gender relations, family structures, languages and means of communication; as well as art and creativity.

\section{UNIVERSITY of the}

From the above definition, it is clear that culture influences attitudes and behaviours related WESTERN CAPE

to the HIV/AIDS pandemic: in taking or not taking the risk of contracting HIV, in accessing treatment and care, in shaping gender relations and roles that put women and men at risk of infection, in being supportive towards or discriminating against people living with HIV/AIDS and their families.

As HIV/AIDS is largely a human sexuality issue, it would be useful to look into various attitudes towards sex. Unless this changes, the HIV/AIDS challenge will become increasingly difficult to address. 
The difficulty in establishing workable HIV/AIDS programmes comes from a lack of openness, in many societies, regarding sexuality, male-female relationships, illness and death, taboo subjects deeply rooted in the cultures of such societies.

\subsubsection{Spiritual and/or religious constraints}

There is a growing momentum amongst religious groupings to become involved in promoting HIV/AIDS awareness and prevention. Essentially they have no choice as increasing numbers of congregants or their loved ones die due to the pandemic. Until recently, I often found that when I talked about sex in public, it was frowned upon as not being a good religious practice. As recently as 2005, when I spoke about sex in the Life Orientation lesson at school, one of the parents wrote a letter to me stating "Don't talk about sex in public, it is not good for a practising Muslim." I strongly contend that if I am serious about playing a meaningful role in taking up the HIV/AIDS challenge then I need to tackle this conspiracy of silenee firmty and resolutely.

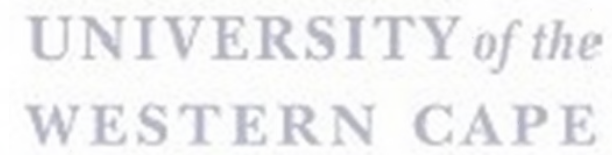

The church or mosque, as a body that claims to be the conscience of humanity and the custodian of moral values, needs to lead in the campaign to break the conspiracy of silence. This seems to be a difficult task as most religious communities have a history of silence on sexual matters, except to condemn. This view is also substantiated by Foster (1985:120):

When people turn to the church for direction in sexual matters, they are usually met with stony silence or a counsel of repression. He concludes that silence is no counsel and repression is bad counsel. And because we have categorized HIV/AIDS as punishment for sinful living, the church has further marginalised the "clientele" it is supposed to serve. In most African countries the issue of silence is compounded by both our cultural socialization and spiritual or theological perceptions. 
Perhaps the reason why the church finds it difficult to handle sex and sexuality related issues is because some church groupings have considered sex as belonging to a domain outside the sovereignty of God. Though we may find it hard to admit, it is true that some human beings, including some church groupings, regard sexuality as a taboo subject that no one wants to be associated with or even discuss. Micah also alludes to this:

HIV/AIDS first appeared in the early 1980's, in the West largely among the North American homosexual community, and in other communities around the world amongst commercial sex workers and intravenous drug users. This helped reinforce the early opinion among many Christians that this disease was a judgement of God on promiscuous sexual behaviour. These were often lifestyles Christians saw as bizarre or wicked. These were embarrassing subjects; ones we felt uncomfortable to even discuss $(2007: 1)$.

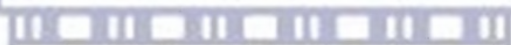

The church seems to be comfortable with the fact that sex education is the responsibility of governments, schools and NGOs. This view might have changed in recent years as the homosexuality debate and the issue concerning same sex marriages has had much attention in church and mosque services recently.

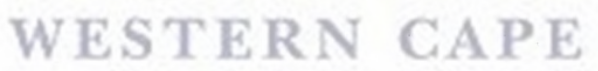

In the past it was taboo to speak about sexual issues in the church and this was mainly due to the way some theologians interpreted the texts. The subject of sexuality was neither approached clinically nor as a natural phenomenon. It has always been veiled behind stigma, taboo and mystique (Roy \& Rizvi, 1998).

Talking sexuality is challenging in itself. With the spread of the HIV/AIDS pandemic, the situation becomes graver as often the victim is further victimised in some 
instances. According to Micah (2007:1):

Hundreds of thousands of women and children have contracted the AIDS virus despite living lives of moral fidelity. For example, in many cultures a woman's highest risk factor is to be faithfully and submissively married to a husband.

Culture and religion have a profound effect in maintaining the gender status quo and upholding social norms and expectations of men and women and can create some of the most significant barriers to effective HIV prevention. A key example is the stance of the Catholic Church on the use of condoms. For the most part, the position taken by organised religion on sexuality and HIV/AIDS is extremely conservative and seldom challenged, yet many people trust their church and turn to its leaders in times of crisis. In Saudi Arabia, the heart of the Muslim world, social stigma associated with HIV/AIDS is complicating HIV awareness and prevention efforts as well (AP/Houston Chronicle Reports 2006/11/27). Although the government recently has begun to address the spread of the virus, HIV prevention efforts often do not include discussions of condoms or safer-sex practices but instead focus on abstinence and the "fear of God" (Kaiser Daily HIV/AIDS Report, 2006/8/8).

Some religious sects might have a point when they put forward the argument that instead of acquiring skills in talking about sex, we resort to the easy way out like distributing condoms to children and adults alike without proper education in matters of sex and sexuality. When one looks at the South African scenario, the flooding of people with condoms has not had much success because the number of people infected is going up, not down. 
In championing the HIV/AIDS debate it becomes critical to view human sexuality positively and thus allow the light of scripture to shine upon the area of sex. Perhaps it will be helpful to avoid traditional clichés like "sex is wrong", "sex is sinful" and "sex is bad". Herbert (1971:48) affirms the viewpoint that both abstinence and faithfulness are positive messages for the human race. This message of abstinence and faithfulness needs to be encouraged and enhanced. It is a message that needs to be understood against the background of a desire to build human character.

\subsubsection{Ambivalence of culture}

As a transmitter of values and moral codes, culture has undoubtedly played a significant role in ensuring that posterity knows what is acceptable and what is not. Contrary to the racist opinion that African people have always been promiscuous, their cultural signposts indicate that African people in general have been proud of their good behaviour. In South Africa, for example, a young woman who is discovered to have lost her virginity before the wedding is said to have caused ihlazo (shame) for her people.

To ensure that young girls kept their virginity, some clans among the amaZulu practice virginity tests. In the modern day culture of human rights such exercises are discouraged, but it is nevertheless important to acknowledge the significance of their background. Another important cultural institution that participated in the teaching of sexual behaviour to young people continues to be initiation schools. According to an 
explanation concerning initiation schools given sometime back by Mbiti (1969: 9):

At separate schools young women and men were taught how to prepare for adult life, how to relate to people of the opposite sex and, in some tribes, how to have sex by simulation. Penetration was firmly forbidden until marriage.

When missionaries came to preach the gospel in Africa, they did away with many cultural institutions, most of which were good and helped to maintain the moral fibre of society. The fact was that missionaries did not come up with a meaningful replacement. This view was also held by Kraft (1979:261) when he mentioned that “... nothing was provided to fill the lacuna created in the process of Christianizing Africa."

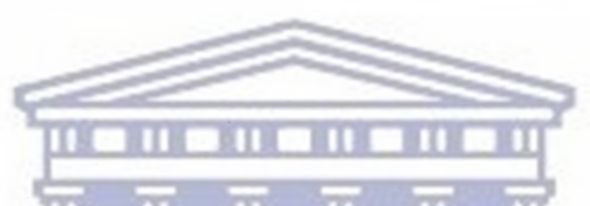

On the flipside of the coin, it appears as if culture has fostered the conspiracy of silence. Generally, in most African cultures talking about sex in public is considered culturally taboo. Even those who try seriously to address sexual matters are shouted down or ridiculed. This is also emphasised even in the case of church ministers. According to Dube (2003a:3);

Ministers are expected to talk about heaven and God, and if they have to talk about sex it is in hushed tones behind closed doors. They are afraid that if the congregation or their superiors find them talking openly about sex they will be disciplined or suspended. Consequently, church ministers end up being simply agents of culture rather than ambassadors of the truth. The conspiracy of silence continues.

The challenge to break the silence about human sexuality needs to be faced if I am to succeed in talking about HIV/AIDS. I would like to agree with the view of Khathide who believes that “... most parents have abdicated their responsibility to give sex education to their children in the hope that schoolteachers and the mass media will fill the void" (2000: 6). 
The first steps in education, and here I would like to include sex education, starts at home. Therefore, perhaps the best place to break that silence should have been the home. Parental guidance remains the most important basis for children's education. Before our children hear about sex anywhere else, they need to hear about it at home first. Parents, however, knowingly or unknowingly, tend to shy away from discussing sex and sexuality issues with their children. I want to agree with Dube (2003b:2) when he says that "the reason parents are ashamed to talk about sex to their children, is because marital partners themselves are ashamed to talk about sex to one another". This view is also held by Smedes, who maintains that:

In marriage, many people are afraid to talk about their sexual problems openly because they do not want to hurt the other partner. Some secretly resolve to be involved extra-maritally. If nothing helps, they may end up divorcing their partners. Often, after divorce, people talk about the real reason why they separated from their partner. We need to look sex in the eye and stop regarding it as an idol of some kind (1976:50).

\subsubsection{Demystifying sex}

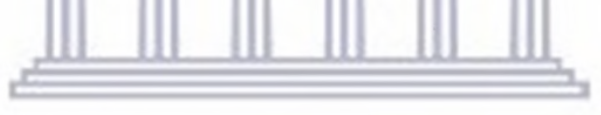

\section{UNIVERSITY of the}

When it comes to sex many people are confused, confounded and inconsistent. I may be sure that I know what is right or wrong about things people do concerning sexuality related matters. But I am not really sure within myself about how I actually feel and how I ought to feel about the sexuality that is woven into the texture of me as a being. On the one hand, some culturally and theologically conservative persons may secretly enjoy the sexual urges within themselves and some even pastorally advise enjoying sex with their marital partners, without openly admitting it. On the other hand, the most liberated persons in a taboo-free age may still have residual feelings of shame about their sexuality. Other people try outrightly to deny their sexuality. Human beings carry within them a complex mixture of feelings about sex. 
It could therefore be imperative to demystify human sexuality. I strongly feel the need to lift the lid off it - the blanket of mystery on sex and related issues needs to be strategically removed. The cultural and spiritual barriers prohibiting any discussion on sexuality must be constantly unpacked and challenged. Discussing sex, which is very much part of being human, will go a long way in helping our community grapple with the scourge of HIV/AIDS in a meaningful way. Those who are infected and affected will hopefully find it easier to talk about their status and feelings more openly.

Understanding what motivates people's behaviour, knowing how to address these motivations appropriately, and taking into consideration people's cultures when developing programmes addressing HIV/AIDS are essential to changing behaviour and attitudes towards sexuality and the pandemic.

\section{UNIVERSITY of the}

At the UNESCO, Paris conference held on 20 November 2004, it was once again highlighted that culture should be taken into account at various levels:

As context - an environment in which HIV/AIDS communication and prevention takes place; As content - local cultural values and resources that can influence prevention education; culturally appropriate content of sensitization messages is mandatory for them to be well understood and received and as a method that enable peoples' participation, which helps to ensure that HIV/AIDS prevention and care is embedded in local cultural contexts in a stimulating and accessible way.

Since the advent of HIV/AIDS the school where I teach at and did my research, has shown no real enthusiasm to get involved in the debate about the pandemic at a public level. This I contend, is probably not due to the lack of interest on the part of the learners, teachers or parents at the school, but rather a safety ploy to steer clear from public stigmatization that 
goes with the virus. Another reason for the silence could be that HIV/AIDS requires discussing human sexuality and sexual practice, traditionally areas where religious schools have not felt comfortable discussing. At the school where I did my research it appeared that the stance taken by some parents and even teachers against HIV/AIDS was one of silence.

\subsection{THE TEACHER RESEARCHER AND CRITICAL THEORY}

It is tempting for researchers and policy-makers to develop idealistic strategies regarding the roles of schools and teachers in combating HIV/AIDS. Gilligan (1998), in his response to protect children from sexual abuse, lists various ways in which teachers and schools might serve children. First, schools can offer children access to caring adults who can serve as instructors, confidants, and positive role models. Second, schools can provide $\overline{d a y}-\overline{b y}$-day monitoring of children's emotional and physical health and behaviour, crucial for identifying hidden problems. Third, schools have the possibility of building capacity in the community, including raising UNIVERSITY of the

awareness of sex and sexuality issues among learners, parents and the community in general, as well as skills that enable children to be better protected. Fourth, schools can represent a secure base and sanctuary for vulnerable children. Fifth, schools could serve as places where relationships can be built with caring adults and other children, something crucial for withdrawn or isolated children, both characteristics of some HIV/AIDS victims. Finally, schools could be resources for overwhelmed and isolated parents and provide hubs for service delivery to children.

If schools are going to do all of the above, they will definitely have to serve as nodes of care and support. For schools to serve as nodes of care and 'sites' of care and not 
just service providers, a 'critical mass' and a critical response to the traditional education theory paradigm schools have confined themselves to is also needed. It is now almost two decades ago since critical education theory started developing as a critical response to the "ideology of traditional educational practice" (McLaren, 1998:xxix).

In using the term "critical theory" I am referring to the Frankfurt School (Kellner, 1989), but the critical theory that I am anticipating is broader than the version developed by the German-American exiles of the 1940's. In the context of theorizing and reconstructing education for the contemporary era, I would include the tradition of critical pedagogy, Dewey's pragmatism and post-structuralism. My appropriation of the latter would encompass the critical theories of gender, race, sexuality and constructions of subjectivity that have developed from a broad range of theoretical streams over the past decades. These themes can enrich critical pedagogy and help with the Deweyean project of democratizing and reconstructing education so that the aims of social justice and progressive transformation can inform pedagogy and practice.

Critical pedagogy is defined by Grundy (1987:156) as one which confronts the real problems of existence, involves processes of conscientization, confronts ideological distortion, and incorporates action as part of knowing. Giroux (1988:20), in his introduction to Freire and Macedo says that a critical pedagogy must take seriously the articulation of a morality that posits a language of public life, emancipatory community, and individual and social commitment. Giroux (1981:83) sees in critical 
pedagogy the bridge between theory and practice. The critical pedagogy which I support is well articulated by McLaren (2006:2):

... one of non-violence, the development of a philosophy of praxis guided by a Marxist humanism, the study of revolutionary social movements and thought, and the struggle for socialist democracy. It is opposed to liberal democracy, which only serves to facilitate the reproduction of capital. It advocates a multiracial and anti-imperialist social movement dedicated to opposing racism, capitalism (both in private property and state property forms), sexism, heterosexism, hierarchies based on social class, as well as other forms of oppression.

I would think that critical pedagogy was partially influenced way back in 1848 by Marxist theories and other revolutionary visionaries. In their 1848 "Communist Manifesto", Marx and Engels made liberation of the working class from bourgeois education and expanded public education for the working class one of their major demands, to constructing socialism: "Public education of all children free of charge. Elimination of children's factory labour in its present form. Combination of education with material production, signals the Marxist philosophy of education that was never fully developed, but it is clear that free public education was a key demand of Marxian socialism. Crucially, Marx and Engels wanted to "... rescue education from the influence of the ruling class ..." Hyppolite (1974:487), arguing that education currently reproduces capitalist-bourgeois societies and must be completely reconfigured to produce alternative ones.

As the twentieth century unfolded, it was John Dewey (1859-1952) who developed the most sustained reflections on progressive education, linking education and democracy. Dewey insisted that one could not have a democratic society without education, that everyone should have access to education for democracy to work, and 
that education was the key to democracy and thus to the good life and good society.

Dewey was a proponent of "strong democracy", of an egalitarian and participatory democracy, where everyone takes part in social and political life. For Dewey, education was the key to making democracy work, since in order to intelligently participate in social and political life, one had to be informed and educated to be able to be a good citizen and competent actor in a democratic context.

According to Kellner (2003:7),

Dewey like Rousseau, and even more so, was experimental, pragmatic, and saw education as an evolving and experiential process in which one would learn by doing. The term "pragmatism" is associated with Dewey, and in one of its meanings signifies that theory should emerge from practice, that education should be practical, aimed at improving everyday life and society, and that by using the method of trial and error, one could learn important life skills, and gradually improve democratic society and education.

From similar pedagogical perspectives, yet from a different historical and geographical location, namely Brazil in the 1960s, Paulo Freire argued that the oppressed, the underclasses, have not equally shared or received the benefits of education and they should not expect it as a gift from the ruling classes, but should educate themselves developing a "pedagogy of the oppressed" (1972; 2000). For Freire, emancipatory education involves subverting the Hegelian master/slave dialectic, in which oppressed individuals undertake a transformation from object to subject and thus properly become subjects and more fully developed human beings. Responding to the situation of colonization and oppression, Freire's pedagogy of the oppressed involved a type of decolonization, a consciousness-raising (conscientizacao) and, in addition, allowed the educated the right to thematize issues of study, to engage in dialogue with teachers and to fully participate in the educational process. 
Developing a "pedagogy of the oppressed" requires the creation of learning processes that will really help individuals better themselves and create a better life through social transformation and empowerment, rather than conforming to dominant views and values. Freire is also famous for his critique of "banking" education and development of a dialogical pedagogy. Freire perceived that education is often a form of indoctrination, of enforcing conformity to dominant values, and of social reproduction in which one is tutored into submission and acceptance of an oppressed and subordinate status. Therefore, a pedagogy of the oppressed has to oppose dominant conceptions of education and schooling and develop more critical and emancipatory educational practices aimed at radical social transformation.

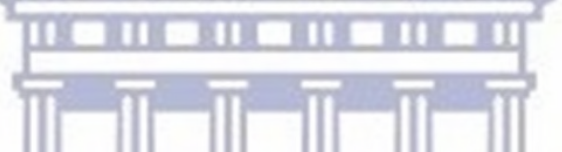

It is interesting that all the classical philosophers of education that I have discussed, as well as Marx and Freire, assume that education is of central importance to creating better and more fully-realized individuals, as well as a good society, and therefore that WESTERN CAPH

a liberating philosophy of education is a key aspect of social critique and transformation. Critical philosophies of education provide radical critique of the existing models of education in the so-called Western democracies and provide progressive alternative models still relevant to our contemporary situation. I want to agree with Best \& Kellner $(1997 ; 2001)$ that many of these philosophies of education, however, work with questionable conceptions of reason, subjectivity and democracy, and neglect the importance of the body, gender, race, sexuality, the natural environment and other dimensions of human life that certain modern theories failed to address adequately. Consequently, the poststructuralist critique of modern theory provides important tools for a critical theory of education in the present age. 
According to Kellner (2003:8),

Poststructuralist theories emphasize the importance of difference, marginality, heterogeneity, and multiculturalism, calling attention to dimensions of experiences, groups and voices that have been suppressed in the modern tradition. They develop new critical theories of multicultural otherness and difference, which includes engagement with class, gender, race, sexuality and other important components of identity and life that many modern pedagogies, neglect or ignore. Poststructuralists also call for situated reason and knowledge, stressing the importance of context and the social construction of reality that allows constant reconstruction.

Poststructuralist theories have empowered women, people of colour, gays and lesbians, and others excluded from modern theory and educational institutions. Feminists, influenced by poststructuralism and multiculturalism, like Bell Hooks (1994), have stressed the importance of gaining agency and voice for oppressed groups and individuals who have traditionally been marginalized in educational practice and social life. Giving a voice within education and society to individuals in oppressed groups marked by race and ethnicity, sexuality, or class, articulates well with the perspectives of Paulo Freire, although he himself did not bring in these domains until his later work (Kellner, 2003). Freire's eventual turn toward more inclusive and articulated gender and multicultural perspectives was in part a response to critique from feminists, critical race theory, gays and lesbians and other oppressed groups, and in part a development of his theory as he interacted with more groups and individuals.

Building on these perspectives enables a philosophy of education to develop a more inclusive philosophical vision and to connect education directly to democratization 
and the changing of social relations in the direction of equality and social justice. Since social conditions and life are constantly changing, a critical theory of education must be radically historicist, attempting to reconstruct education as social conditions evolve and to create pedagogical alternatives in terms of the needs and problems of people in concrete situations. Hence, a critical theory of education involves conceiving of what education could be, in how radicalizing education could help change society.

A critical theory signifies a way of seeing and conceptualising, a constructing of categories, making connections, mapping, and engaging in the practice of theoryconstruction, and relating theory to practice. A critical theory is interdisciplinary, involving a critique of academic disciplines and fragmentation and transdisciplinary connecting material from different domains to craft a multiperspectival optic on contemporary society. Critical theory is boundary-crossing and mediating, bringing together various dimensions of social life in a comprehensive normative and historical thinking.

Of course, some versions of the Hegelian-Marxian critical theory are excessively totalizing, reductive, teleological and ideological, but one can avoid these pitfalls by mediating Hegelian/Marxian/Modern conceptions with poststructuralist epistemologies and analyses of emergent post-modern conditions that put in question previous pedagogies and educational philosophies. Moreover, to democratize and reconstruct education, one can combine modern and post-modern perspectives, theory and practice, as I attempt to do in this thesis. 
My experiences and the insights gained from the critical theorists and poststructuralists were used to inform my understanding of practice in the workplace. It guided and motivated me to improve my practice and strengthen my commitment to political and educational change.

It seems that much of what Giroux spoke about in his situation is very much applicable to the public schooling scenario of today:

Educators at the public school levels are under massive assault in this country. Not only are they increasingly losing their autonomy and capacity for imaginative teaching, they increasingty bear the burden, especially in the urban centres, of overcrowded classes, limited resources and hostile legislators (Giroux, 1988:26).

With the changes in the country, the traditional way teachers perceived their roles in the communities has also been altered. This together with the HIV/AIDS pandemic, the rationalising, right-sizing and the streamlining of education has made teaching amongst the most challenging occupations. In spite of all this, teachers have the choice to remain in the teaching fraternity and to continue taking up the challenges and complexities of change in the South African educational scenario. As a teacher concerned about the devastation impact of HIV/AIDS, I somehow believed that as a primary school teacher I could make a difference. Here I want to agree with Elliott (1989:57) that teacher-researchers are well placed to analyse and improve their classroom practices. To take up the present day HIV/AIDS challenge as a critical teacher- researcher, I therefore take my work seriously as knowledge creation. 
This view is also held by McNiff when she says:

I think as teachers we have much to contribute to public debates about education and educational research, from the grounds of the authority of our experience, and also from the grounds of our evidence-based research practices (2007:2).

In my study 'Breaking the culture of silence in checkmating HIV/AIDS as a teacherresearcher', I have learned how action research and teaching are interlinked. Action research enabled me to critically reflect and describe what I did, as well as how and why I did it.

In the following chapter, (chapter three) I discuss the research methodology followed in this study. I also explain why I chose emancipatory action research with its reflective practice as a research methodology to break the HIV/AIDS culture of silence in my classroom practice. 


\section{CHAPTER THREE}

\section{TOWARDS AN EMANCIPATORY ACTION RESEARCH APPROACH}

\subsection{INTRODUCTION}

In the previous two chapters I pointed out how the HIV/AIDS pandemic impacts on sub-Saharan Africa with special reference to the South African educational scenario. I made the point that HIV/AIDS is, to a large extent, a human sexuality issue with attitudes and behaviour change being amongst the major challenges. I also elaborated on the difficulties in establishing effective HIV/AIDS programmes due to the lack of openness in many societies, regarding sexuality, male-female relationships, illness and death, as well as many other taboo subjeets deeply rooted in many cultures across the diverse spectrum in a country like Seuth Africa.

Effecting behavioural change is a complex task and difficult to bring about. It requires an appropriate strategic pathway. As mentioned earlier (Chapter One, p10), for this behavioural change to take place continuous processesfof self-reflection, selfawareness, planning and appropriate action are essential. The central question that arises is, Is it possible for action research projects to contribute to behavioural change? According to the literature on critical theory and the critical theory approach to teaching, and here I draw on the views of Habermas (1972), Kemmis \& McTaggart (1982), Carr \& Kemmis (1986), McKernan (2000), Cohen, Manion \& Morrison (2000), Meerkotter (2002) and McNiff \& Whitehead (2005 and 2006) about reflective practice, resulting in meaningful behavioural change as one of the ultimate purposes of an emancipatory action research approach. 
Action research is not a new approach to research. It has a history and has been used and defined by researchers and practitioners in a variety of ways. There are many ways of looking at action research, different schools of thought tend to emphasise different aspects of the action research process. My view about action research is that it provides a way for teachers to reflect on and research their classroom practice with a view to improve their practice.

In this chapter I provide a brief historical background of the development of action research, define it, explain how it operates and give an indication as to why I decided to use this research methodology. I also elaborate on the resources used in this process.

\subsection{THE DEVELOPMENT OF ACTION RESEARCH}

According to McKernan (1991:8) action research has developed from a complex web of scientific and social enterprise. The term "Action Research", was a concept that was already used in the 1940s by Kurt Lewin while doing social research in human relations (Oja \& Smulyan, 1989:1). The basis of Kurt Lewin's thinking, a German scholar that emigrated to the United States, was the idea of Karl Marx (1870), that it is not enough "... merely to understand and interpret the world, but to change it" (cited in Cohen, Manion \& Morrison, 2000:226). According to these three authors, Lewin in his own work intended to change the life chances of disadvantaged groups in terms of housing, employment, prejudice, socialisation and training. Thus, the concept of action research was not first used in an educational context.

McKernan (1991:8) states that there is evidence of the use of action research by a number of social reformists at more or less the same time as Lewin's projects. Examples 
of the use of action research by social reformists are Collier in 1945, Lippitt \& Radke in 1946 and Corey in 1953. McTaggert (1992:2) cites work by Gestettner \& Altricher which makes mention of a physician named Moreno using group participation in 1913 in a community development initiative with prostitutes in Vienna. And Freideres (1992:34) asserts that the concept of participatory research emerged in the 1970s from development work in low income countries.

Lewin although not the first to use and write about action research, nevertheless did "...construct an elaborate theory and made action research a respectable inquiry for social scientists" (McKernan, 1991:9). Lewin argued that in order to "understand and change certain social practices, social scientists have to include practitioners from the real social world in all phases of inquiry" (McKernan, 1991:10). Elliott (1984:74) explains Lewinian Action Research, which was first used in industry, as an

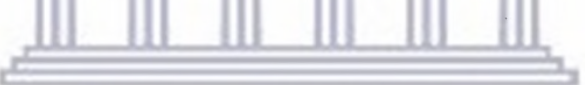

... activity engaged in by groups or communities with the aim of changing their circumstances in ways which are consistent with a shared conception of human values. It is a means of realising the common good - rather than a merely individual good. It is a reflexive social practice in which there is no distinction to be drawn between the practice being researched and the process of researching it.

The idea of Lewin's action research was later taken up in the late sixties by Lawrence Stenhouse to improve educational practice. This is also pointed out by Cowan (1990:4) where she states that

... the beginning of a serious attempt to use action research in education was given momentum in England when Lawrence Stenhouse (1975) encouraged teachers to view themselves as researchers.

In 1975 Stenhouse specifically referred to teaching as a process of enlightenment, making the point that to enhance one's practice one would need to reflect on one's own teaching. 
According to Stenhouse,

... the improvement of teaching is a process of development. I mean by the first, that it is not to be achieved by a change of heart but by the thoughtful refinement of professional skill; and second, that the refinement of professional skill is generally achieved by the gradual elimination of failings through the systematic study of one's own teaching (1975:39).

Stenhouse's idea of research where teachers become researchers and contribute to the development of the curriculum, was then taken up further and given a more critical perspective by writers such as Elliott (1985), Adelman (1985), Hopkins (1985), Walker (1985), Carr \& Kemmis (1986), Grundy (1987), Winter (1989), McKernan (2000), Robinson \& Meerkotter (2003) and McNiff \& Whitehead (2005 and 2006).

In South Africa, an emancipatory form of action research as an educational initiative was first cited in a book, entitled Action Research: justified optimism or wishful thinking? edited by Flanagan et al (1984). The idea of action research as a research methodology was given more prominence when it became part of a formal and structured master's programme in the Education Faculty at the University of the Western Cape (UWC) in 1987 under the guidance of Owen van den Berg and later Dirk Meerkotter (1988). According to van den Berg (1993:15)

... Action Research can be a powerful force in freeing South African teachers from the shackles of their socialization ... action research needs space in the academe to flower rather than to perish.

Having sketched a brief historical background of action research, I provide an outline as to what action research is all about, as I understand it. 


\subsection{WHAT IS ACTION RESEARCH?}

According to O'Brien (1998:2), “Action research is known by many other names, including critical research, participatory research, collaborative inquiry, emancipatory research, action learning, and contextual action research, but all are variations on a theme". Put simply, action research is "learning by doing" with a view to improve a particular practice, a problem in the process is identified, something is done to improve the process, the outcome is evaluated, and if not satisfied, more attempts are made.

While this is the essence of the approach, there are other key attributes of action research that differentiate it from other problem-solving activities that one engages in every day. The combination of action and research has contributed to its attraction to researchers, teachers and sectors of the academic community, such as teacher educators and educators preparing students as health professionals. Many workplaces now encourage practitioners to undertake formal action enquiries as part of their professional development.

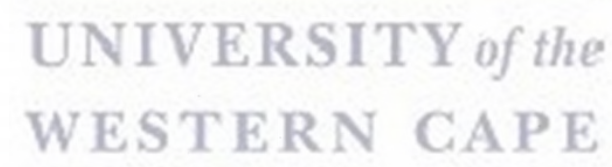

There is no one agreed definition of action research as various writers have described it differently. McKernan (2000:5) considers the following a minimal definition:

$\ldots$ action research is the reflective process whereby in a given problem area, where one wishes to improve practice or personal understanding, inquiry is carried out by the practitioner - first, to clearly define the problem; secondly, to specify a plan of action - including the testing of hypothesis by application of action to the problem, evaluation is then undertaken to monitor and establish the effectiveness of the action taken. Finally, participants reflect upon, explain developments and communicate these results to the community of action researchers. Action research is a systematic self-reflective scientific inquiry by practitioners to improve practice. 
An earlier, yet more succinct definition, is given by Gilmore, Krantz \& Ramirez (1986:161):

Action research... aims to contribute both to the practical concerns of people in an immediate problematic situation and to further the goals of social science simultaneously. Thus, there is a dual commitment in action research to study a system and concurrently to collaborate with members of the system in changing it in what is together regarded as a desirable direction. Accomplishing this twin goal requires the active collaboration of researcher and client, and thus it stresses the importance of co-learning as a primary aspect of the research process.

Thus, action research has some unique attributes that separates it from other types of research methodologies. Primary is its focus on turning people involved into researchers. All involved in the research process become active participants. It has a social responsibility dimension as the research takes place in real-world situations and aims to solve real problems. Finally, the initiating researcher, unlike in many other approaches, makes no attempt to remain objective, but openly acknowledges their bias to the other participants.

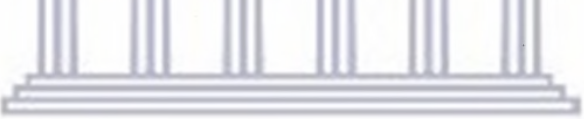

A commonly used definition of action research is the one provided by Carr \& Kemmis two decades ago (1986:162):

Action research is a self-reflective enquiry undertaken by participants in social situations in order to improve the rationality and justice of their own practices, their understandings of these practices, and the situations in which these practices are carried out.

The above definition, and here I am supported by Davids (1991:40), makes the point that the aim of action research is the improvement of "rationality" and "justice" in a social context. 
McNiff also holds the viewpoint that self-reflection is a major component in action research (2002:5):

The idea of self-reflection is central. In traditional forms of research empirical research - researchers do research on other people. In action research, researchers do research on themselves. Empirical researchers enquire into other people's lives. Action researchers enquire into their own. Action research is an enquiry conducted by the self into the self.

The reflexive - dialectical character of action research is also brought out by Delhaas \& Koekkoek (1989:68) who states that action research is:

... a qualitative scientific enquiry, aimed at a jointly planned change of the learning environment through deliberate collaborative and emancipatory action at reflective and executive levels, and resulting in transfer of results through adaptation rather than adoption.

\section{TI: 11 m}

Davidoff \& van den Berg (1990:28) define action research as

... a way of taking a systematic, close, critical look at the way in which we teach, with the view to changing it so that the classroom experience becomes a more meaningful one for all those involved in it.

\section{UNIVERSITY of the}

This definition dispels the idea that action research is a disorganized and ill-planned process. It is, in fact, systematic and requires researchers to be focused and directional. It therefore, strengthens the case for teachers to become researchers in their classroom practice. To look critically into improving and possibly changing their classroom practice. Who best can report on the teacher's activities than the teacher and her students and who best can improve the teacher and student's sense of "rationality" and "justice" than the teacher working and striving towards a common goal with the students.

To put it simply, my understanding of action research is to research one's own action(s) with a view to improve one's practice. Action research is a way of doing research that 
may or may not be emancipatory or transformative. Its potential for transformation depends on the way in which it is done, who is involved in the process, the type of questions which are asked, and how this research enables the teacher to change the micro, meso and macro conditions in which a particular category of practice occurs.

Making use of action research, however, does not necessarily imply that one is a critical researcher.

\subsection{THREE MODES IN WHICH ACTION RESEARCH MAY BE CARRIED OUT}

Grundy (1987:10) describes three modes of action research, namely "technical", "practical" and "emancipatory". Masters (2000) and Cohen, Manion \& Morrison (2000) also mentions these three types of action research and state that most definitions fit one type of action research better than others. Holter \& Schwartz-Barcott (1993:301) discuss three types of action research, that of a technical collaborative approach, a mutual collaborative approach and an enhancement approach. McKernan (1991:16-27) lists three types of action research: Type 1: the scientific-technical view of problem solving; Type 2: practical-deliberative action research; and Type 3: critical-emancipatory action research. McCutcheon \& Jurg (1990:145-147) discuss three perspectives of action research: a positive perspective, an interpretivist perspective and a critical science perspective.

It is not in the methodologies that the three modes of action research differ, but rather in the underlying assumptions and world views of the participants that cause the variations in the application of the methodology (Grundy 1982:363). The ultimate test to 
determine whether research is indeed transformative in character is to find out if it benefits the public good and reduces oppression and other injustices (Williams 2002:62).

The technical mode of action research places emphasis, according to Grundy (1987:148)

... on how better to control the environment and to produce the desired outcomes of the (proposed) project... Here action research is employed as a methodology which co-opts the participants in ways which may superficially lead to improvement in their social situation, but which fundamentally makes no change to the power relationships implicit in the social practice.

It therefore becomes clear that in the technical mode, action research is utilised as a scientific method for solving practical problems. It results in the accumulation of predictive knowledge, the major thrust is on validation and the refinement of existing theories.

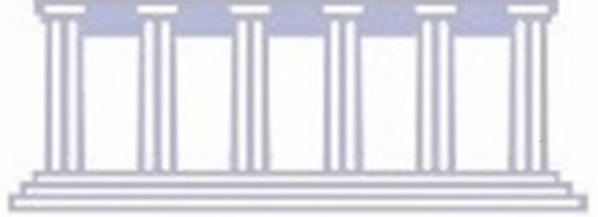

The practical mode of action research considers the experiences and viewpoints held by the actors involved in the situation, but fails to contextualise this within an understanding of power relations within society. Thus practical action research, according to Grundy (1987:148), places

... a fundamental interest in understanding the environment through interaction based upon a consensual interpretation of meaning.

The third mode of action research is emancipatory action research. Emancipatory action research is according to Grundy (1987:148), the mode which tries to be consistent with the principles of improvement, involvement and emancipation. Emancipatory action research as expounded by Cohen, Manion \& Morrison (2000:231) has an explicit agenda 
which is political as it is educational. Reason \& Bradbury (2001:1) have the following to say about emancipatory action research:

Emancipatory action research is a participatory, democratic process concerned with developing practical knowing in pursuit of worthwhile human purposes grounded in a participatory worldview... It seeks to bring together action and reflection, theory and practice, in participation with others, in pursuit of practical solutions to issues of pressing concern to people, and more generally, the flourishing of persons and their communities.

It (emancipatory action research) is also described by Carr \& Kemmis (1986:203) as an empowering process for participants in that it engages them in the struggle for more rational, just, democratic and fulfilling forms of education. Thus, high on the agenda of emancipatory action research is the issue of empowerment (the taking control of one's life in an autonomous, responsible way). This type of action research approach seemed to suit me as I wished to empower the students that I worked with, including myself. On this, Walker (1990:61) says that action research allows

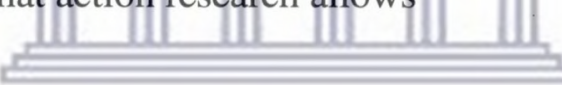

... teachers' voices and those of their pupils as partners in the research enterprise to be heard as producers of educational knowledge.

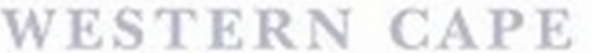

Unlike technical and practical action research, emancipatory action research encourages the full participation of the groups involved. It becomes clear that emancipatory action research, unlike traditional research (the research that is most often used), acknowledges that it has a political agenda. Williams (2002:63) makes the assertion that critical action research is not only suitable, but also imperative, as we engage in the struggle to democratise the South African education system. The teacher and students are not only concerned with changing and improving their practice in the classroom, but will also be concerned with changing unequal relations in the wider social context. Here processes in the school are viewed in relation to the macro environment in which the school is 
situated. Knowledge is looked at critically in terms of how it is socially constructed and how it, in turn, shapes and hopefully changes reality. This is illustrated clearly in the following words of Lather:

Emancipatory knowledge increases awareness of the contradictions hidden or distorted by everyday understandings, and in doing so it directs attention to the possibilities for social transformation inherent in the present configuration of social processes (1986:259).

\subsection{HOW THEN DOES EMANCIPATORY ACTION RESEARCH OPERATE?}

The action research approach normally makes use of what can be called four phased cycles or spirals. These can be repeated continuously, with each cycle establishing a new layer of understanding and improved practice. Carr \& Kemmis (1986:165) point out that ... the (Action Research) project proceeds through a spiral of cycles of planning, acting, observing and reflecting with each of these activities being systematically and self-critically implemented and interrelated.

According to Denzin \& Lincoln (2000:595), the process may not be as neat and final as in some other procedures, as the stages will overlap and mutual plans may quickly become obsolete in the light of learning from experience. This is also pointed out by McNiff (2002:11):

Remember that things do not often proceed in a neat, linear fashion. Most people experience research as a zig-zag process of continual review and readjustment. Research reports should communicate the seeming incoherence of the process in a coherent way.

In the paragraphs that follow, I discuss the different, but interrelated phases of the action research process. 


\subsubsection{The Planning Stage (Phase One)}

I suppose when one decides to do an action research project one needs to have a general idea as to what one wants to improve or change. On this, Kemmis \& McTaggart (1984:18) offer the following advice to the potential researcher:

You do not have to begin with a "problem". All you need is a general idea that something might be improved. Your general idea might stem from ... the recognition that existing practice falls short of aspirations.

McNiff (1988:57) also gives guidance to the potential researcher how to identify problem areas:

1. What is your concern?

2. Why are you concerned?

3. What do you think you can do about it?

4. What kind of evidence could you collect to help you make some judgements about what is happening?

5 . How would you collect such evidence?

6 . How would you check that your judgement about what has happened is reasonably fair and accurate?

McNiff (2002:12) gives a modified version of Jack Whitehead's action plan:

1. What issue am I interested in researching?

2. Why do I want to research this issue?

3. What kind of evidence can I gather to show why I am interested in this issue?

4. What can I do? What will I do?

5. What kind of evidence can I gather to show that I am having an influence?

6. How can I explain that influence?

7. How can I ensure that any judgements I might make are reasonably fair and accurate?

8 How will I change my practice in the light of my evaluation?

Another of McNiff's (1988:44) useful contributions to the way action research operates is the identification of what she calls "spin-off-spirals". These are problems that the teacher-researcher picks up as the research process proceeds. 
Thus the planning stage, which is the accepted first phase of the action research cycle, involves the teacher-researcher forming a general idea of what it is he/she wants to research. This can be done by asking questions as proposed by McNiff (see above). This will involve looking more carefully at what is happening in one's classroom from a number of different perspectives. Here it is necessary to look at both the micro and the macro context. One cannot plan a project which is entirely isolated from the socio-political set-up of a local context or even a country.

The teacher-researcher could ask an "outsider" to assist in the planning and reflection of this process. The "outsider", who is possibly a colleague, then takes the role of what is called a triangulator in action research. This will enable the teacher-researcher to develop a clearer focus on the issue s/he wishes to research. The triangulator can also assist in giving advice during the planning phase of the project. It is important that the triangulator be regarded as a participant in the research, not only by the teacherresearcher, but also by the students. IVERSITY of the

\section{WESTERN CAPE}

During the planning stage the teacher-researcher must have negotiations with everyone involved in the research process as action research is a collaborative learning process. Negotiating with the relevant participants, the triangulator and the students form an integral part of the planning stage of the research. The importance of negotiation is stressed by Boomer below.

If teachers set out to teach according to a planned curriculum, without first engaging the interest of the students, the quality of learning will suffer... Negotiating the curriculum means deliberately planning to invite students to contribute to, and to modify, the educational program, so that they will have a real investment both in the learning journey and in the outcomes (1990:51). 
It is important at this stage, according to Cowan (1990:20),

"... to gain agreement from students on confidentiality with respect to data." Another aspect that needs to be considered during the planning stage is the assessing of the physical resources one requires. Here one has to make arrangements for the logistical changes one would need to make, for example, the classroom may need to be rearranged.

During the planning stage the teacher-researcher needs to plan his/her time. It is recommended that the teacher-researcher draws up a timetable of the intended action $\mathrm{s} / \mathrm{he}$ is going to take and the amount of time this might involve.

The gathering of data also needs to be planned. Data collection is an important aspect of research and influences the outcome of one's research inquiry. Like other research methods, action research makes use of its own data collection techniques, such as personal field notes, questionnaires, student diaries, interviews, triangulation and audio/visual recordings. Hopkins (1985:41) advises action researchers that "... any method used must not disrupt the teaching commitment, and must not be too demanding on the teacher's time."

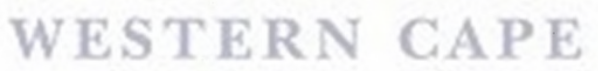

A final word on planning is that it should be flexible enough to adapt to constraints (unexpected early closures, disruption of classes) in the school situation.

\subsubsection{The Acting Stage (Phase Two)}

Here the teacher-researcher will carry out what he/she has planned in a systematic and thoughtful way. The teacher-researcher should observe his/her action while he/she implements it. The teacher-researcher must also be prepared for unanticipated events as plans do not always work out as initially planned or prepared. 


\subsubsection{The Observation Stage (Phase Three)}

During this stage, the teacher-researcher gathers information about his/her action. These actions could be recorded as personal field notes. During this phase the students and the triangulator also record their observations. It is also particularly useful to audio and video tape recordings which will capture not only people's words but also their expressions and body language.

\subsubsection{The Reflecting Stage (Phase Four)}

In this phase the teacher-researcher compares data with what s/he has planned to do and can try and arrive at an understanding of the processes that have taken place. Contradictions in one's data will provide one with useful starting points to get different perspectives on understanding the forces that impact on the classroom. At this stage, the research findings should be discussed and debated with one's triangulator, as well as with the students and other relevant stakeholders, in order to enrich the level of analysis and ensure their involvement in the process of being "ăgents of change".

The teacher-researcher will now use this collective evaluation to plan the next action cycle. S/he may wish to involve the students and triangulator/s in the next planning phase. This is the phase of the project, as Davidoff \& van den Berg (1990:47) put it, "... where you are looking back on your efforts in order to look forward on your future plans." 


\subsection{WHY I CHOSE ACTION RESEARCH?}

I saw action research as an investigation of my own practice with a view to understanding and improving that practice (Carr \& Kemmis, 1986; McNiff, 1988; 2002; 2005; 2006 and 2007). This resonated with my own research aim as I looked to a deeper understanding of HIV/AIDS and sex and sexuality issues in my classroom practice. Furthermore, the deeper purposes of my research echo the principles of action research, namely the creation of a just and caring society; building coalitions of shared knowledge across domains, institutions and cultures; encouraging practitioners to take responsibility for the development of the profession; and an interest in issues of identity and personal development (Walker \& Winter, 1989).

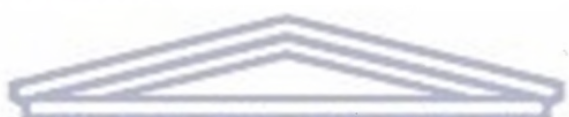

As discussed earlier, HIV/AIDS is largely a human sexuatity issue with attitudes and behaviour change being amongst the major challenges. Effecting behavioural change is a complex task and one which requires a good plan and a strategic pathway. As mentioned already (see Chapter One p10) the central question that arises is, Is it possible for action research projects to contribute to behavioural change? According to the literature on critical theory and the critical theory approach to research and here I draw on the views of Habermas (1972), Kemmis \& McTaggart (1982), Carr \& Kemmis (1986), McKernan (2000), Cohen, Manion \& Morrison (2000), Meerkotter (2002) and McNiff \& Whitehead, (2005 and 2006) behavioural change is an ultimate purpose of action research.

My interest in an action research approach was enhanced by the kind of cyclical research design usually associated with it. It emphasises the point that my research is a "process" and not an event. It leaves the door open for further inputs, scrutiny, 
improvement and further research. This view is also expressed by (Kemmis \& McTaggart, 1982:7; Winter, 1989:11-15, McNiff 2002:12).

- Develop a plan of action to improve what is already happening;

- act to implement the plan;

- observe the effects of action in the context of what occurs;

- reflect collaboratively on these effects, as a basis for further planning and subsequent action through a succession of cycles

If I am serious about emancipation and transformation then I cannot possibly accept the technical mode of research because that is located within a paradigm which places emphasis on control rather than improving or changing the social environment. In my opinion it does not address a social problem in a humane way. Any project which denies the full development of an individual's reflective capabilities and critical scrutiny of one's life cannot be used for social upliftment.

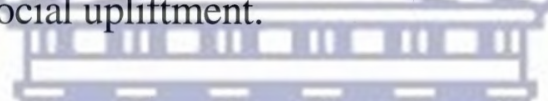

Human well-being should be the focal point and aim of the total research endeavour and development process and includes well-being on all levels: the social, economic, technological, political, cultural and spiritual potential of people in their communities (Kondrat \& Julia, 1997:37).

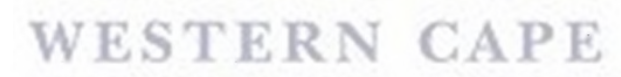

The critical "voice" in emancipatory action research makes a bold statement against the overarching language of Taylorism that has overwhelmed the ideas of the public school as I have come to know it. When the language of business had become the lexicon of the school, the business domination of schools was complete (Kincheloe, 1993:94). In my constant attempt to become a critical action researcher, I am painstakingly reminded by Taylor, the American industrial engineer, who in the early part of the twentieth century argued that "... his scientific methods could bring about a rational society, an efficient workplace, higher productivity, and more docile workers" (Fay, 1975:19,44-5). Taylor's research was implemented in industry and was transferred directly to American schools as it became the prototype for educational administration. Taylor's idea that you must 
"run your school like a business" is the buzz word still used in many educational hierarchical quarters today. Taylor advocated a top down approach to management and reduced the role of the labourer to one who must merely enact instructions without applying creative thought. As Taylor told a mechanic working under him, "You're not supposed to think; there are other people paid for thinking around here" (cited in Wirth, 1983:12). Kincheloe (1993:91) sees this, Taylorism, as an excellent example of instrumental rationality. The means of improving worker efficiency and productivity take precedence over the end of respect for human dignity.

What further attracted me to action research is the idea that the researcher is not only the research expert who shares research skills, but also the co-learner who recognises and benefits from the skills and knowledge of the group members (McNicoll, 1999:52). The emancipatory action research model focuses on working with and for people, rather than on people as such. In the atmosphere of shared control and support, stakeholders must be encouraged to participate actively in the total process. People, are helped to recover and release themselves from the constraints of irrational, unproductive and unsatisfying social structures that limit their self-development and self-determination (Denzin \& Lincoln, 2000:597).

I believe education is essentially a socio-political act. One cannot just teach, isolating the social issues impacting on the lives of one's students. One cannot just accept the status quo and be silenced in the establishment. Some people say it is not possible to change established ways. I want to agree with McNiff's response that action researchers are change agents:

First, we have to believe that it is possible to change things, otherwise we might as well give up right now on every effort and programme to improve 
the quality of life. If we live in hope, at least we have some idea of what we can achieve. If we do not, we can be sure of a zero outcome. Action research is one way to influence social change (McNiff, 2002:26).

I support the notion of moving away from what Davids (1991:34) calls a classroom practice characterised by a "product-orientedness to a process-oriented approach which is a shift towards an emancipated and democratic teacher-pupil interaction mode of classroom practice". This "process-oriented" approach to classroom practice becomes meaningful once teachers question the "what" and the "how" of teaching instead of just accepting and then slavishly depositing pre-packaged curricula into the memories of students. I strongly contend that emancipatory action research offers that much needed vigour to assist teachers in their daily practices. McNiff (1988:5-6) notes:

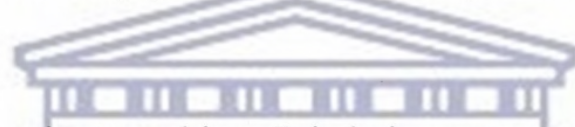

Action Research is not just teaching. It is being aware and critical of that teaching, and using this self-critical awareness to be open to a process of change and improvement of practice. It encourages teachers to become adventurous and critical in their thinking, to develop theories and rationales for their practice, and to give reasoned justification for their public claims to professional knowledge. It is this systematic inquiry made public which distinquishes the activity as research.

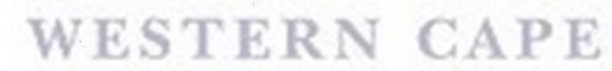

It is precisely because I needed to be self-critical of my teaching practice that I chose to engage in action research. In being self-critical, I might possibly move beyond reliance upon the development and refinement of traditional practice and improve or change my teaching practice. This view is also held by Grundy (1987:191) when she says,

... [t]he exciting implication which action research has for teachers is that of opening up the possibility for practitioners to exercise a greater degree of autonomy and responsibility with regard to their own work experiences for the students with whom they work. 
I am aware that action research is a continuous process and that it can provide teachers with a powerful tool to improve their classroom practice, as well as possibly affect changes in the wider society. If I take account of the constraints placed upon teachers within the present schooling system, it becomes difficult to assess the potential action research can have in transforming the oppressive material conditions in which most South Africans live. I would, however, agree with Walker (1990:62) that to dismiss action research would be to dismiss the contribution which teachers can make in the "shaping of a critical pedagogy".

\subsection{RESOURCES USED IN THIS RESEARCH}

Research is an intellectual journey in which the researchers must constantly engage with their purposes, subject, theories, methods and data. The constant interaction between reading, thinking, perusing materials and data, analysing etc is the essence of research activity. (Hardiker, 1989:6)

\subsubsection{Literature Reviews UNIVERSITY of the}

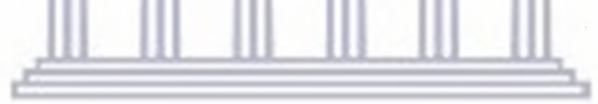

The theory that I gathered from the literature I engaged with, together with my experience as a teacher in practice, forms the basis of my research. When I started this study, the first piece of work that a fellow critical researcher asked me about was my literature review. At first I was sceptical, as I was of the opinion that I will do my literature review whilst doing my action research project. Initially, I thought this would be an easy exercise, but as I travelled through this educational journey of research, I realised that the literature review most certainly forms the basis of one's research process. When I selected my reading material I consciously set about reading about and around the issues of my topic. To guide my decisions and activities in practice I reviewed and reflected on the work of some education theorists, in 
particular, Gramsci, Dewey, Habermas, Freire, Giroux, McLaren, Carr, Kemmis, Elliott, Hopkins, McNiff and others. Thus, my research practice was informed by theory. My initial awareness of a different way to approach my education practice however, was also informed and influenced by local (South African) critical theorists such as Da Costa, Fataar, Lazarus, Julie, Meerkotter, van den Berg, Waghied and Holtman based at the University of the Western Cape. The bibliography indicates the range of literature that was reviewed in this research process.

\subsubsection{Participant Observer}

As a participant observer I was involved in the activities, events, workshops, behaviours and peer group culture of my students, parents and co-educators. As the deputy-principal at the school where I did the research I was already involved in the process of people development and employee relations in the workplace. What I initially negotiated with participants, was how I would be placed in this specific UNIVERSITY of the

research project (McKernan, 1991:63). At no time did my co-educators or the students feel that I was speaking with an authoritative voice as the communication and recordings were focused and open to any participation and follow-up. Action research was used as a framework for the research process and the experiences resulting from this, were reported on and reflected on, as the results were fed back to the learners and other stakeholders involved in the process, for scrutiny and criticism.

\subsubsection{Interviews}

Interviewing, as well as observation, is probably amongst the most used method for gaining information in any qualitative educational research setting. Unlike a 
questionnaire, an interview is a personal face to face contact situation allowing for more focussed and relaxed conversation between the interviewer and the interviewee. Wiseman \& Aron (1972) liken interviewing to a fishing expedition and, pursuing this analogy, Cohen (1976:82) adds that “... like fishing, interviewing is an activity requiring careful preparation, much patience, and considerable practice if the eventual reward is to be a worthwhile catch." In my research I interviewed, in 2005/2006, grade 6 and 7 students, parents of learners who attended my classes, and the teachers who engaged in teaching the same grade 6 and 7 students.

In developing one's interview thorough preparation needs to be made. Preparing the interview questions in advance and sharing them with the participant(s) remains the most important role of the researcher. Before one starts to design one's interview questions and process, clearly articulate to yourself what problem or need is to be addressed using the information to be gathered by the interviews. This helps one keep clear focus on the intent of each question. A major adyantage of interviewing is thus its adaptability. During an interview one cân also/ask a question that was not considered in your initial planning.

The materials I used during interviews were the following:

Journal, note paper, writing materials

Tape recorder, videotape recorder

List of interview questions prepared beforehand.

The capturing of data becomes essential for after the interview, one will need to transcribe (copy) exactly what was said during the interview. This can be a very slow 
and time-consuming process, but it is critical that one takes down exactly what was said. Whilst busy with the interview occasionally verify the tape recorder. Ask one question at a time not to confuse the participants. Encourage responses by asking open ended questions. It is recommended by a management organisation online (23 June 2006), "that you provide transition between major topics e.g., we've been talking about (some topic) and now I'd like to move on to (another topic)". Remain focussed and don't lose control of the interview. After you have copied the interview, replay the interview again and compare it to your notes. Make any corrections necessary. Share the written copy of the interview with each one of the participants to make sure that they agree with, and affirm, the contents of the interview.

\subsubsection{Focus Groups}

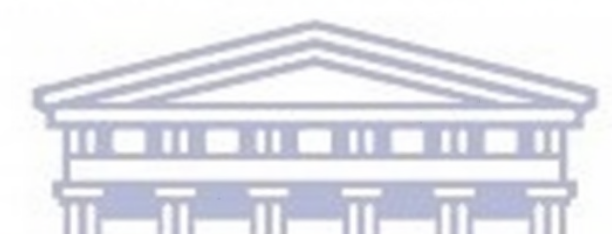

I utilised two focus group activities in my research process. The participants were actively engaged in both the drawing up and moderating of reports, which made it the ideal research tool for doing research "with" instead of research "on" participants.

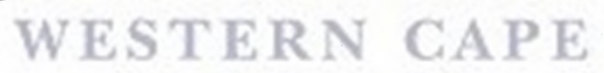

Focus groups are under-used in social research, although they have a long history in market research (Morgan, 1988), and more recently in medical research (Powell \& Single, 1996). Powell et al define a focus group as

... a group of individuals selected and assembled by researchers to discuss and comment on, from personal experience, the topic that is the subject of the research $(1996: 499)$.

Focus groups are a form of group interviewing but it is important to distinguish between the two. Group interviewing involves interviewing a number of people at the same time, the emphasis being on questions and responses between the researcher and 
participants. Focus groups, however, according to Morgan (1997:12), rely on interaction within the group based on topics that are supplied by the researcher.

Thus, it seems that focus groups combine elements of both interviewing and participant observation. At the same time, focus groups capitalize on group dynamics. The hallmark of focus groups is the explicit use of the group interaction to generate data and insights that would be unlikely to emerge without the interaction found in a group. Thus, the technique inherently allows observation of group dynamics, discussion, and firsthand insights into the respondents' behaviours, attitudes, language, and so on.

Focus groups can be used at the preliminary or exploratory stages of a study (Kreuger, 1988); during a study, perhaps to evaluate or develop a particular programme of activities (Race et al, 1994); or after a programme has been completed, to assess its impact or to generate further avenues of research. They can be used either as a method, especially for triangülation (Morgan, 1988) and validity checking. Focus groups can help to explore or to generate hypotheses (Powell \& Single, 1996) and to develop questions or concepts for questionnaires and interviews guides (Hoppe $e$ t al, 1995; Lankshear, 1993).

Focus groups range from a gathering of 4 to 15 people who share some characteristics relevant to the evaluation. The recommended number of people per group is usually six to ten (MacIntosh, 1993), but some researchers have used up to fifteen people (Goss \& Leinbach, 1996) or as few as four (Kitzinger, 1995). 
Organising focus group interviews usually requires more planning than other types of interviewing as getting people to group gatherings can be difficult and setting up appropriate venues with adequate recording facilities requires a large amount of time. It is recommended that a focus group session should not exceed two hours at the maximum. Besides making the main objective of the focus group clear to the participants, it is recommended that five to six questions be carefully developed for the planned session. Before starting the focus group session, it is useful to lay down the ground rules. Because the session is often a one time occurrence, short ground rules to keep participants focussed, are important.

Three ground rules that I considered during my focus group activities were:

a) to remain focused,

b) to maintain momentum, and

c) to get closure on questions
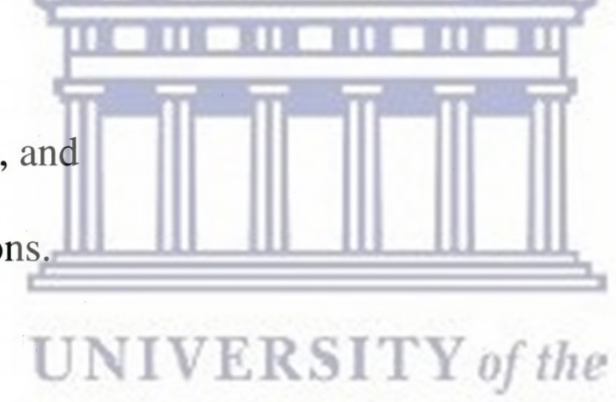

In drawing up the agenda for the focus group session, I/considered the following:

- Welcome,

- Review of Agenda,

- Review of Goal of the Meeting,

- Review of Ground Rules,

- Introductions,

- Questions and Answers,

-Wrapping Up and

- Vote of Thanks. 
In the two focus group sessions that I held, I made use of name tags to identify the participants and I also provided refreshments to welcome and to thank participants.

The materials I used during my focus group activities included journals, note papers, writing materials, a tape recorder and a videotape recorder.

A focus group is indeed a useful tool for doing qualitative research. The focus group concept is about 50 years old, and like many modern innovations, its roots date back to World War 2. It seems that focus groups will become more popular as a research technique in education scenarios in the post-post modern research era.

\subsubsection{Questionnaires}

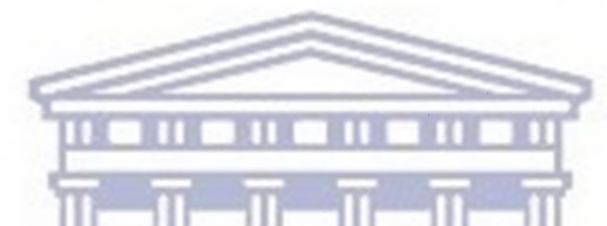

In this research, I made use of questionnaires to collect initial responses from parents, teachers and students of the grade 7 classes I taught. The questions were more probing and open-ended to stimulate contrasting viewpoints. Y of the

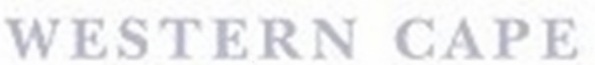

\subsubsection{Field Notes}

Making field notes seemed to be a convenient method of capturing ongoing activities in my classroom and in my intended workshops with the parents and teachers involved. This was the case in the Ford Teaching Project (Elliott, 1981) where it was found that the field notes acted as a good "on-going record" and "aide-memoire". 


\subsubsection{Student Diaries}

Besides providing one with interesting feedback from a pupil's perspective, the diary could play an important role in the pupil's self-reflection. In a large class of 45 learners, the diary provided that longed-for personal contact between student and teacher and vice-versa.

\subsubsection{Survey}

This served as an addition and became useful once it was compared with information received from the other research instruments used. The survey gave me a general idea of the way the learners perceived education and also informed me concerning their socio-economic backgrounds.

\subsubsection{Triangulation}

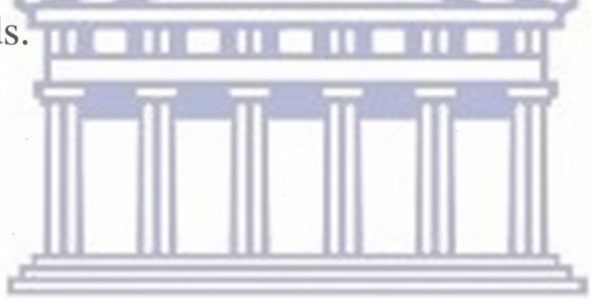

I made triangulation an integral part of the methodology for this research. Triangulation may occur in many ways as data can be collected by observing a project from different perspectives: using various settings; using different enquiries; using multiple research methods. However, the data collected in a triangulation process must be directly fed back to the participants who offer critical comment on the data (McKernan, 2000:192). Thus the triangulation process assisted me to understand the action research cycle more clearly. 


\subsection{ETHICAL CONSIDERATIONS}

Ethics is concerned with how one treats individuals with whom one interacts and is involved (Mathison, Ross \& Cornett, 1993:1). In an activity of inquiry, caring and openness, fairness and truth seem to be important values regarding this relationship. More technically, inquiry should make knowledge more meaningful and precaution must always be taken not to harm the subjects of the inquiry. Informed consent, the true form of dialogue, and anonymity must be respected wherever necessary and the rights of people should be a priority. My intention was doing research "with" and not "on" the respective participants.

Studies that focus on community problems for example drug abuse, and in the case of this research, human immunodeficiency virus infection run the risk of stigmatizing such communities or inadvertently reinforcing common misconceptions within the dominant culture. Community members also may be harmed by the way they see themselves or one another in the tight of data that emphasizes negative aspects of community life and neglect positive aspects of the community or culture. In this research project the school community and the individuals who participated in it emphasized the positive aspects of HIV/AIDS prevention. Participants were proud to be associated with this emancipatory action research project as the data emphasized positive aspects and the project gave the community a "voice".

I constantly updated the Western Cape Education Department, the school principal, the school governing body, the teachers, the parents and the learners concerning my research (See Appendices 1, 2, $3 \& 4$ for documents concerning permission to do research forwarded to the Western Cape Education Department, the school principal 
and governing body). I also received permission to use the name of the school during the research process. I constantly assured the participants of the value of their contributions towards my research and also provided them with regular feedback concerning research findings. The confidentiality expected from my engagement with the various participants was also upheld and respected. For the purposes of this research I kept the names of the learners anonymous although most of them did not have a problem if I mentioned their names in the thesis. The participants, who were mentioned by name, gave their written consent, which is included (in Appendix 10).

\subsection{TOWARDS MY FIRST ACTION RESEARCH PROJECT}

In the following chapter I give an account of my first action research project that I undertook in my classroom. I wanted to break down the "culture of silence" concerning the HIV/AIDS pandemic in my classroom by using an emancipatory action research approach. This project, as I have indicated in chapter one, was an attempt on my part to give my students a "voice". A voice to empower them about sex and sexuality issues, a voice understanding the seriousness of the HF/A円S pandemic, and most of all, a “critical voice” as purported by Freire (1972; 1980), Giroux (1988; 1991), McLaren (1988; 1991), Meerkotter (2002) and McNiff (2006; 2007). 


\section{CHAPTER FOUR}

\section{MY FIRST PROJECT: TAKING UP THE HIV/AIDS CHALLENGE}

\subsection{BECOMING AWARE}

Towards the end of the first chapter I pointed out how I realised that there appeared to be a "culture of silence" in my classroom when it came to HIV/AIDS and sex and sexuality issues. In Chapter Two I engaged with the HIV/AIDS debate in more detail with special reference to the educational scenario. As already mentioned earlier, the emphasis of this research is not biomedical, but rather lends itself more to the educational meaning, impact and consequences of the pandemic. In Chapter Three I provided reasons for taking up an action research approach. In this chapter I provide the details of my first action research project in which I made an attempt to break down the "culture of silence" concerning HIV/ADS. My emancipatory action research project took place over a period of six weeks during the months of August and September 2005. In this chapter, I also discuss various aspects of action research, which could, in my opinion, benefit potential action researchers to understand and possibly improve and change their classroom practice.

In starting out, putting it simply, I don't believe emanicipatory action research has a start, nor an end, as it involves a continuous cycling and spiralling process. This action research project must, however, not be seen as a blueprint or a recipe for changing one's classroom practice, but should rather be viewed as an effort by a teacher who attempted to give "voice" to, and "empower" his students to make meaning of their existence, as well as to himself as well. 


\subsection{TAKING UP THE CHALLENGE}

As the deputy principal I did not have a register class but, I was responsible for teaching Life Orientation to all the Grade 6 s and Grade 7s of the school. The school where I teach and did my research has three Grade 6 and three Grade 7 classes consisting of about 40 students per class. For the purpose of this research, and to have enough contact time with the researched class, I chose the Grade $6 \mathrm{~A}$ class. I chose this class because since the beginning of that year (2005), they had shown enough evidence that they would be the most co-operative. In addition, I knew I would have a follow-up in 2006 when the class is promoted to Grade 7.

\subsection{DECIDING ON MY TOPIC}

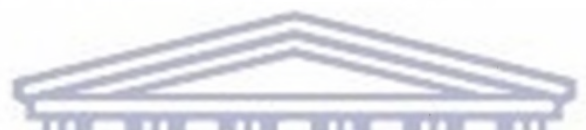

In my first action research project, my mind was set on attempting to address the "culture of silence" that appeared to be clouding the HIV/AIDS debate, as well as sex and sexuality in my classroom. I intended to change and jimprove my practice and approach towards HIV/AIDS e education,II wanted to break the "culture of silence" surrounding HIV/AIDS at the school where I taught. I also intended to change the way the learners were thinking about sex and sexuality. Thus, my research was geared towards changing and improving my classroom practice with the view of empowering my students to make informed decisions when it came to issues about sex and sexuality. In order to carry out my research, which was an emancipatory action research approach, (see Chapter Three) it became necessary for me to understand my learners better. By understanding my learners better, I would then be able to structure my lessons according to their needs. This was also recommended sometime ago by Giroux (1989:197) who states that student experience must be given pre-eminence in an emancipatory 
curriculum. This may seem risky and in some cases dangerous, as students are not necessarily all on the same cognitive development level. However, it provides the basis for understanding the way students see the world.

In order to understand my students better, I embarked on a series of interviews (structured and unstructured), surveys and two case studies. Thus, I was also adhering to Albert Shanker's question (New York Times, 22 October 1989) "What's Wrong with Schools? - Ask the Kids ". He is quoted by Sarason (1991:112) as stating:

We often act as though students are the products of school, when in fact, kids must be workers in order to learn. They must want to come to school, and they must be willing to work, even when no one is hanging over them. If we can't achieve this, no kind of school reform, however ambitious, will improve student learning and public education. So it's hard to explain why we don't routinely ask kids - especially kids in trouble - about how to improve schools.

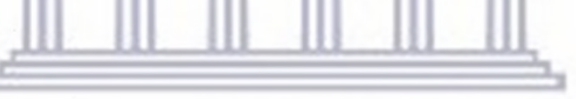

According to the survey done with-my students in February 2005 (see Appendix 5, p212, for survey carried out), IV found that they came from diverse socio-economic backgrounds. Of the 42 students, $70 \%$ came from two parent families and the other $30 \%$ came from single parent families. I discovered that one of the problems was unemployment amongst some of the parents. Of the 42 students in my class, 32 came from active working (employed) home backgrounds and 10 came from home backgrounds where the parents were unemployed. Unemployment is undoubtedly linked to poverty and according to Ramphele \& Wilson (1989:4) "... poverty is a profoundly political issue." The Australian Government Commission of Inquiry into Poverty as far 
back as 1979 , concludes that

Education points towards no kind of easy solution to structurally generated poverty and social neglect. Far from being a way out for poor people, schools act as a sorting, streaming mechanism, helping to maintain the existing distribution of status and power. Education cannot serve as a panacea for poverty (Nasson, 1983:8).

I believe that the spread of HIV and the effects of AIDS are closely linked to development problems such as poverty and gender inequality (Holden, 2004:2). I am also of the opinion that sexual behaviour is to a large extent determined by people's economic and social circumstances. My view is further enhanced in the Soul City magazine where it argues that people, who are poor, are sexually at risk as they may do the following things:

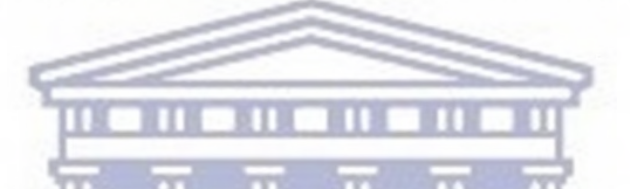

They may engage in sex work/so that they can survive and support their families. They may not have access to information about sexual health, and thus may not know how to protect themselves and their partners from HIV. They may not have easy access to health services. The distance and costs of getting to a clinic for an HIV test, treatment for STIs or even free condoms may be great, especially if you are unemployed or earning very little (2004:18).

While this small scale classroom survey gave me an insight into the problems that some of my students faced, I remained conscious of the fact that other students, possibly in other classes in our school, as well as in other schools, were experiencing similar or even worse domestic problems.

My research question emphasised a critical inquiry into my practice as a teacher. I also wanted to find out how prepared 12 - 13 year olds were to take up the HIV/AIDS challenge. What are kids doing to cope with the pandemic? How do they think and talk about sex and sexuality issues? How well are primary schools (more specifically 
the school where I teach), suited to assist or serve as a site of contestation to curb the spread of the HIV/AIDS pandemic? Can schools become nodes of care and support?

\subsection{CONSTRAINTS}

Soon after I started with my project, I began to realise some of the constraints I faced. As the deputy principal of the school where I did my research, I did not have a registered class and my administrative duties limited my classroom activity. Being an active organiser of the school's extra-mural activities also placed a constraint on my classroom activity. At the time, this pressure had been intensified with the Department's refusal to provide substitute teachers when colleagues left the school or went on study leave.

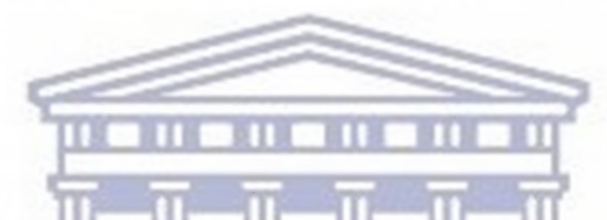

What could also be seen as a constraint in my case was the fact that I was teaching at a traditional and to a certain extent, a conservative religious school, where speaking about sex and sexuality issues could become problematic.

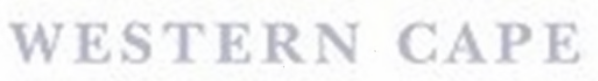

Focusing also too much on HIV/AIDS during my Life Orientation periods, could give the learners an obscured vision of the broader context of Life Orientation as a learning area.

\subsection{NEGOTIATIONS}

I felt that it was ethically correct to negotiate and discuss what I was planning to do and research in my classroom practice with the various participants involved. Emancipatory action research, being a collaborative learning process, needs the support of the parties involved such as the students, principal, other teachers and 
possibly the parents. My topic was geared specifically towards the teaching of HIV/AIDS to my Grade 6 class (2005) who became the Grade 7 class in 2006. When I asked the learners' permission to do research (hopefully with them and not on them) they responded positively and with much enthusiasm. I suppose it was due to the fact that they were probably eager to break from the normal schooling routine. I tried to explain to them that my project was geared towards giving them a "voice" about HIV/AIDS, as well as sex and sexuality issues.

I explained to the students that the project was part of my studies and that it would be expected of them to be prepared to be interviewed by me or another person (the triangulator), to complete survey forms, keeping a diary, and so forth. When I spoke to my principal concerning my research project he sounded positive and indicated that it would be useful if I could raise the debate of HIV/AIDS and action research in our scheduled staff meeting. When I raised the issue of action research during the set staff meeting of Thursday 10 February 2005 , I was surprised to hear some of the comments passed.

- Action Research will break the discipline at school.

- If teachers do research with children then the children tend to become too "big for their boots".

- Primary school children are too young to think for themselves.

- You can't teach and do research, you must take study leave.

After this meeting with the staff, I got the impression that the majority of the teachers were not prepared to change or make an attempt to change their teaching practices. They appeared set in their ways and an innovation such as mine was not welcomed. It 
seemed to me as if some of them probably felt that they were already experts in their professions. Interestingly, there were a few teachers who felt that action research seemed a noble and stimulating idea. Three teachers offered to act as observers for my project, an offer which I readily accepted. After the staff meeting, the principal also indicated that he would support my proposed action research project and offered his assistance. In our discussions the principal and I also came to the conclusion that action research could be useful in Whole School Development and Evaluation. He also felt that putting my proposal before the parents at our parent-teachers meeting, could be useful for my research project.

Initially, I thought that if I consulted the parents of the learners, I would get a negative response, but during my deliberations with the parents at a Grade 6 and Grade 7 meeting held at the Wittebome Civic in Wynberg on Monday 19 February 2005, I was surprised to hear some of the encouraging comments passed. In my field-notes, I noted the following comments: NIVERSITY of the

- We must teach ouñ kids about sex matters at an early age.

- Our religion expects us to prepare our kids for the future.

- HIV/AIDS education must be part and parcel of all subjects.

The meeting was not without its expected conservative comments either:

- Primary school children are too young to think for themselves.

- Debates about matters relating to sex must be done at home.

- A male teacher cannot speak to female teenagers about sex. 
After this parent meeting, I felt a bit despondent, considering the way some parents placed limitations on how and what teachers need to do and not to do in teaching their children. In spite of this, I felt good getting a mandate from the parents to continue with my proposed research activity.

\subsection{MY DATA COLLECTION}

Data collection is an important phase for evaluating one's actions in specific situations and also provides some yardstick whereby one can monitor one's judgement. In making use of my data gathering techniques, I adhered to the advice given by Hopkins (1985: 41), that

... the teacher's primary job is to teach, and therefore any method used must not disrupt the teaching commitment, and must not be too demanding on the teacher's time.

The data techniques I decided to use were the following:

\subsubsection{Field Notes}

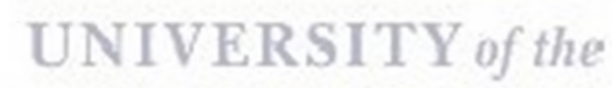

Making field notes seemed to me the most convenient method of capturing the ongoing activities in my classroom. This method of data gathering was also used sometime ago in the Ford Teaching Project (Elliott, 1991) where it was found that the field notes acted as a good "on-going record" and "aide-memoire". In starting off with my project, I made use of field notes in gaining general impressions of what went on in my classroom. Through that, as pointed out earlier, I was able to make the important observation that I dominate all discussions and that the pupils' "voices" were limited when it came to discussing HIV/AIDS and sex and sexuality issues. 


\subsubsection{Student Diaries}

Besides providing one with interesting feedback from a pupil's perspective, the diary can play an important role in the pupil's self-reflection. Pupils, who are the most important participants in a classroom situation, need avenues to voice their opinions (agreements or disagreements) and the diary provides this outlet. In a big class of 40 pupils the diary can provide that longed-for personal contact between student and teacher and vice versa.

\subsubsection{Interviews}

Interviewing is probably the most used method for gaining information in any classroom. This happens regularly in teacher-pupil and pupil-pupil interaction. Interviews, however, can also occur between an observer and a pupil or between an observer and a teacher. During the project, my observer (triangulator) and I interviewed some pupils and we in turn were also interviewed by them. This assisted in building a closer relationship with my students. Some-students, however, distanced themselves when it came to debating their own experiences (see Actiyity Two, p.121).

\subsubsection{Questionnaires}

A questionnaire removes the face-to-face contact and is easy to administer, and if anonymous, gives direct responses for which an individual will not be held responsible. The pupils completed two questionnaire papers which I gave them. The first one was handed out at the beginning of the new school year and I primarily wanted to gather their opinions of HIV/AIDS and sex and sexuality. In the second one, which they had to complete at the end of the project, they had to express their opinions concerning the project. I felt that the information received from the questionnaires would be very useful once it was compared with information received from my other research instruments. 


\subsubsection{Triangulation}

Triangulation is commonly used to refer to the process of obtaining information on a subject from three different points of view, viz. the teacher, pupils and a participant observer or other third party (McNiff, 1988:15).

During this project I invited three people to act as triangulators in my classroom activity.

One was a loveLife co-ordinator from the Wynberg area and the others were teachers at the school. They made observations as triangulators (co-observers) while the lesson was in progress, and I asked them to look at the teacher-pupil responses and attitudes during the HIV/AIDS role-play sessions.

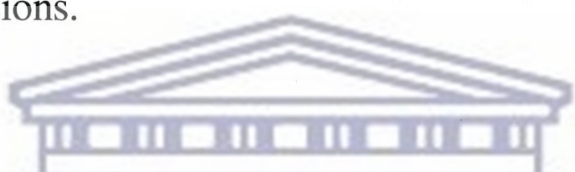

\subsection{PLANNING MY CLASSROOM ACTION RESEARCH}

With only a limited period of time set out for my first action research project, I immediately revealed my plan of action to my students. I was going to attempt to give them a "voice" in my lessons. As already mentioned, they also agreed to complete questionnaires and to allow themselves to be interviewed by the triangulators and myself. We had an understanding that they did not need to hand in their questionnaire forms or diaries should they feel uncomfortable in doing so, or that they need not write their names on the questionnaires or diaries. (I gave them little exercise books to be used as diaries.)

After I consulted with them, we agreed to have the following series of lessons specifically with regard to the teaching of HIV/AIDS. We also decided to participate in the formation of a Human Chain as part of the School AIDS Awareness Week that was scheduled for 8 September 2005 . 
My plan consisted of the following series of lessons:

a) Discussion of a worksheet in groups of two. The worksheet was an introduction to HIV/AIDS.

b) A narrative lesson in which the teacher gives a brief outline of the HIV/AIDS and sex and sexuality topics. Here we agreed to have a triangulator present to check the teacher-pupil relationship prevalent in the classroom.

c) Role-play in group activity. Pupils were allowed to divide themselves into groups and could do anything to depict any incident/s concerning HIV/AIDS.

d) Open Book Test. Here pupils were to be encouraged to look up and read up certain answers from their notebook. I wanted to retieve them of the pressure and demands of memorisation as expected in a normal class test.

e) Field Trip. Pupils from Grade 6 and Grade 7 walked to Rosmead Avenue in Wynberg to be part of the Human Chain as part of School AIDS Awareness Week.

\section{UNIVERSITY of the}

In selecting this series of lesšñns, had certain höpes and expectations. I hoped that by working in groups, pupils would feel more comfortable to speak in a learning situation. They would feel free to consult, share ideas and discuss issues with one another without the threat of being embarrassed. In my narrative lesson I was hoping to detect if the pupils were more relaxed as opposed to the way they had been in the past. To assist in this venture I approached Rashaad Schroeder, a local loveLife co-ordinator, whom I had been informed was engaged in facilitator activity to promote classroom HIV/AIDS information. I asked him specifically to focus his attention on the atmosphere prevailing in my classroom activity. During the role-play session a teacher at school was to assist me in monitoring the pupils' and my actions. My fourth activity, which was an open 
book test, would serve both as a monthly controlled test and also as food for thought for pupils as to the way they wanted examinations to be structured in the future. The Field Trip could also assist as an evaluation tool to see how empowered the students had become concerning HIV/AIDS.

Having set the scene for my action research, I proceeded to the implementation phase of my research.

\subsection{CARRYING OUT MY PLAN}

What follows is an account of my sessions with the pupils. With the use of my data gathering techniques, I had hoped to get enough feedback to assist me in my endeavour to transform my classroom practice and to empower my students concerning the HIV/AIDS pandemic.

\subsubsection{Activity One}
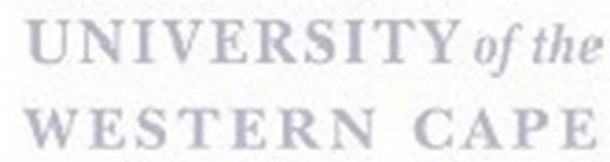

On 31 August 2005, I started with an introduction to HIV/AIDS. I divided my pupils into groups of two to discuss the given worksheet (See Appendix 6, p 215). The worksheet included questions and instructions such as,

- What is the difference between someone who has HIV and someone who has AIDS?

- When and where was the first time you heard of HIV/AIDS?

- Do you think we need to be concerned about this pandemic? Why do you say so?

- How can we go about educating people about HIV/AIDS?

- What do you understand by the terms sex and sexuality?

- What has drugs and drug abuse got to do with HIV/AIDS?

- Draw up an exciting "Holiday Programme" to make people aware of HIV/AIDS. 
I must admit that my lesson was not as exciting and captivating as I had expected.

Questions 1 and 5 received limited responses. This was later confirmed by my field notes dated 31/08/2005 and by some pupils' diary entries also dated 31/08/2005. My field notes stated that most groups did not clearly understand the difference between HIV, AIDS, sex and sexuality. One pupil clarified this in his diary:

- HIV/AIDS is all about "moffies" who did wrong stuff and sex and sexuality is about a male and female being attracted to each other just for sex.

Other diaries contained the following comments:

- HIV/AIDS is when you had sex without a condom or any protection.

- Sex and sexuality is when a boy and a girl have sex together.

- When a male and female makes babies that is sex and sexuality.

What was interesting to note was the link between HIV/AIDS and drugs. Most II

learners commented that a person who uses drugs was more in danger of becoming HIV infected because a drug user has a tendency to behave irrationally. The drug user might use HIV infected needles and might also be tempted to have sex with any partner without using a condom.NIVERSITY of the

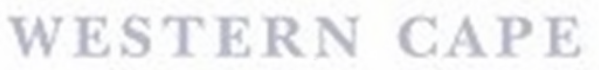

To assist in monitoring my second lesson, I thought of getting in an "outsider". The "outsider", I felt, might assist me in gathering some interesting points that I might have overlooked in my judgement. Meanwhile, I went around to some groups of learners to encourage them to continue their discussion of the given worksheet.

When I enquired from one group as to how they were doing, they appeared shy and tried to cover their worksheets. They did not want me to see what they were writing. I then explained to the class that we can only learn if we are open with each other. I 
made the point that we don't get only one correct answer and teachers are not experts of knowledge as they also form part of the learning process.

After this short motivational intervention, it appeared as if the pupils felt more at ease to continue their discussion. By trying to "break down" the "culture of silence" in my class, I had to let my pupils see me as part of them. I had to be less of an authoritarian figure.

A question that received a good response was, "How can we go about educating people about HIV/AIDS?" Some pupils suggested plays, excursions to HIV/AIDS patients - visit hospitals, watch educational videos and get HIV/AIDS patients to address people at our school. Others indicated that we have a placard demonstration in Main Road, Wynberg, whilst some felt a mass march would go a long way towards making the community aware of HIV/AIDS.

\section{UNIVERSITY of the}

The amount of input from the learners and their subsequent enthusiasm assured me that some sort of HIV/AIDS awareness was being made in my Grade 6 class.

\subsubsection{Activity Two}

In my narrative lesson I was hoping to give the learners some basic information concerning HIV and AIDS as Activity One indicated that some of them still did not have all the facts about HIV and AIDS. For assistance in this venture, I approached Rashaad Schroeder, a local loveLife co-ordinator, whom I had been informed was engaged in facilitator activity to promote classroom HIV/AIDS information. I asked him specifically to focus his attention on the attitude of the learners towards the HIV/AIDS debates in my 
classroom. This was well symbolised in the loveLife sweater he was wearing at that time, with the words, "Get Attitude!"

Schroeder an ex-student of the school as well as a student who I taught some years ago was indeed enthusiastic about his facilitator role. On Friday, 2 September 2005 I invited Rashaad to observe my classroom activity. That day I was to give a learner-centred lesson in which the teacher narrates the history of HIV and AIDS. In narrating the story I had to capture and hold the interests of my pupils. Pupils can so easily become bored if the narrative is not well prepared. Also, the narrative should be geared to suit the audience. I would like to add here that this type of lesson is not all that simple, especially with an observer present. During the lesson it appeared to me as if my pupils were extra attentive, as was usual when an outsider watches a teacher perform at school. Towards the end of the lesson, I asked the observer to share his ideas concerning HIV/AIDS to the pupils. I ended up being the observer. The learners appeared to be more responsive to his vibrant way of narrating to them about the pandemic. At that stage of my own Aids awareness, I had always heard of the ABC method used to prevent HIV infection. He, however enthusiastically explained the ABCD approach. He wrote on the board in large upper case writing:
$\mathrm{A}=$ ABSTINENCE
$\mathrm{B}=\mathrm{BE}$ FAITHFUL
$\mathrm{C}=$ CONDOMISE AND
$\mathrm{D}=$ DEATH OR DISEASE CONTROL

In his input he also emphasised the following:

Those who refuse to abstain, who cannot be faithful, or who refuse to use a condom, must be prepared to accept the hard truth that their behaviour is likely to bring about their own untimely demise, as well as that of others (Schroeder, 2005). 
It would be useful to quote the voice of Schroeder, my triangulator before he left:

... the attitude of the learners seems relaxed and they are quite happy to engage in debates and questions on HIV and AIDS. They however seem to distance themselves when it comes to debating their own experiences. Having a play on HIV and AIDS would get them talking more (2005).

\subsubsection{Activity Three}

On Monday, 5 September 2005 we began with the long-awaited role play activity. I did not want to dictate what the group formations ought to be, so I allowed the pupils to divide themselves into groups. The groups consisted of a minimum of five learners and a maximum of seven learners. I tend to agree with Toseland \& Rivas (2001:12) who defines group work as a:

... goal directed activity with small groups of people aimed at meeting socio-emotional needs and accomplishing tasks. This activity is directed to individual members of a group and to the group as a whole within a system of service delivery.

During Session One the learners, who were now in the various groups were given the opportunity to interact with each other and to discuss their plays about HIV/AIDS. I also asked my fellow teacher to serve as a triangulator/co-observer to assist in the monitoring of the group dynamics. He was particularly interested in group work activity as he was researching group work dynamics. He was going to observe how pupils set out forming groups and how pupils interact with one another once a task had been set for them. The task seemed quite straight forward as the pupils were allowed to do a role-play on HIV/AIDS awareness that they would later act out in class.

It took a while before the class settled down. Once in their groups it appeared that some groups were confused and struggled to come to an agreement. Although they seemed 
enthusiastic, they soon realised that composing an act was not all that easy. Some thought that they had some act going, only to realise that they had nothing.

During the interval of that day my triangulator brought his observations to my attention. The triangulator found the group dynamics interesting and drew my attention to issues regarding gender. He pointed out that some pupils were still very shy to mix freely with their peers. Being interested in drama and group activity dynamics, he seemed very interested to see what the pupils were going to come up with in their plays. I then made an appointment with him for Wednesday 7 September 2005 where I was going to continue with the pupils' role-play activity. In the interim period I was encouraged to see my students rehearsing their plays during breaks. Some groups also arranged to spend time with one another after school. They were obviously interested in making a success of their plays.

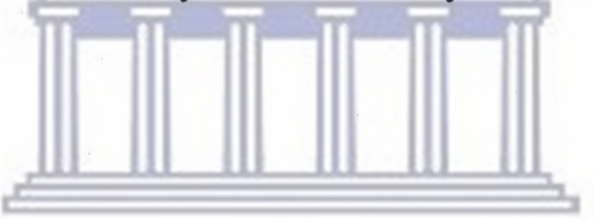

On Wednesday 7 September 2005, I continued with Activity Three as I had planned with the pupils. Initially, I was hessitant to continue because my triangulator was absent on that day. I could not, however, disappoint my pupils, so we continued without the triangulator.

When I arrived at class for my session, the pupils appeared enthusiastic and quite eager to perform their role play activity. Some pupils had play costumes and needed about ten minutes to dress up and prepare. This gave me some time to listen to the views of the pupils of the two groups who indicated that they were not ready with their plays. One group felt there was no co-operation amongst them. The girl who had to type and copy the script of the play was absent, and in the other play, the lead actor with all the 
apparatus, had been absent for three days. This destabilized the entire functioning of the group. Be that as it may, my observation of this activity attracted me to the idea of group work (co-operative learning). For the first time pupils could see the importance of sharing and caring for each other. Group work has the potential to assist students getting to know one another and build a sense of class unity. Group work, as an approach to helping people solve their own and their community's problems, and as a means to developing their own and their community's strengths, is well suited to address the wide range of challenges arising from the HIV/AIDS pandemic. In this scenario group work was being used to raise the consciousness of the pupils about the disease, and to challenge the stigma and stereotypes associated with the disease, as well as to facilitate the empowerment of the learners in addressing the impact of HIV/AIDS.

\section{0}

The plays were of a high standard, if one took into account that the pupils, in most cases, prepared their acts with very little or no guidance from me. As my triangulator was not present during this session, I had to rely on my field notes $(07 / 09 / 2005)$ and my pupils' responses for feedback.

The first group had a role-play on HIV/AIDS and Sport. The students were involved with volleyball practice but one student refuses to touch the ball and wants to resign from the team because she heard that one of the students in her team had been diagnosed HIV-positive. The sports teacher then addressed the issue of stigma and some facts about HIV and AIDS. The sports teacher explained that non-risk activities include:

- Ordinary physical contact, such as the shaking of hands.

- "Dry" kissing.

- Embracing and cuddling. 
- Sharing eating utensils.

- Physical contact with material objects, such as toilet seats, door handles, and so forth.

The "moral of the story" according to the narrator, was "One can still live a normal life if you are HIV-positive."

Group Two started off by dancing to disco music from a tape-recorder. Their play was about HIV/AIDS and drugs. The students were at a disco where "tik", a drug, was being sold and made readily available. The students are forced to share drug needles and one girl who gets "high" later has sex outside, behind the disco. Weeks later she goes to the doctor and is then diagnosed as HIV-positive. According to the narrator the story expresses how drugs can damage your minds and lead to irresponsible behaviour thus making you vulnerable.

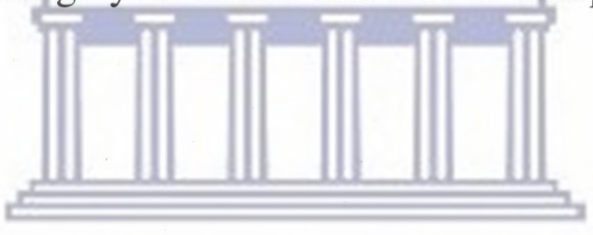

Group Three had a role-play about HIV/ADS and gangs: The play emphasises how a "macho" gang leader, who robș anduses drugs recklessly, treâts everyone he meets with contempt. He rapes a prostitute and then visits the local clinic where he is diagnosed HIV-positive. Initially, he is in denial, but as he becomes weaker, everyone discards him and he becomes a homeless street beggar and ultimately dies on the side of the road. The moral of the story, according to the narrator, is "being self-centred and mean is not a good way of conducting your life." Taking up the challenge against HIV and AIDS means to live in harmony with one another.

Group Four once again emphasised healthy living as opposed to taking drugs, belonging to a gang and going to discos. The role-play also pointed to irresponsible behaviour on 
the part of the teenagers, who saw taking drugs and having sex as "cool" (macho). This is depicted in the title of the play, entitled "Fools Ain't Cool!" According to the narrator, the moral of their story is that one should never associate with gangs, because they can lead you astray. This is detected in her concluding speech:

Don't hang around with them and think that you will now become popular and cool. Drugs are the first priority of gangsters and they are somehow clever enough to let you fall for their plans to take drugs in any form whether it is smoking, drinking or anything else that is harmful to your body. You don't have to be a fool to be cool.

Besides relying only on my field notes, I made use of my pupils' responses. Verbal responses and responses via their diaries also captured my interest. For most of them, HIV and AIDS was a result of an unplanned and irresponsible activity. According to what I could understand from the plays, the children's views were that the primary causes for becoming HIV-positive, was due to the taking of drugs, sharing needles and having unplanned sex.

\subsubsection{Activity Four}

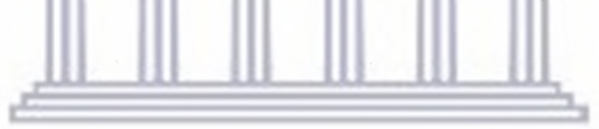

On Tuesday, 13 September 2005 we planned to have an open book test to consolidate work done during the third quarter. Here pupils were to be encouraged to look up and read up certain answers from their notebook or any other references. As mentioned earlier in the chapter, I wanted to relieve them of the pressure and demands of memorisation as is generally expected in a class test. The test was basically in the form of a questionnaire from which I wanted to gain feedback on the HIV and AIDs lessons and activities we had during the third term. (see Appendix 7, p. 216).

My triangulator, a teacher who was still strictly traditional and very conservative in her outlook, was at odds with this type of test. She felt that the pupils were not really 
tested and that this type of testing was going to encourage pupils to be lazy. She also felt that the relaxed atmosphere in the classroom would later lead to disciplinary problems. I nevertheless thanked her for her contribution and advised that it would be interesting to have a discussion on the issue of examinations at a later stage.

The pupils' response to the open book test was somewhat different to the response of my triangulator. One pupil remarked that testing in this way makes exams a more pleasant experience. The questions were mostly open-ended and allowed for a wide range of responses from the pupils. Watching how involved and concentrated the learners were whilst they were answering the examination questions was enough evidence for me that they had become aware of the HIV/AIDS pandemic.

\subsubsection{Activity Five}

On Thursday, 15 September 2005, we went on a HIV and AIDS educational field trip. The pupils from Grade 6 and Grade 7 walked to Rosmead Avenue in Wynberg to be part of the Human Chain as part of School AIDS Awăreness Week. Our pupils were joined by about five other schools from the area and the road was filled with banners and placards. Slogans such "Let's Unite against AIDS!" and "HIV/AIDS Kills" were displayed all along the main road. The sounds of car hooters with motorists acknowledging their support for the HIV/AIDS cause could be heard for the full duration of the Human Chain activity that lasted for an hour from about 12:30 to 13:30.

Despite the seriousness of the activity most of the pupils appeared to be more in a festive and "jolly" mood as some of them even waved condoms to passing motorists. Upon reflecting, I felt a bit disgusted and disappointed in the attitude displayed by some 
pupils. It appeared to me that their behaviour was not reflecting the knowledge and the awareness they had gathered about HIV and AIDS. When the Human Chain activity was completed the learners made their way back to their various schools. I kept some of my pupils behind in order to pick up litter that was virtually strewn all over the main road. How can we fight for one cause, and then neglect another cause?

In my attempt to get feedback from my pupils, I spend the last period of that day discussing their experiences of the Human Chain event. Some felt it made them more aware and conscious about the pandemic, while others felt it was a futile exercise as most of the pupils were ill disciplined. One pupil, in particular captured my interest when she remarked that even though we have all the awareness programmes in the world - this will still not prevent the pandemic from spreading. Another pupil remarked that he is tired of hearing about HIV and ADS and was of the opinion that we need to do more interesting things. The "voice" of this learner left an impression on me for some time as I began to reflect on my project.JNIVERSITY of the

\section{WESTERN CAPE}

\subsection{REFLECTING ON MY PROJECT}

I could never affirm that my project was emancipatory if I was not prepared to be selfreflective. This attribute is necessary for any action researcher, as pointed out by Kincheloe (1991:19),

... [c]ritically grounded action researchers must promote a self-reflective form of analysis which improves the rationality and justice of their own practices.

This is the phase of the project, as Sue Davidoff and Owen van den Berg (1990:46) put it, “... where you are looking back on your efforts in order to look forward to your future plans." In reflecting about one's project one need to be forthright and this can very well 
put off potential action researchers. It is not always easy to accept failure, or defeat, or to realise that no tangible "gains" had been made from one's efforts.

What, then, have I learnt from my project? Clearly, the hope of a template of work, which can be adapted for the HIV/AIDS complex contexts has not been realised. But, the process of recognising my own ideals and naivety has been unusually useful. In reflecting on the experience that I gained from this project, I had to be realistic and remind myself carefully at what a solution for AIDS awareness would and could mean, and what it is not likely to be.

My classroom based research experience-was important in providing me with the opportunity to engage with $12-13$ year olds about HIV/AIDS and sex and sexuality issues. The central lesson taken from this way of working was rather different from what I anticipated. I learnt partly about new ways of thinking and about how to change my practices, but probably more significantly, Erealised the importance of monitoring and learning from my own emotional engagement with my pupils and their ideas.

My project, I must concede, left me with mixed feelings and a notion that giving pupils a "voice" and making them aware of HIV and AIDS was not enough to prepare them for the AIDS reality. The day to day challenges that youngsters are exposed to are "right in their faces". In carrying out my lesson plans I almost became "positivistic" in my endeavour for success. I wanted to see instantaneous changes. To be honest with myself, I thought if I followed this grand scheme of giving a series of innovative HIV/AIDS lessons, accompanied by a democratic and liberatory teaching methodology, I would gain immediate success. In retrospect I realised that a quick-fix solution does not go 
hand in hand with action research as action research is a continuous ongoing process. This same notion applies to the HIV/AIDS scenario. Taking up the HIV/AIDS challenge was never going to be a "a walk in the park".

To sum up, I must admit that my project was indeed a learning curve for all role-players involved. For the mere fact that my pupils were allowed to demonstrate and speak their minds about the pandemic is enough evidence to indicate that the "culture of silence" surrounding HIV/AIDS issues was being broken down in my teaching practice.

Even if I did not succeed completely in breaking down the "culture of silence" concerning HIV/AIDS, sex and sexuality issues in my classroom, I have come to realise that transformation and change cannot happen overnight. It is a goal that one needs to aspire to. I am aware that action research as a vehicle for change is a continuous process and this being only my first action research cycle has, indeed made me, I would like to believe, more self-reflective and more critical.

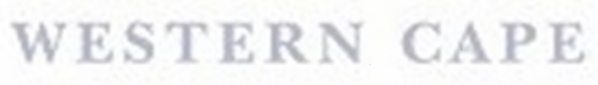

\subsection{TOWARDS A SECOND PROJECT}

Looking ahead, I envisaged the need to continue with a second action research cycle in my endeavour to take up the HIV/AIDS challenge. The question, I asked myself was, what could be done to prepare students to become creative enough to take up this daunting task? I realised that awareness about HIV and AIDS without more, was not going to be enough to prepare the learners for the AIDS reality. The day to day challenges, such as abstaining from sex or drugs, that our students are exposed to demands immediate decision-making. I had to work on the idea to improve and sharpen the way the kids make decisions which in some instances, might become life threatening. 
I then decided on a second action research cycle, whereby I set out to checkmate HIV/AIDS. I describe this action research project in detail in the next chapter.

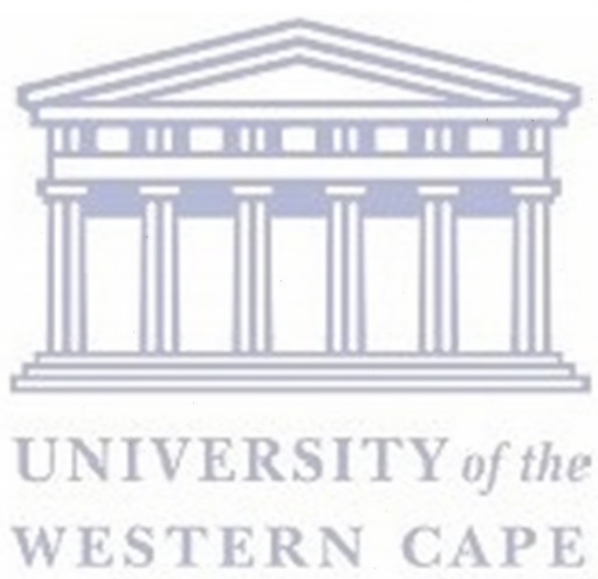




\section{CHAPTER FIVE}

\section{MY SECOND PROJECT: CHECKMATING HIV/AIDS}

\subsection{THEORY IN ACTION - “GET THE NATION TO PLAY!”}

In this chapter I give an account of my second action research project, which was a continuation of the first action research project where I tried to break down the "culture of silence" concerning HIV/AIDS and sex and sexuality in my classroom. My projects emphasised "prevention" and it would be useful to note that at the $16^{\text {th }}$ World Aids Conference held in Toronto from 17 - 20 August 2006, prevention was once again prioritised as the main response to the HIV/AIDS pandemic. On reflecting upon Project One, I realised that awareness alone was not going to be enough to take up the HIV/AIDS prevention challenge. I strongly contend that it is how one infuses awareness with one's actions that is going to make the difference. I believe theory and awareness are portrayed in one's actions and the way one behaves. Human behaviour and the decisions one takes are significantly controlled by the mind. In order to live a full life one needs to have an open mind and has to think, coherently and logically. After some deep reflection and intense introspection on my own life and the things that formed and shaped my framework of thinking, I came up with the idea of teaching the students a game that made a difference in my life - chess. My view that chess can help students in their life and enhance their chances in life is well supported by David MacEnulty (2007:2),

Chess has been called the gymnasium of the mind and has been shown to greatly improve reading, thinking, creativity and analytical skills. The skills learned from chess are not limited to moving plastic pieces around a board. Benjamin Franklin said "Chess is like Life." World Champion Bobby Fischer changed that to "Chess is life." The great chess author/teacher Bruce Pandolfini improved on them both with his statement that "Chess isn't like life; it's much more important!" 
Chess being a mind game encourages deep logical thinking which lends itself to responsible action. Thus, promoting the play of chess could be amongst the creative and strategic ways in taking up the HIV/AIDS challenge.

As partners against HIV/AIDS, together we pledge to pool our resources and to commit our brain power (Thabo Mbeki,2000)

Sport has indeed contributed in rallying the masses to voice their opposition to the Apartheid government in the past and has also been a rallying point in South Africa's Transformation and Nation Building agenda. It was also used as a motivating factor to fight crime as the famous cliché by the late Minister of Sport, Steve Tshwete is often quoted: "A child in sport is a child out of court." Recently, sport has also been widely integrated as part of Youth Wellness and Development programmes such as that advocated by loveLife and by some achoc government programmes to 'Get the Nation to Play'.

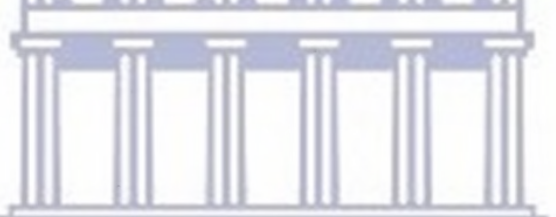

In this project I focus specifically on one code of sport-chess. I set out to discuss the potential of using this code of sport to take up the HFV/AIDS challenge. Likewise, other codes of sport can be addressed in similar, or in more creative ways, to take up the daily challenges and risks our youth are faced with. This methodology is not very different to the employment of sport as used in the fight against Apartheid.

\subsection{ESTABLISHING A CASE FOR CLASSROOM CHESS}

As a National chess administrator and coach I spent many hours investigating and researching chess and its educational benefits. There are a surprising number of studies that all point towards making chess part of the curriculum of a school. Chess embodies our most prized intellectual skills - abstract thinking, memory pattern recognition, calculation, inductive and deductive reasoning, visual imagery, creativity, 
problem-solving and decision-making. Simply put, chess encourages one to think. Before making a move on the chess board one needs to think at least three moves ahead. Way back in 1876, Benjamin Franklin recommended chess as a life skill and Blanco (1999: 25) quotes him:

Chess fosters valuable qualities of the mind, useful in the course of human life that are to be acquired or strengthened by it, so as to become habits, ready for all occasions. Life is a kind of chess, [requiring] 1. Foresight ... 2. Circumspection ...3. Caution ...

4. Perseverance ..."

America's Foundation for Chess (AF4C) conducted a comprehensive survey of the world's scientific literature and identified numerous research studies that confirm the benefits of chess instruction on students' academic performance, particularly mathmatics and reading. Most of the published articles that I read conclude the same thing: there is a positive effect of chess on intellectual achievement; not a single report fails to find such a connection.

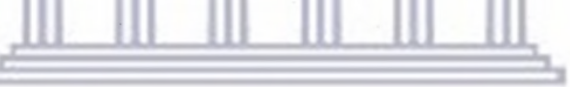

The compiled research studies done by the America's Foundation for Chess investigate the impact of chess on a broad spectrum of/academic areas, and document improved performance by students of diverse ages, intellectual abilities and economic and cultural backgrounds. Below are specific examples highlighting the impact of chess on children:

1) Rifner (1993) studied the effect of chess education on sixth and seventh grade students. He showed that the problem solving skills that chess teaches may transfer to tasks in other academic domains, including reading comprehension and mathematics, and to enhanced performance on standardised tests of academic achievement. 
2) Smith \& Cage (2000) conducted a landmark study on the effects of chess instruction on southern, rural, black, secondary school students. They found that students who received chess instruction scored significantly higher on all measures of academic achievement, including math, spatial analysis, and nonverbal reasoning ability. The authors emphasize the ability of chess to increase students' patience, perseverance, concentration and creativity.

3) Fifth and sixth grade students in suburban Texas were the subject of a study by Liptrap (1997). Students receiving chess instruction scored significantly higher in standardised tests of both math and reading.

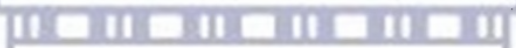

4) Van Zyl (1991), who studied South African high school students, concluded that chess nourishes latent learning abilities, and reinforces skills in logical and abstract thinking, impulse control, endurance and determination. This was manifest as a significant improvement in both verbal and non-verbal IQ scores after three years of chess instruction.

5) Smith \& Sullivan (1997) studied African American teenagers in the rural south. They concluded that chess education has a substantial positive effect on analytical thinking skills which are important in math, engineering and the physical sciences. The impact was particularly strong among girls.

6) Frank \& D'Hondt (1979) gave one year of chess instruction to teenagers in the Democratic Republic of Congo. They came to the conclusion that chess 
education had a strong positive influence on the development of verbal and math abilities.

7) Celone (2001) studied 7 to 14 year old students in suburban Connecticut. One year of chess instruction significantly increased student scores in tests of non-verbal intelligence, which reflected increased abilities in abstract reasoning and problem solving.

The above is useful evidence that chess improves logical reasoning skills, concentration and self-esteem. This explains why for decades and even centuries, chess has been taught and played at schools around the world and countries, such as Russia, Iceland, Venezuela and China include chess instruction in the classroom. It is also the reason why America's Foundation for Chess is working to make chess a standard part of the American curriculum

\section{UNIVERSITY of the}

\subsection{INTEGRATING SPORT/AS A STRATEGY TO PREVENT HIV/AIDS}

The cry for improving the impact of HIV/AIDS education and prevention programmes to stop and even curb the spread of the pandemic among young people gets louder and louder. Campaigners worldwide are looking for innovative approaches of how best to reach groups who are most at risk and how to increase the effectiveness of the interventions. Sport has been identified as a key tool in the fight against HIV/AIDS among youth and adolescents. The assumption is that sport may facilitate their access to the HIV/AIDS message because sport is not only a favourite pastime, but is also considered to be a good way of promoting respect for diversity, tolerance, non-discrimination and solidarity. 
On 1 June 2004 the International Olympic Committee (IOC) and the Joint United Nations Programme on HIV and AIDS (UNAIDS) signed a Memorandum of Understanding (MoU) in Lausanne, Switzerland, on the use of sport to raise awareness about HIV/AIDS, particularly among the sport community. The MoU had two major objectives: 1) to exchange regular information and lessons learned in order to enhance the role of sport organisations in the fight against AIDS at community and national level; 2) to organise AIDS awareness activities with coaches, athletes and sport personalities (UNAIDS \& IOC, 2004).

The declaration of the Fifth World Conference on Sport and Environment (Torino, Italy, December 2003), the so-called" "Torino Commitments on Sport and Environment", emphasized the role of sport in addressing "social and economic priorities such as the fight against poverty and the spread of HIV/AIDS; and in the promotion of social justice, human welt-being and gender equity." (Torino Commitments, 2003).

In June 2004, HIV/AIDS experts from UNAIDS, the National Red Cross and Red Crescent Societies and the National Olympic Committees from 13 sub-Saharan countries were brought together at a workshop in Johannesburg, South Africa, to identify ways in which sport could be used to raise awareness among the public, and particularly among young people, about HIV/AIDS and to fight the stigma and discrimination associated with it (Gomo, 2004). Sport was identified as an important tool to break down barriers, promote self-esteem, teach life skills and healthy behaviour. Athletes are called to act as role models for young men and women. At the 
Olympic Games held in Athens in August 2004, 11000 athletes were given HIV/AIDS awareness cards and red ribbons in their welcome kits. In many countries the National Olympic Committee has undertaken activities for organising awareness raising campaigns, training, seminars and advocacy activities on the issue, alone or in partnership with other national or international organisations.

In 2005, the IOC and UNAIDS published a tool kit for the sport community on the prevention of HIV/AIDS (IOC/UNAIDS, 2005). The tool kit is designed to be used in training programmes for young people, sports persons and sport personnel with the aim of increasing their "AIDS awareness competence" and their capability of communicating properly about HIV/ADDS. The kit gives clear and accurate answers to a series of questions about HIV/AIDS: what it is, how is it transmitted, how to prevent it, where and why to test and where to go for care and treatment. The kit also pays attention to the effect of sport on HIV and the effect of HIV on sport, how to minimize the risks of HIV transmission on the sport field and how to start working on HIV/AIDS prevention with different age groups.

When talking about sport and HIV/AIDS, the focus is mainly on how to use sport as a tool for creating awareness, improving knowledge and changing attitudes to HIV affected people. The experiences are still very recent and it is probably too early to assess their effectiveness and the impact on the sexual behaviour of young people.

This project "Checkmating HIV/AIDS!" is an attempt to infuse awareness with action in sport whilst I focus specifically on chess. I am almost sure that we can also use other codes of sport to impact on the lives of young people. At the recent International 
AIDS and Sports Conference held at the University of the Western Cape from 10-12 April 2006 I presented a paper on my planned project, "Checkmating HIV/AIDS". I received an encouraging response from other researchers in the audience. In the question and answer session that followed I received feedback from Davies Banda of the United Kingdom who said that he planned to do a similar project with basketball which he called "Dunking AIDS Out (DAO)".

\subsection{TOWARDS A SECOND ACTION RESEARCH PROJECT}

My second action research project was scheduled for the Third School Term of 2006. This was roughly nine months after I had completed my first action research project which ended in October 2005. The nine months between the two projects were mostly taken up by the end of year examinations, school vacation and the planning of the project. During this time I reflected on my first project but I was also acquiring materials and resources for my second action research project. As mentioned earlier, in this project, I focus specifically on one code of sport, chess and I set out to discuss the potential of using this code of sport to take up the HIV/AIDS challenge. This project I was led to believe would not only be a model for the sporting fraternity in taking up the HIV/AIDS challenge but would also contribute in breaking down the "culture of silence" surrounding the pandemic.

\subsection{NEGOTIATIONS}

Before I commenced with my second action research project I felt that it would be ethical to discuss my work and negotiate around these with the various participants involved in my research project. As Ely (1999:218) puts it, “... [q]ualitative research 
is an ethical endeavour." I could not possibly claim to be empowering the students if I did not involve them at the start of the research process.

For reasons of continuity, I asked the same pupils I worked with in the first project, whether they would be willing to be part of my second action research project. Although they all agreed, I nevertheless questioned them as to why they were allowing me this freedom as they also had the right to disallow me to continue doing research with them in class. Their responses were important to me as I saw them as being key participants in my project. Some made the following remarks:

- Projects are exciting and make school interesting.

- Sir, why can't we do something exciting-something practical?

- Sir, we will be away that week on excursion.

- Sir, what has chess got to do with fighting Aids?

These comments by my students concerning their involvement in my project, says much more than simply a "yes" answer. Besides giving, the teacher-researcher a clearer notion of what the stüdents want it also goes a long way in clearing the conscience of the teacher as researcher. For, as an action researcher, I would like to believe that it is important not just to accept a "yes" or a "no" answer but to critically scratch below the surface. After receiving the go-ahead from the pupils, I explained what was expected of them as co-researchers/co-learners. As with the first project it would be expected of them to be prepared to be interviewed by myself or a triangulator, complete survey forms, keep a diary and, if they were comfortable, to hand in their diaries to me at the end of this second action research project. 
When I spoke to the principal about my planned project he was supportive as he was also of the view that sport is an integral part of life and that the Life Orientation Learning Area encourages what I plan to do. He, however, encouraged me to speak to the Head of Department (HOD) and the Teachers of the Grade Seven classes to get their permission and support for my proposed project. At the Grade Seven teachers' meeting, I forwarded my proposal to the teachers who felt that it was a good idea but that I should also consult the parents as well. Although there were some arguments that did not please my way of thinking, I was still satisfied with the outcome of the meeting. At the scheduled Grade Seven Parents and Teachers Meeting held on 5 June 2006 at the school hall, I was given a slot on the agenda, which included the following:
a) Welcome
b) Principal's Address
c) June Examinations
d) School Tour
e) Checkmating HIV/AWS!
f) General
g) Closure

What surprised me was the attendance. Virtually all the students were represented. It seemed as if the parents were interested to hear about the June examinations and the proposed school tour. This annual school tour seemed to be the highlight of the Grade Seven school experience at Muhammadeyah. When I told the parents of my studies and my planned action research project with their children, they overwhelmingly gave me the go ahead. One parent commented as follows: "Why don't you arrange to do 
the project with the students who will not be going on the school tour to George, Knysna and Port Elizabeth?" One of the teachers remarked that it was a good idea as not all the Grade Seven classes, including him, will be going on the excursion.

This meeting definitely had an impact on me. I felt fully mandated to carry out my research. I had to plan my project according to the number of learners not going on the school's scheduled excursion.

At a staff meeting held the following day (6 June 2006), I was given an opportunity by the principal to present my proposed project. Below is the input paper that I made available to the staff.

\section{Checkmating HIV/AIDS!}

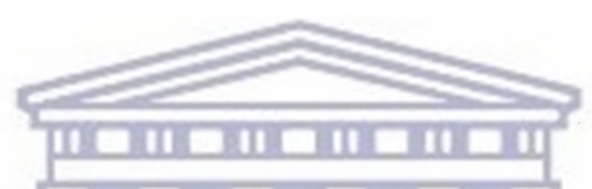

a) Introduction

Sport has indeed contributed in rallying the masses to voice their opposition to the Apartheid government in the past and has also been a rallying point in South Africa's Transformation and Nation Building agenda. It was also used as a motivating factor to fight crime as the famous cliché of the late Minister of Sport, Steve Tshwete is often quoted, "... A child in sport is a child out of court." Recently, sport has also been widely integrated as part of Youth Wellness and Development programmes such as that advocated by loveLife and by some ad hoc government programmes to 'Get the Nation to Play'.

In this paper I focus specifically on one code of sport, Chess and I set out to discuss the potential of using this code of sport to take up the HIV/AIDS challenge. I am 
almost sure that other codes of sport could be used in similar or more creative ways to take up the daily challenges and risks that youths are faced with.

\section{b) Motivation for Project}

The impact of HIV/AIDS remains a major health threat and continues to have a devastating impact on the socio-political and economic well-being of the global population. Nowhere has the impact been more devastating than in sub-Saharan Africa. During 2003 an estimated 2,2 million people died of AIDS in sub-Saharan Africa (UNAIDS, 2004). According to Holden, (2004:5),

...[m]ore than 90 per cent of HIV-positive people live in developing nations, and sub-Saharan Africa-alone is thought to account for about two thirds of the global total of cases. The worst affected region in the world, Southern Africa, is home to about two per cent of the world's population - but thirty per cent of all the people in the world who are living with HIV/AIDS live in Southern Africa.

It is clear that the response to HIV/AIDS cannot be sectoral but should be multisectoral. There is still no cure for HIV/AIDS. Nothing can prevent infection except one's own behaviour. One's behaviour is mostly controlled by one's mindset. In order to have a responsible and open mind one needs to think logically. Chess, being a mind game encourages deep logical thinking which lends itself to responsible action.

Promoting the play of chess is a creative and strategic way in taking up the HIV/AIDS challenge.

As partners against HIV/AIDS, together we pledge to pool our resources and to commit our brain power (Mbeki, 2000). 


\section{c) Vision}

To empower all schools and communities in South Africa to develop thinking skills by playing chess and to utilise the strategy applied in the game to combat the HIV/AIDS pandemic.

\section{d) Mission}

To promote chess as a Code of Sport in South Africa and to be involved in HIV/AIDS awareness in the School Enrichment and Wellness Programme.

\section{e) Objectives}

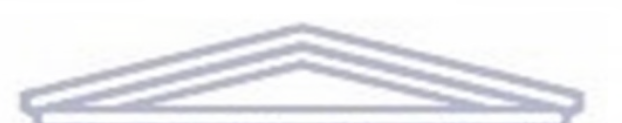

1) To use chess as a vehicle to promote a "positive lifestyle" and to make pupils in schools and communities aware of the HIV/AIDS pandemic.

2) To train teachers and learners in playing, coaching and administering chess activities.

\section{UNIVERSITY of the}

3) To increase cognitive skills and tô improve learners' ability to think rationally.

4) To promote in young players a sense of self-confidence and self-worth.

5) To promote gender equity as chess allows girls to compete with boys on a non-threatening, socially acceptable plane.

6) To promote healthy competition and socialisation in a safe environment.

7) To teach children to try their best to win, while accepting defeat with grace.

8) Ensure a bias towards the target group most at risk and where there is a greater threat of HIV infection.

9) To promote the brand awareness, "Checkmating HIV/AIDS" and to promote and market other HIV preventative strategies. 
10) To encourage inter-class, inter-school, inter-regional, inter-provincial and international chess activity.

\section{f) Basic requirements to stage the project}

1) The target group is all school-going children with specific focus on the $12-17$ years old age group.

2) The project will initially focus on young people from disadvantaged and poverty-stricken areas.

3) The project is developmental and will therefore emphasise training and skills enhancement of players, participants, officials, administrators, educators and organisers.

4) The programme must lead to greater participation at inter-school level and school leagues must be the natural starting point to identify schools that will progress to the Zonal, Regional, Provincial and National Chess competitions.

5) The theme for the project is "Checkmating HIV/AIDS!"

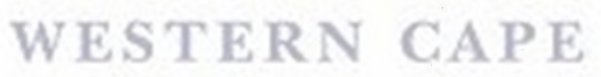

\section{g) How will the programme be organised?}

1) A school will be identified, within a primary school Grade $6 \mathrm{~s}$ and Grade $7 \mathrm{~s}$ will be targeted and within a secondary school all grades will be targeted.

2) The game of chess will be introduced by a trainer or administrator.

3) Participants will be seated in pairs with a chess board, chess pieces, pens, notation book (includes HIV/AIDS information and particulars of chess)

4) Trainers will introduce learners to the basics of chess. 
5) Once the learners are chess competent, they will be given a chess board and pieces and a chess competency certificate with symbols emphasising “Checkmating HIV/AIDS!”

6) All participants including the administrators and trainers will be wearing sweaters with the logo "Checkmating HIV/AIDS!"

\section{h) Concluding Remarks}

This project, together with other sport code projects with similar aims and objectives can, in my opinion, contribute towards making our youth aware and skilful enough to deal more responsibly with the HIV/AIDS pandemic.

After my input we had a short question and answer session which I recorded in my diary. During the question and answer session I was reminded by one of my colleagues who said:

- It is all well and good to have plans on paper but/to enact this is the major challenge.

The meeting was concluded by the principal who said that he looked forward to the outcome of my proposed project and that the school fully supports my project as I had proven over the years to be an "insider" when it comes to the school.

\subsection{COLLECTING OF DATA}

As already mentioned in my first project, data evaluation is an important phase for analysing one's actions in specific situations and also provides some yardstick whereby one can monitor one's judgement. According to Grundy \& Kemmis in 
Robinson (1989:68):

The function of data in action research is to provide a basis for reflection.

Data represents action in such a way that enables it to be reconstructed rather than only recollected.

I think it would be appropriate to mention that my research is definitely not based on what is called "hard data". Many traditional researchers have in some instances used data and manipulated it to expound half-truths and thus obscured, rather than illuminated truth or reality. My data collecting techniques were practical, suited my needs for my research and nevertheless served their purpose. In choosing my data collecting techniques, I adhered to the advice given way back by Hopkins (1985:41),

Any method used must not disrupt the teaching commitment, and must not be too demanding on the teacher's time.

The data collecting techniques I decided to use for this project were the following:

\subsubsection{Field Notes}

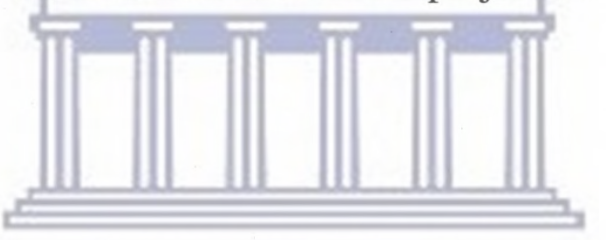

Making field notes seemed to me the most convenient method of capturing the ongoing activities in my classroom. It definitely assisted me in gaining general impressions of what went on in my classroom. Through that, I was able to make the important observation that I dominate all discussions and that the pupils' "voices" were silenced and marginalised. I could also give a report on what was exactly happening during the lessons, whether the pupils were involved constructively or merely occupied in passing time in school.

\subsubsection{Student Diaries}

As in the first project, they provided me with interesting feedback from a pupil's perspective. It served as interesting contrasts to my own field notes. A problem I 
encountered with diaries in my first project was that not all pupils were consistently writing in their diaries. Nevertheless the information that I received provided me with enough evidence of what was happening and how the students felt about the lessons and activities they were engaging in.

\subsubsection{Interviews}

Interviewing proved to be a valuable way of gaining information during my first project. I therefore hoped to continue with it in my second action research project. It assisted in building a closer relationship with my students.

\subsubsection{Focus Group Activity:}

The focus group discussion was held on 21 August 2006 at the Dominican School for the Deaf in Wynberg to gather responses from neighbouring Life Orientation educators concerning an action plan for HN/AIDS. This focus group activity comprised of eight educators. My interaction and discussion with them served as a motivation for me to continue with my project.

\subsubsection{Questionnaires}

A questionnaire at the end of my second project would give me a good overall picture of pupils' opinions towards the project.

\subsubsection{Triangulation}

Elliott (1984) refers to the triangulator as a participant- observer. The three triangulators who assisted me in my project proved to be just that. Instead of being removed from the action in the classroom they participated and got into the "flow of things". I had invited 
three triangulators to sit in. Their feedback served as valuable information with regard to my reflection on my teaching practice.

\subsection{PLANNING FOR PROJECT TWO}

My second action research project - Checkmating HIV/AIDS took some planning and preparation and in this regard, I was reminded by Fullan (1991) who argued that three key factors determine the success of the initiation phase of any innovation. These are the relevance of the innovation to the teachers, the resources available to support the change, and the readiness of the school to initiate, develop or adopt a given innovation. He isolates two aspects of school readiness, namely individual and organisational readiness:

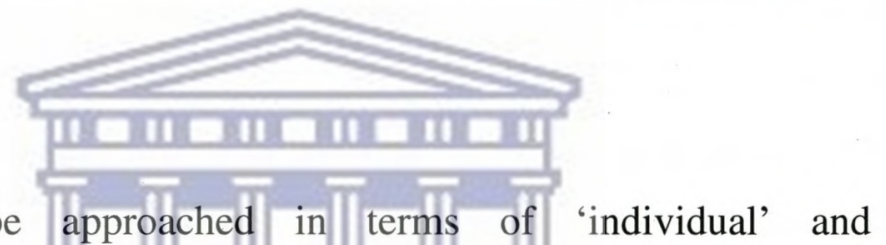

Readiness may be approached in terms of 'individual' and 'organisational' factors. For individuals: Does it address a perceived need? Is it a reasonable change? Do they possess the requisite knowledge and skills? Do they have the time? For organisations: Is the change compatible with the culture of the school? Are facilities equipment, materials and supplies available? Are there other crisis or change efforts in progress? (Fullan, 1991:63),

As mentioned earlier, in this project I focus specifically on one code of sport; Chess and I set out to discuss the potential of using this code of sport to take up the HIV/AIDS challenge.

As already mentioned, my students also agreed to keep diaries and allow themselves to be interviewed by the triangulators and myself. We had an understanding that they did not need to hand in their diaries should they feel uncomfortable in doing so, nor that they need write their names on the diaries. As in Project One, I provided them with exercise books to be used as diaries. 
After I consulted with them, it was agreed to have a series of lessons specifically with regard to the teaching of chess. From a quick survey done during the consultation period I discovered that only one student knew how to play chess. To assist me with the actual training of the game I planned to make use of a chess coach from the Western Province Chess Trainers Association (WPCTA). I had a meeting with the executive of the WPCTA and presented the proposed project. They seemed enthusiastic and took a keen interest in the proposed innovation. I also approached the Development Committee of Chess Western Province to assist me with some resources such as chess boards and sets. I also obtained sponsorship from AK Jacobs Printers in the form of t-shirts and notation booklets with the logo, "Checkmating HIV/AIDS!" One of the parents, Mrs Aneesa Adams, who showed an interest in the Parents' meeting held earlier in the year agreed to serve as an observer and scribe for the project. I consulted and informed both Rotary and the Ackerman Foundation Trust about the project and they in turn asked permission to sit in on one or two of the lessons. They seemed to have bought into the idea that chess, being a thinking sport, could assist in tackling the HIV/AIDS pandemic.

As part of my overall planning I utilised a focus group activity that I scheduled for 21 August 2006. Focus groups can be used at the preliminary or exploratory stages of a study (Kreuger, 1988); during a study, perhaps to evaluate or develop a particular programme of activities (Race et al, 1994); or after a programme has been completed, to assess its impact or to generate further avenues of research. They can be used either as a method, especially for triangulation (Morgan, 1988) and validity checking. Focus groups can develop questions or concepts for questionnaires and interview guides 
(Hoppe et al, 1995; Lankshear, 1993). In my action research project I utilised a focus group activity just prior to my lesson activities.

Here follows a report on the Focus Group activity held on 21 August 2006 at the Dominican School in the Wynberg vicinity:

The focus group discussion was held to gather responses from neighbouring Life Orientation educators concerning an action plan for HIV/AIDS. This focus group comprised of eight educators from different schools in the Wynberg area who discussed tentative implementation plans for School AIDS month earmarked for September 2006.

Data Collection techniques used for the hour session were the following:

1) Video Tape Recorder

2) Field Notes

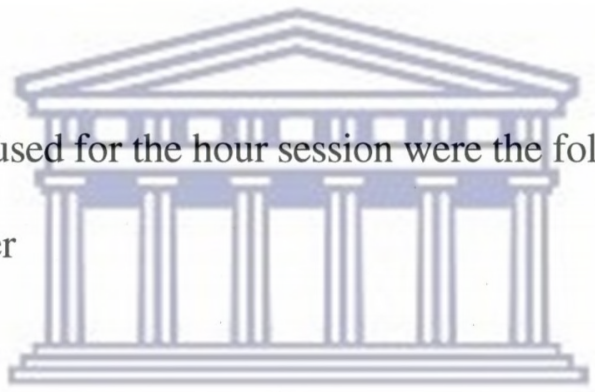

3) Interviews

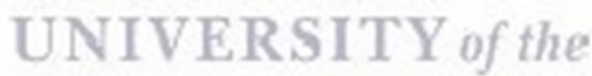

4) Participant Observer

According to Mr Nceba Jalamba, (21/08/2006), the AIDS co-ordinator for the EMDC South Metroplole, schools need to inform the Education Department concerning their HIV/AIDS education activities. The National Policy of the DoE expects schools to draw up their own Implementation Plan.

We then began to debate five critical areas which I outline below:

a) Prevention

- Curriculum 
- Awareness

- Safety Issues

b) Care and Support (Educators)

- Counselling

- Emotional support

- Workload

- Disclosure / Confidentiality

c) Care and Support (Learners)

- White Paper 6

- Treatment of children

- Academic support

- Counselling

- Visitations
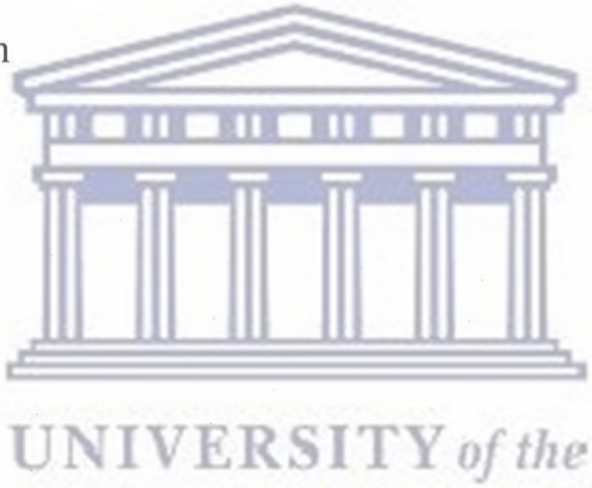

d) Partnerships

- Multi-sectoral response

- Forums - Child Care Units

- Resource Mapping

e) Monitoring

- Evaluation systems (Evaluate impact of September programs)

Most of the educators mentioned that their pupils seemed to be aware of HIV/AIDS but they needed an action plan. The educator from Ottery Methodist Primary School 
mentioned that the attitude of some teachers remain a worrying factor. "How do we measure success? We are doing things in the dark and in isolation. Theory and practice are not related," the teacher said. The Dominican School educator, Mrs Greef (21/08/2006), then made the following input:

Guarantees or not - we as teachers must do our little bit. We need to try to change the mindset of our teachers and learners. Although we cannot reach everyone maybe we can reach at least one. If we can reach one then we might make a difference.

I then put my action plan forward and gave an input on "Checkmating HIV/AIDS!" I once again emphasised that whilst I am using the game of chess I am sure we can use other codes of sport as well to capture the minds of our learners. I then used the overhead projector to outline my proposed plan

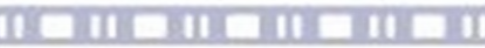

HIV/AIDS Action Plan of Muhammadeyah Primary

Priority One

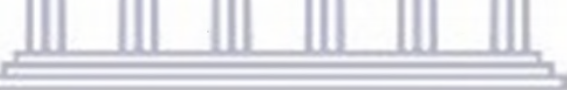

Prevention

Date

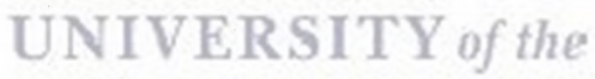

February 2006 - October 2006.

\section{Participants}

SGB, SMT, UWC, School Based Support Team.

\section{Action}

Checkmating HIV/AIDS! Pupils are taught to play chess and are made aware of HIV/AIDS.

\section{Activities}

1) Planning of campaign

2) Contact role players and stakeholders

3) Discuss with staff how to use HIV/AIDS as a teaching theme 
4) Fundraising

5) Invite guests

6) Carry out campaign as planned.

\section{Resources needed}

1) Chess Demonstration Board

2) Chess boards

3) Chess pieces

4) Pens

5) Notation book (includes HIV/AIDS information and particulars of Chess)

6) Trainers

7) Certificates

8) T-Shirts

9) Catering

\section{Indicators of Success}

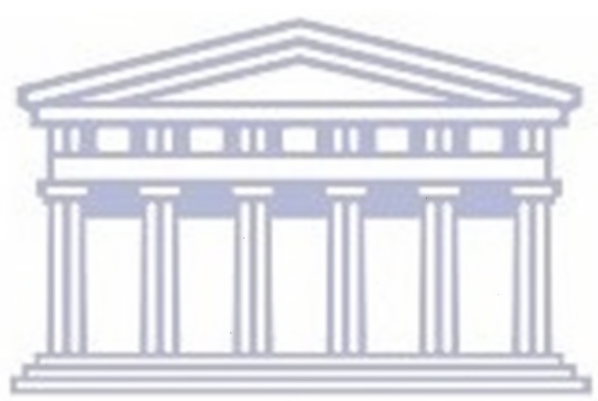

1) There is a programme of activities in place SITY of the

2) Comments by speakers

3) Learners, educators and the community around the school become aware of the spread of HIV/AIDS and start to speak about it.

Most of what I said and what the educators said were captured on video. The focus group session lasted for a half an hour longer than originally planned. Mr Nceba Jalamba thanked everyone on behalf of the DoE. I closed the session by thanking everyone for their invaluable contributions towards my research and invited everyone to have some snacks and interact with each other. 
As an active participant in the focus group session I indeed picked up some valuable points from the educators' "voices". The focus group discussion boosted my confidence and motivation to continue with my research plan. I then looked forward to putting my plans into action because it seemed to be appropriate for the contemporary needs of our surrounding schools and our community at large.

My plan consisted of the following lesson activities:

a) Activity One - Linking Chess play with Life Orientation and HIV/AIDS.

b) Activity Two - Describing of the Board and Movement of Pieces. "Making the Right Move" and "Touch is a Move".

c) Activity Three - Consolidation and Strengthening of Playing Skills.

d) Activity Four - Each One Teach One. Sharing of strategy and ideas.

e) Activity Five - Demonstration Game and Simultaneous.

f) Activity Six = Graduation Day = Receiying of HIV/AIDS certificates, Chess colours, notation pads, Chess boards and pieces.

Having decided on my plan, I now felt optimistic that things would turn out well as I headed into the implementation phase of my second action research project. As mentioned earlier (see p. 140) my second action research project was scheduled for the Third School Term of 2006. Activity One started on 29 August 2006 and Activity Six, my final activity, took the form of a Graduation ceremony which culminated on 21 September 2006 on our school's HIV/AIDS awareness day. 


\subsection{CARRYING OUT MY PLAN}

What follows is an account of my sessions with the students:

\subsubsection{Activity One: Linking Chess play with LO and HIV/AIDS}

On 29 August 2006, I began the project with the Grade 7 learners of Muhammadeyah Primary. After much deliberation and planning with the principal, Grade 7 teachers, school governing body members, parents and learners my project got underway. I was assisted by Ms Aneesa Adams who took photos and made a video of the training sessions. I also secured a Chess Trainer Mr Athon Willenberg from the Steinitz Chess Club, to assist with the coaching of chess.

I started the session by giving reasons for bringing Chess to the LO (Life Orientation) class. I also handed out the school's HIV/AIDS Policy document (see Appendix 12 p. 225). I then provided an outline of the project and stated the aims and objectives of the project (see pp. 9-10). I also told the pupils that this project was part of my $\mathrm{PhD}$ research work and that it was important for them to take notes and diarise everything they were doing.

I commenced the first lesson by providing each pupil with a set of pieces and a chess board that had the words "Checkmating HIV/AIDS!" printed on it. I laid down some ground rules and also gave them some incentives. They were informed that as soon as they can move the pieces, they will get a free set of pieces and a board to take home.

After my introduction, I called on $\mathrm{Mr}$ Athon Willenberg to do the actual training concerning the game. This gave me an opportunity to observe and take notes while 
Mr Willenberg taught. Towards the end of the day we also received a visit by Ms Jackie James, President of Rotary Wynberg, who also indicated her interest in the project.

Athon gave a short introduction to the history of chess and then started with the actual playing of the game. "Before you move you need to think. You need to anticipate your opponents' moves before deciding on your own move," he explained. The first lesson, that lasted for an hour, emphasised the ways in which the different pieces move. He explained the way the pieces move starting from the pawn and finally explained how the knight moves. The most interesting and unique piece, is the knight, which can jump. These statements captured the imagination of the pupils. The lesson ended at $12 \mathrm{~h} 40$ when the learners took a break.

Input from Ms Aneesa Adams (29/08/2006): III || || ||l|

Very Interesting! You have to be alert and think and concentrate. I think I can get hooked on this. Interesting to note that chess was first only played by the aristocracy and elite. The kids were very attentive and hungry to learn the new game, called chess. They were very eager to start the game, but two more moves were still to be taught by the instructor, the castling move and the en passant $\left(5^{\text {th }}\right.$ rank pawn capture) move, which really got the students attention.

I am quite surprised at the interest shown of the students towards this game, as questions were frequently asked throughout the demonstration of the game. I also observed that the way in which the instructor explained this game was done in a way that these students could easily understand the game. I too, had no knowledge of how the game works.

My conclusion of today's lesson is that this is a game that gets you thinking, can boost your self-confidence and keeps you positive.

When the instructor had finished, the bags wherein the pieces were kept were torn apart and the students could not wait to pack the pieces so that they could start 
playing. At the end of the class, the students were asked to repack the boards and asked questions on the day's lesson, which they responded to enthusiastically. They were asked what colour moves first, to which they answered white. They were asked if the lesson was interesting, to which they all shouted "yes!" After giving them some opening tips, I sent them home and asked them to read up on chess and to find out more about the game.

When the students left, I spoke to Ms Jackie James, (29/08/2006), President of the Wynberg Rotary "branch", who made the following comments:

We are interested in long term development of people and chess appears to be a sound investment. I would like you to present Checkmating HIV/AIDS! at our next Rotary executive meeting that is held on Thursday evenings normally the first week of every month, at Constantia Nek.

\subsubsection{Activity Two: "Making the Right Move!"}

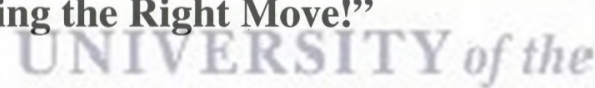

I started this session at $10 \mathrm{~h} 30$ on 30 August 2006 by welcoming the learners and the co-ordinators and guests for the day. Both Aneesa and Athon were now seen as insiders as the pupils were becoming accustomed to them being around. I welcomed Mr Abdurakiep Jacobs who came to confirm the sizes for the $t-$ shirts that he was making for the learners, administrators and trainers.

Aneesa wrote in her field notes dated 30 August 2006:

In the second session $\mathrm{Mr}$ Esau welcomed everyone (10h30) and introduced Mr Jacobs who will be making the sweaters. Mr Esau also reminded the students why they were in the class and the advantages chess can have in the long run, in their lives. The game reflects the way you live your life. It also portrays how you plan your life. In today's session you will learn how to strengthen your moves. 
Before we started the actual chess lesson of the second session I allowed for some comments from students who had the following to say:

Umar: Sir I went home and told my mom how interesting it was to play chess and I then challenged my brother.

Gadija: I told my brother that I can now "whip his ass" in chess.

It appeared from the comments of the students that most of them told their family members that they were taught chess and that they were enjoying it. This was enough evidence for me that the project was being discussed at home.

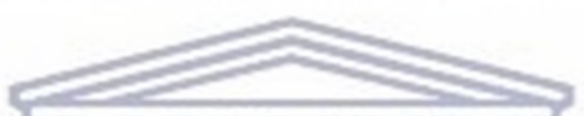

I also allowed for some input from Mr Abdurakiep Jacobs (co-observer) who said the following (30/08/2006):

Making the right move in your everyday life can have far reaching consequences. The nature of the game (chess) is a thinking game and in everyday life we need to think. If we want to prepare or take up any challenge in life be it AIDS or "TIK" then we need to sharpen our thinking skills.

The importance of making the right move on the board and in life was also emphasised in the diary (30/08/2006) of Aneesa:

As the game started, I actually found out that total concentration was needed and careful thinking and planning before making a move - the right move. One game could take quite a while, or with quick thinking you could check mate in no time.

My observation of Lesson Two was that it was an interactive session during which the learners all focussed on the big demonstration board placed in front of the class. The objective of the game was to reflect on the logic of the moves made. The objective of the second lesson was also expounded by the trainer, Athon, when he mentioned: 
Today we will engage in an interactive game, where each one will come to the board and make a move - the right move. Each move made needed to be substantiated as to why the move was being made.

As the lesson progressed the trainer emphasised the idea of "touch is a move". He also mentioned that now that the class knew how to move the pieces they could be satisfied that they have progressed to Level Two.

To ensure that they all knew how to play I then questioned the students to establish whether they indeed knew how to play. I gave an exercise with the knight and the pawns. I exclaimed that the knight is powerful and if in the centre, it has the power to control everything around it.

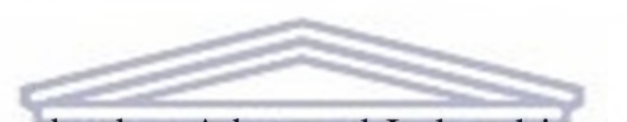

To conclude the activity for the day, Athon and I played in a simultaneous (playing more than one player at a time) against the students to check if they could play. According to Aneesa, this was a challenge for the students, as they went up against the coach and instructor. The students were nervous but at the same time excited to "show-off" what they had learnt. It looked as if the coach and the instructor were up for a challenge. Each one played 16 players at a time.

The aim of the simultaneous games was to see if the students knew the game. There was one student, Mariam Hanekar, who portrayed, through her play, discipline and potential to become a top player in chess. I was soon told by the other learners that she also portrayed this same discipline as the head student of the school.

I left the final words of this session to Athon who then congratulated the students for their co-operation and attentiveness in class. He told them they were developing thinking skills. 


\subsubsection{Activity Three: Consolidation and Strengthening of Playing Skills}

On 31 August 2006 we planned to have two activities with the learners. The morning was going to be used as revision whereby we consolidate and strengthen the playing skills of the students. Immediately after interval each player would teach another Grade 7 student the game. "Each One Will Teach One" was the motto. Towards the end of the day, Athon and I would once again have a simultaneous play with the new players to check if they have been taught the game correctly by their peers.

According to the field notes of Aneesa Adams (31/08/06 - 09h00 - Muhammadeyah Hall),

Today Mr.Esau asked the class what they have learnt. They replied that they have learnt about points and that the king was the most important piece on the board. They also mentioned that they are quite eager to come to school, for the mere fact that the highlight of the day was the chess class. His input was followed by Athon, the coach who also tested their knowledge and skills of the game.

Initially, I thought that the consolidation phase was going to be boring for the students but unlike the normal run of the mill reaction that you find when revising and memorising maths "times-tables" the students seemed quite enthusiastic and involved. The coach then went over the basics of the game once more. He tested their knowledge and skills on the opening, middle and end game theory by showing them different interesting positions.

In general all the students felt proud of their acquired skill and achievement:

I really feel good about myself as I never thought I will be able to understand and be able to play chess just over three days (Yusuf, interview, 31/08/2006). 
Prior to the end of this session I explained to the students that they will be put to the test with another class being brought in. The class has no knowledge of the game, and they are to apply what they have been taught over the past three days and teach these new students. They seemed quite eager to take up this challenge. They were asked how they would go about teaching the class and how they would start.

The co-observer, Ms Aneesa Adams was impressed as noted in her diary (31/08/2006):

Wow! After three days, they have learnt the game and they now have the skills to teach another class. I am impressed!

5.8.4 Activity Four: Each One Teach One After the first break at about 11 h00 the other class of 30 students joined those that we had taught over the past three days. I wetcomed them, including their teacher $\mathrm{Mr}$ Karbelkar-Pheiffer, and said the 30 students will be taught how to play the game of chess by their peers. I expounded that "Each one will teach one", a common phrase used in the Apartheid era to enlighten people, will be our strategy for this activity. I was reminded by Brown (1992:8) who defines group work as follows:

Group work provides a context in which individuals help each other; it is a method of helping groups as well as helping individuals; it can enable individuals and groups to influence and change personal, group, oganisational and community problems.

My framework of thinking was also enhanced by Becker (2005: 219) who sees group activity as an empowering process:

We have seen how a supportive network becomes created through commonality of needs and mutual aid and how interpersonal connectedness generates power. The culture of silence, oppression and 
apathy that marginalised people's experience can be overcome using groups as forums for education and empowerment.

To further introduce the lesson for the day I asked Athon Willenberg, the coach, to give his input. His words to the pupils were the following:

Today we have a special treat for you; your fellow class mate will teach you the game of chess. First introduce yourself to each other and then start teaching as best you can. You only have an hour to teach $(31 / 08 / 2006)$.

They introduced themselves to their fellow learners before they began explaining the game. They explained in a manner they best knew and applied what they were taught. The coach also instructed them to begin by showing the moves instead of explaining too much in detail. The noise level was amplified but I was happy because intensive and inter-active learning was taking place. I observed that most of the new class learners were completely enthralled by their young peer coaches. They seemed interested to learn from their peers.

Aneesa Adams (31/08/2006) commented in her diary:

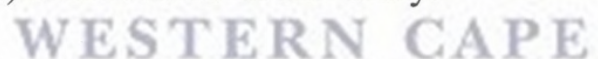

I went around the class to observe if the first group of learners actually knew what that they doing and I must say I was very impressed with what I saw.

Mr Karbelkar-Pheiffer (31/08/2006) commented:

I am very much impressed with the student coaches. Learners are enjoying themselves. I am thrilled with the enthusiasm.

Towards the end of the activity I once again clarified the project "Checkmating HIV/AIDS" to the combined classes and also emphasised the idea of putting in practice what they have learnt, by thinking strategically and being innovative and creative. I pointed out that whenever you play chess; you have to think three moves ahead. In everyday life, when faced with peer pressure, decision making is necessary. 
The conclusion of this session was captured by Ms Aneesa Adams in her field notes (31/08/2006):

$\mathrm{Mr} \mathrm{K}$. Pheiffer's response was that he was impressed by Mr Esau's speech and said if every child could play chess, it would improve their skills. He emphasised that the wrong move could mess up your life. He would like to see all children play chess and it would improve their maths. He told the kids to go home and tell their friends and parents what is going on and to encourage them to become interested. He told them to make use of the opportunity as it would benefit them in the long run. Mr Esau said that they must take the gift of chess and when they move to a higher level, they must teach their fellow mates.

The view of the coach was also well noted in Mr K. Pheiffer's field notes

(31/08/2006):

Athon applauded Mr Esau for initiating this project, and described chess as tool that we could use to improve and change our lives. The coach repeated Mr Esau's view that - Before you make a move, you need to investigate that move. It will make you more reflective and open minded and will also broaden your horizon as well.

Towards the end of this session I once again thanked the students for their enthusiasm UNIVERSITY of the

and participation in the project. I also assured the class that at the end of the programme they will be given their own chess board and set, a "Checkmating HIV/AIDS!" t-shirt and a certificate.

\subsubsection{Activity Five: Demonstration Game \& Simultaneous:}

After a break, a demonstration game was held on the board. The kids were shy at first but one child volunteered to demonstrate his ability of the game. The demonstration was quite interactive as everybody was enthusiastically involved in the exercise. Whenever a move was made on the demonstration board, everyone could comment on the move. 
With the number of learners having doubled to 58 , the demonstration lesson became somewhat boring to some. Nevertheless, the majority was actively involved. Some were even playing amongst themselves. Options and opinions were constantly discussed.

After about 15 minutes the exercise was concluded. The last activity for the day began. This was a simultaneous session whereby the coach and I played against twenty players to test what they had learnt. A week's playing was concluded and the students gained much as indicated by their performances that afternoon.

According to Ms Aneesa Adams (31/08/2006):

A final game was played to see if they (the students) had improved. The game got off to a good start as the kids were very eager to play and determined to check-mate the coach and $\mathrm{Mr}$. Esau. I also observed that not a lot of hesitation was endured as both learners and new students helped each other in making the next move. Both.Mr. Esau and the coach were impressed with the progress of the students as they somehow knew that their method of teaching seemed to have worked.

I also found the comments of $\mathrm{Mr}$ Athon Willenberg who had been the cotrainer/coach with me for the duration of the course quite motivating and encouraging. In his diary $(31 / 08 / 2006)$ the coach stated that:

After the three days the students walked home with the knowledge of how to play the game, discipline has been installed in them, they had a more positive outlook on them, and after all the talks Mr. Esau gave them on checkmating HIV AIDS, they looked at life just a little bit more different and appreciated life much more.

Before leaving the class, they were asked to repack their boards one more time as it is a standard practice to encourage the pupil to double check that all the pieces are in place for the next game. I once again thanked the students, the coach, the scribe and my colleague for their assistance and for contributing towards the success of the 
project. I handed out questionnaires for the learners to complete and return to me at their earliest convenience. We then decided to hand out the chess boards and sets, notation pads with HIV/AIDS information and the certificates at our HIV/AIDS awareness day, which would take place on 21 September 2006.

\subsubsection{Activity Six: Graduation Day}

This activity was moved from 15 September 2006 to 21 September 2006 because I was not able to complete the certificates that I promised the students in time for the Graduation Day. Although I was concerned that the impact of the project might have been lost, due to the fact that, it had been twenty days since the last activity, it turned out to be a great success This ceremony formed part of our schools AIDS awareness day. I was also looking forward to listen to the comments of the students and the school principal concerning the "Checkmating HIV/AIDS project".

\section{TTNTYRTSTTY of the}

Prior to our ceremony, which took place between $08 \mathrm{~h} 30$ and $09 \mathrm{~h} 30$ a musical play was held by some invited guests to make learners aware of HIV/AIDS. The main actor captured the attention of the entire school assembly because of his ability to sing and dance well. Once the play was finished the principal called on me to introduce the various role players who participated in the "Checkmating HIV/AIDS!" project. I introduced Mr Athon Willenberg, the coach, Ms Aneesa Adams, the scribe, Mr Hamdulay, the chess teacher assistant and two matriculants; Enrico and Joe from the Vrygrond area (an impoverished area near Retreat and Lavender Hill) whom we also taught chess as part of the "Checkmating HIV/AIDS!" project. The Rotary representative Jackie James had asked me to teach the pupils in the Vrygrond area to play chess and to link it with HIV/AIDS. This I did on 11 and 12 September 2006. 
The two matriculants from Lavender Hill High School, Enrico and Joe, showed so much dedication and enthusiasm that I invited them to be part of the graduation day as well.

The contribution of the "Checkmating HIV/AIDS!" project was well received by the Muhammadeyah School as this became evident in the speech of the school principal at the assembly:

Encouraging deep and logical thinking about our actions are crucial for decision making. In our country where HIV/AIDS is a major threat we need to pull out all stops to take up the AIDS challenge. Checkmating HIV/AIDS is an interesting way to get learners to think. In order to make the right move in our lives we need to think and playing chess does just that. Allow me to compliment Mr Esau and his team for bringing this innovative project to our school. Students must want to come to school and this project according Mr Karbelkar and others, captured their attention ( $\mathrm{Mr}$ Ebrahim Ismail, principal of Muhammadeyah Primary, transcript of speech, 21/09/2006).

As promised certificates, chess boards and sets were handed out to all the participants, who felt a sense of achievement. The success of the project was also well articulated by one of the students in her speech:

These chess pieces will always remind me to be sensitive towards Aids patients. Whenever, I get myself involve with anything I will first think, analyse and then make my move (Gouwa Damon, 21/09/2006).

The vote of thanks was passed by the coach who also encouraged the pupils to now put into practice what they had learnt from the project:

Like life, chess is a continuous interaction with the mind. There are not only one or two options but there are numerous choices or moves that one can make. Making the right move must include the safety element first. Our learners have all passed the chess test but they must now implement what they have learnt on the board in their real life $(\mathrm{Mr}$ Athon Willenberg, 21/09/2006).

The Graduation ceremony concludes the account of my documented work concerning my project with the Grade 7 learners. I now set out to critically reflect on this project 
which I feel had been emancipatory as well as transformative. Not only have we broken the culture of silence surrounding HIV/AIDS but as a result of the processes engaged in, the pupils have also been provided the space to make their "voices" heard.

\subsection{REFLECTING ON PROJECT TWO}

I could never assume that my project had been an emancipatory action research project if I was not prepared to be self-reflective in my action. As with Project One, I also reflected on my second project. As mentioned earlier, in Project One I wanted to make my pupils aware of the HIV/AIDS pandemic but this was not enough to take up the HIV/AIDS prevention challenge. I wanted to see if they could put the awareness that they gained in the first project into action. My second project which I also utilised as my thesis title "Checkmating HIV/AIDS!" provided an opportunity to empower the pupil participants further to take up the HIV/AIDS challenge.

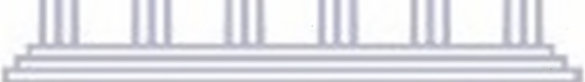

I believe that it is how one infuses awareness with one's actions that is going to make UNIVERSITY of the

the difference in the struggle against HIV/AIDS. The way one behaves portrays the depth of one's awareness. The behaviour and the decisions I take as an individual is controlled by the mind. Chess, being a mind game, encourages deep logical thinking which lends itself to responsible action.

During the first activity, it seemed that the project captured the minds of the pupils, as was recorded by Ms Aneesa Adams (29/08/ 2006):

Very Interesting! You have to be alert, think and concentrate. The students were very attentive and hungry to learn the new game called chess. They were very eager to start the game ... I am quite surprised at the interest shown by the students towards this game, as questions were frequently asked throughout the demonstration of the game. My conclusion of today's lesson is that this is a game that gets you thinking, can boost your self confidence and keeps you positive. 
If the project were not appealing to the HIV/AIDS cause then Ms Jackie James, President of the Rotary organisation of Wynberg would not have made the following comments (29/098/2006):

We are interested in long term development of people and Chess appears to be a sound investment". I would like you to present "Checkmating HIV/AIDS!" at Constantia Nek at our next Rotary executive meeting ...

The body language of the pupils expressed their enthusiasm to be part of this project and their willingness to participate showed that they were eager to acquire the necessary tools to improve their chances in life. What was interesting in this activity was that they saw that the school's HIV/AIDS policy was interrelated to the “Checkmating HIV/AIDS!" project. (See Appendix 12 for the School's HIV/AIDS Policy document). All this was enough evidence for me that the "culture of silence" surrounding HIV/AIDS at Muhammadeyah Primary School had been eroded significantly.
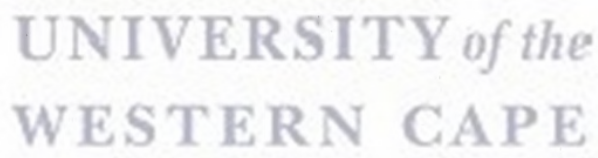

During Activity Two, I initially tried to consolidate the work done in Activity One. Here I emphasised the idea of "making the right move" and its implications for the outcomes in life. It appeared from the comments of students as if most of them discussed the project at home. This also served as evidence that the pupils were discussing HIV/AIDS and chess at home with their families and peers.

Activity Three was once again used to consolidate the work done in the previous two activities and was also used to sharpen the playing skills of the pupils. The interaction between teacher and pupils and the enthusiastic involvement of the pupils in 
demonstrating strategic moves, strengthened my perception, that the pupils had been empowered. Cullingford, a qualitative researcher, who has worked at a variety of schools, would have found solace in the experience our pupils were having at school.

When one studies children's experiences of school rather than the curriculum, management or teaching styles, some personal and consistent insights emerge... indeed one of the most fundamental insights that children have of school is their own powerlessness, their helplessness in the face of a given system (1999:195).

Activity Four with its liberatory phrase "Each one Teach one" was undoubtedly the highlight for all participants involved in the project. This activity dispelled the myth that teachers owned the educational rights to be the only guardians of education in a given classroom. It took our team of coaches three days to educate and train 30 learners but it took 30 learners to teach another 30 learners just over an hour to do the same task. Instead of leaving the pupils to do their own thing or to become laissezfaire I informed, assisted and directed the pupils during this activity. As early as 1985, Barnes already commented on this issue with the warning that:

Teachers should avoid on the one hand a teacher domination that discourages pupils from active learning and on the other the abandonment of pupils from active learning, and on the other the abandonment of pupils to their own devices. Thrown in at the deep end, some pupils might learn something, but teachers would be abdicating their duty if they did not take some responsibility for what their pupils learn (1985:78).

What enthralled me was that after these interactive activities with the pupils, I then began to notice things and looked at certain aspects in my daily teaching practice more critically and differently, instead of accepting things as being merely "normal". A teacher can direct and control the learning activities in a classroom and is therefore responsible for the creative and the active learning engagement of the pupils. 
Activity Five was my final lesson with the pupils. I used this time to test whether all of them could play chess. It is useful to reiterate the words of the coach $\mathrm{Mr}$ Athon Willenberg (31/08/2006) once more:

After the three days the students walked home with the knowledge of how to play the game, discipline has been installed in them. It appeared that they had a more positive outlook and, after all the talks Mr. Esau gave them on checkmating HIV AIDS, they looked at life just a little bit differently and appreciated life much more.

These words sounded a bit over-simplistic to me at the time but provided me with some indication that I was addressing the "culture of silence" and that I was indeed busy “checkmating” HIV/AIDS in my primary school classroom.

Activity Six was Graduation Day for all involved in the project. This activity became part of our school's AIDS awareness day. This was an opportunity to take the project out of the classroom into the community. It was after this Friday assembly (21/09/2006) that I was approached by Ms Anne Emmert, the personal consultant of the Ackerman Trust, to put forward a proposal to take the "Checkmating HIV/AIDS" project to other schools in the country. This invitation could indeed serve as evidence that the project was an empowering event and already having an impact on the community and its leaders. It also seemed as if the "Checkmating HIV/AIDS!" project had made a definite impact on the school that I was teaching at and where I was doing my research. To re-iterate the words of the school principal:

Encouraging deep and logical thinking about our actions are crucial for decision making. In our country where HIV/AIDS is a major threat we need to pull out all stops to take up the AIDS challenge. Checkmating HIV/AIDS is an interesting way to get learners to think. In order to make the right move in our lives we need to think and playing chess does just that. Allow me to compliment Mr Esau and his team for bringing this innovative project to our school. Kids must want to come to school and this project according Mr Karbelkar and others captured their attention (Mr Ebrahim Ismail, principal of Muhammadeyah Primary, transcript of speech, 21/09/2006). 
Although, in view of some comments it appeared as if the project had been a success, I somehow still felt sceptical amidst all the praises. The project was probably a success because I kept busy those pupils that did not go on the Grade 7 class outing to George, Knysna and Outshoorn. Would I have achieved similar praises if I had to do the project during a normal school day? I got the impression that some teachers saw this project as an "add-on" and not as part of the official Life Orientation syllabus.

I am however, comforted by the words of Meerkotter and van den Berg (1994:2):

Innovation in South African schools today is almost inevitably seen as a politically provocative or dangerous act.

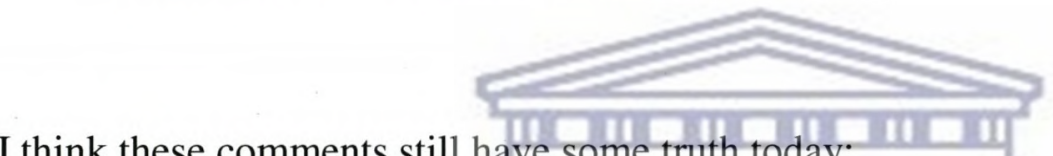

I think these comments still have some truth today:

The project confirmed for me the idea that change is a slow process and that one cannot expect to see the desired results almost immediately, I therefore want to agree with the statement by Fullan, that " $\$$. change is ă process not an event" (1991:39).

In concluding this chapter, it must be emphasized that even if I did not succeed completely in breaking down the "culture of silence" and "checkmating HIV/AIDS in my classroom, I have come to realise that change is a continuous process and that no critical educator or action researcher can ever sit back and say "I have arrived" or "I have achieved $100 \%$ success."

Teaching, and more so liberatory teaching, I would like to believe, is not just a smooth and easy road, but full of obstacles and challenges. Teachers, more so in 
South Africa, must believe that their actions will and can make a difference in taking up the contemporary challenges such as HIV and AIDS.

In this chapter, I have set out to give an account of my second action research project. Checkmating HIV/AIDS had been an innovative and creative project whereby the sport code of chess was utilised as an educational tool. I am almost sure that there are other sporting codes that could also be used to break the silence surrounding the HIV/AIDS pandemic. With South Africa hosting the 2010 World Cup Soccer event, one needs to critically analyse how one could utilise this event as an example of taking up the HIV/AIDS cause further.

In the following chapter, which is the final one, I summarize, reflect on, and attempt to explain how my two action research projects had been emancipatory and fulfilling. I also address the issue concerning teachers as "transformative intellectuals" and teacher researchers and how they could contribute in taking up the HIV/AIDS challenge. In conclusion, I put forward recommendations for further research. 


\section{CHAPTER SIX \\ CONCLUSION}

\subsection{REFLECTING ON WORK ACCOMPLISHED}

The preceding chapters reflected the interplay between the development of a teacherresearcher and that of a critical pedagogy to address the "culture of silence" surrounding the HIV/AIDS pandemic, and made specific reference to teaching and learning in the primary school classroom. I have developed my understanding of the usefulness of action research as a systematic approach to getting things done and effecting change, such that I would happily choose this approach now for future projects where the direction of enquiry is not fully known beforehand. My investigation embodied a variety of concepts drawn from the literature on critical pedagogy and teacher development. The chatlenge in this research was to explore the possibility of change and I looked at the work of some critical theorists to enable me to develop a theoretical position which could inform my practice. My work was particularly influenced by theorists such as Gramsci (1971), Habermas (1972), Freire (1982), Giroux (1988), McLaren (2006) and McNiff (2007).

The research emphasises the idea of teachers as researchers as well as strengthening the view that teachers should be regarded as professionals. In reflecting on my own practice as an educator, and in building on the work of other researchers in the field, I pursued the reinforcing of a case for teachers to be seen as reflective practitioners or critical inquirers of their own practice.

In this concluding chapter I revisit the findings of the research, and offer some suggestions regarding the implementation of action research as a viable option for 
teachers who need to pursue the quest to reflect, analyse, evaluate, understand and change their teaching practice to confront contemporary challenges such as HIV/AIDS.

In this project I focused specifically on one code of sport, namely chess, and I pointed out and discussed the potential of using this code of sport to take up the HIV/AIDS challenge. I am almost sure that other codes of sport could also be used in similar or in more creative ways to take up the daily challenges and risks the youth are faced with. With the Soccer World Cup to be held in South Africa in 2010, I am sure it could be an ideal opportunity to use this event to highlight the HIV/AIDS challenge that the world is facing.

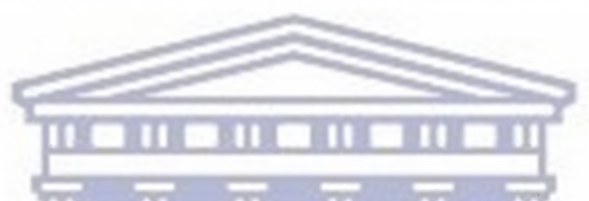

Barnett and Whiteside (2002) argue that when there is an openness and a willingness to talk about HIV/AIDS, the prevention of infection becomes more viable. This is a perspective that is adopted in my research experience with the hope that the actual benefit of my two action researrch projects in my Life Orientätion lessons goes beyond the classroom. The belief is that if my projects have allowed students to transfer the discussion about their raised awareness to their families and friends, then it is a contribution challenging the "culture of silence" and the process of "checkmating" HIV/AIDS would, hopefully, be well on its way. 


\subsection{FROM CLASSROOM PRACTICE TO COMMUNITY INTERACTION}

My classroom project "Checkmating HIV/AIDS!" was also acknowledged by the Vrygrond community as they tried to take up the HIV/AIDS challenge. My interaction with them culminated on 25 November 2006 when the Generation for Change, the youth in the Vrygrond community, hosted its first ever Chess tournament under the banner "Checkmating HIV/AIDS!" Nick Barnett from the Weekend Argus, 2 December 2006, wrote the following:

Vrygrond Library last Saturday hosted its first chess tournament. As part of a community effort to encourage young people to advance their talents, Chess SA development officer Omar Esau coached the enthusiastic players and also taught them the rules of the game. ... Chess W.P. is promoting chess as an activity under the slogan "Checkmating HIV/A円S" in order to encourage young people to think about their next move both on Iand off the chess board, and the consequences of making choices in life.

A week later I was also approached by Ruth Saunders, the Cape Peninsula University of Technology sports administrator, to run a similar project in the Langa community. I was, in addition, also recently contacted by the Goodwood Prison's supervisor to do the "Checkmating HIV/AIDS" project amongst the prisoners. At a meeting held with the Department of Sports and Recreation of the Western Cape I was requested to organise a "Checkmating HIV/AIDS" workshop for August 2007 with 240 sports officials. This, I would like to believe, is enough evidence for me that my small project that began in my classroom, had been more successful than I could, realistically, have imagined. Taking all of this into consideration provides me with a feeling of hope that my action in the two action research projects had, after all, not been in vain. It could, however, be classified as a start or a small attempt towards Checkmating HIV/AIDS in my classroom, in particular, and in the community at 
large. On reflecting on my actions I am reminded by Robinson (1993:5) that:

One small step for one teacher may indeed be one great leap for emancipatory practice, depending on how that small step is harnessed, supported and shared.

\subsection{EMANCIPATORY ACTION AND UNDERSTANDING CHANGE}

I believe that as an emancipatory action researcher I can never claim that my actions had been truly liberatory as this would sound too "technicist". Alternatively, what I can say is that I tried or made an attempt to become increasingly liberatory. The HIV/AIDS pandemic has not been "checkmated" but it is being "checked" to a larger extent in and outside of my classroom, more than before. I do not, in other words claim that my students and I had won the game against AIDS but at least that my students and I have become aware of the threats on the board. Our antennas are up and our defence mechanisms are in place, and it appears that my students and I are taking control of the game to an increasing extent.

\section{UNIVERSITY of the}

If my action research project claims to be an attempt to become liberatory then it would be more than useful and appropriate to measure my actions and reflect according to the definition of emancipatory action research as formulated by Carr and Kemmis (1986:205):

Emancipatory action research is an empowering process for participants; it engages them in the struggle for more rational, just, democratic and fulfilling forms of education. It is 'activist' in that it engages them in taking action on the basis of their critical and selfcritical reflection, but it is prudent in that it creates change at the rate at which it is justified by reflection and feasible for the participants in the process.

Judging my actions against the definition above, I want to motivate that my action research projects have been fulfilling and liberatory. The mere fact that I have made 
an attempt to 'empower' my students, as well as myself, assured me that I was active in a process which Freire (1987:45) refers to as "illuminating reality". By also involving the parents in the research procedure, I expanded my role as a teacher. This could be classified as a liberatory act as the school became an agent promoting democratic practices which are dedicated to the ethos of inclusion and negotiation. According to Kincheloe (1991:20),

... [i]t is important to note that teachers are not the only educational actors who engage in research. If we are serious about Dewey's notion of a democratic community where all parties have a voice in the formulation of policy, then parents and community members must be participants in the public conversation about education. These people will also be empowered by an understanding of critical research.

My two action research projects made me realise that one can never claim that one is completely liberated. One can, however make the assumption that one is part of a liberatory process.

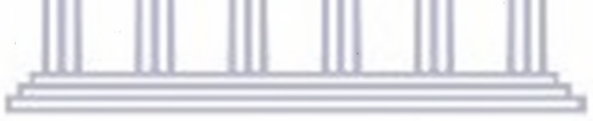

In claiming that one wants to change or to have undergone change, it becomes essential for me to understand the dynamics of this process. According to Fullan (1991:16),

... the process of educational change in modern society is so complex that the greatest initial need is to comprehend its dynamics.

Change is not just a pleasant or cosy trip from one place to the next but it is as Marris (1975), quoted in Fullan (1991:31), put it, so that “... all real change involves loss, anxiety, and struggle." I also want to agree with the reasons given by Fullan (1991:32), why change is not all that pleasant.

... real change involves changes in conceptions and role behaviour, which is why it is so difficult to change. 
Fullan (1991:102) also indicates that

... [c]hange is full of paradoxes. Being deeply committed to a particular change in itself provides no guidelines for attaining the change.

In what follows, I attempt to reflect on the changes which my pupils and I underwent during the two action research projects. To what extent, these changes were liberatory or not remains difficult to answer.

In my two action research projects, I aimed at breaking the "culture of silence" concerning HIV/AIDS in my classroom. My projects entailed the teaching of Life Orientation to my Grade 6 class (2005) and Grade 7 class (2006). My first project emphasised awareness of HIV/AIDS and my second project was promoting chess as an activity under the slogan "Checkmating HIV/AIDS" in an attempt not only to sharpen awareness, but to make it part of my practice on a continuous basis.

\section{UNIVERSITY of the}

My first action research project emphasised the following series of lessons with regard to the teaching of HIV/AIDS.

a) Discussion of a worksheet in groups of two. The worksheet was an introduction to HIV/AIDS.

b) A narrative lesson in which the teacher provides a brief outline of HIV/AIDS, sex and sexuality. It was agreed to have a triangulator present to check the teacher-pupil relationship prevalent in the classroom.

c) Role-play in group activity. Pupils were allowed to divide themselves into groups and could present anything to depict any incident/s concerning HIV/AIDS. 
d) Open Book Test. Here pupils were to be encouraged to look up certain answers from their notebook. I wanted to ease the pressure and demands of memorisation as expected in so many "normal" class tests.

e) Field Trip. Pupils from Grade 6 and Grade 7 walked to Rosmead Avenue in Wynberg to be part of a "Human Chain" as part of School AIDS Awareness Week.

In selecting this series of lessons, I had certain hopes and expectations. I hoped that by working in groups, pupils would feel more comfortable to speak in a learning situation about HIV/AIDS and sex and sexuality issues. They would feel free to consult, share ideas and discuss things with one another without the threat of being embarrassed. In my narrative lesson I was hoping to establish whether, the pupils were more relaxed as opposed to the way they had been in the past. To assist in this venture I approached Rashaad Schroeder, a local loveLife co-ordinator, who proved to be vibrant and shared the information concerning HIV/AIDS in a very interesting and enthusiastic way. Being a young activist as well as an ex-student he was able to relate easily to the learners and contributed not only to the AIDS awareness programme, but also to the process of breaking the culture of silence concerning the pandemic.

During the role-play sessions it became evident that the learners had a sound knowledge of the social ills and the causes, as well as, the detrimental effects of HIV/AIDS. My fourth activity, which was an open book test, served both as a monthly controlled test and an opportunity, to conscientise the pupils to take up the HIV/AIDS challenge in society. The field trip which culminated in a massive HIV/AIDS "Human Chain" was arranged as part of the annual World AIDS Day held on 1 December of each year. This 
also assisted as an evaluation tool to see how aware and enlightened the students had become concerning HIV/AIDS.

After evaluating and reflecting on Project One, I felt that awareness alone was not going to be enough to take up the HIV/AIDS prevention challenge. I then came up with the initiative of using a sport code, namely Chess, to amplify and sharpen the awareness of the pandemic amongst the learners in my classroom. Sport has indeed contributed in mobilising the masses to voice their disagreement to the Apartheid government's policies in the past and in my project, Checkmating HIV/AIDS, I set out to demonstrate the potential of using one code of sport to take up the HIV/AIDS challenge.

My second action research project consisted of the following lesson activities.

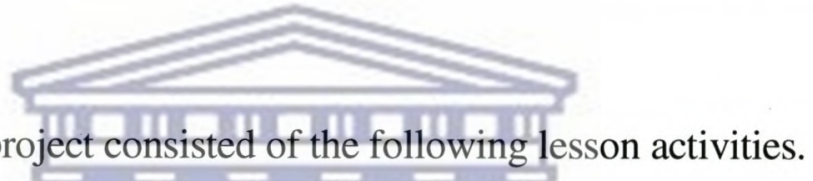

a) Activity One - Linking chess play to Life Orientation and HIV/AIDS.

b) Activity Two Describing of the Board and movement of pieces. "Making the Right Move" and "Touch is a Moye".

c) Activity Three + Consolidation and strengthening of playing skills.

d) Activity Four - Each One Teach One. Sharing of strategy and ideas.

e) Activity Five - Demonstration game and simultaneous games.

f) Activity Six - Graduation Day - Awarding of HIV/AIDS Certificates, chess colours, note pads, boards and pieces.

As the project promoted the game of chess I was reminded of six aspects regarding the characteristics of games and the playing of games by Schaefar \& Reid, (1986:4):

- Playing a game is an enjoyable activity.

- Games have an 'as if' quality that separates them from real life and allows for fantasy experience. 
- Rules exist or are created that define and restrict the behaviour of the players and add organisation and structure to the game.

- A contest is implicit or explicit in games, in that players compete either with each other or with themselves in order to win the game.

- Games, by virtue of their structured, competitive makeup pose a challenge to the participants. At the lowest level, the challenge is to play with other people in a self-controlled, cooperative fashion. More complex games require more in terms of emotional control, intellect, and social skills.

- Game-playing usually involves interaction between two or more players.

According to Schaefer and Reid (1986:5):

Chess is classified as a game of strategy that permits informal observation of the child's intellectual strengths and weaknesses. Another advantage is that it allows expression of aggression without the physical arousal associated with physical games.

My second action research project provided the opportunity for social learning in several specific ways: communication with others, respect of and obedience to rules, selfdiscipline, co-operation with others, learning how to function within a group, and competition within a social context. Whilst I use the game of chess as an educational tool to infuse strategic ideas to take up the HIV/AIDS campaign, I remain convinced that other games and codes of sport, may be employed in a similar or more creative fashion.

\subsection{FURTHER RESEARCH}

Having made the students in my Grade 7 classroom aware of the HIV/AIDS pandemic and after capacitating them with the game of chess as an empowerment tool, it is recommended to do a follow-up with these students, if possible, when they are in Grades 10, 11 or 12 or even at a later stage in their lives. It would be more than 
useful to engage and analyse how their two primary school action research projects impacted on their behaviour during their high school careers. I believe educationists also need to constantly review the importance of a quality primary school education system. And quality primary school teachers at primary schools are amongst the first sites of defence. Children remain the most vulnerable group in almost any community.

I also recommend that further research relating to sport and HIV/AIDS as preventative measures in South Africa be undertaken. Currently, sport and the playing of sport, have been given much media coverage, which provides, an ideal opportunity for critical researchers to contribute meaningfully. $\mathrm{I}$ am, however, of the view that the sporting fraternity as much as the educational sector in the South African context need some form of intervention to become more active in the addressing of HIV/AIDS related challenges. Sport which is highly technical and organised in accordance with strict rules necessitates critical and reflective interventions to stimulate much needed creativity, so as to enhance alternatives that the sporting world can offer to humanity. If the Chess Federation in South Africa is checkmating HIV/AIDS and Basketball South Africa is dunking HIV/AIDS, then Bafana-Bafana and the South African Soccer Federation can most definitely 'tackle' the HIV/AIDS pandemic.

Sport, wellness and HIV/AIDS education need to be woven into the curriculum throughout the educational system. In this hi-tech age of fast cars and fast foods, schools need to become centres for the enhancement of sport and wellness programmes that would cater for the student in her entirety. This holistic integration cannot be over-emphasised as the physical wellness condition as well as the creative and innovative mindset of the post modern human being is currently being challenged 
to a larger extent by environmental and wellness matters than ever before. Critical research into how schools could infuse the development of a healthy physical body and a healthy state of the individual's critical mindset could prove more than useful in this contemporary society.

\subsection{CONCLUDING REMARKS}

Emancipatory action research, though not a magical cure for HIV/AIDS and for all that ails education, can become a powerful force supporting the transformation of our society from defeatism to one of hope and possibility. My optimism comes from my personal experience. I have experienced the power of inquiry in my school and other schools where I have worked, with fellow educators and in my own classroom.

This action research process has been an empowering experience. It has indeed been relevant to my students as well as to me at a personal level. Relevance is guaranteed because the focus of each research project is determined by the researchers, who are also the primary consumers of the findings. Seeing students grow is probably the greatest joy educators can experience. I agree, with Sagor (2000), that, when teachers have convincing evidence that their work has made a real difference in their students' lives, the countless hours and endless efforts of teaching seem worthwhile.

Finally, HIV/AIDS will remain a problem for a long time to come. Addressing the "culture of silence" and the continuous "checking" of HIV/AIDS by teacherresearchers will be a phase that contemporary society will have to sustain to take on challenges such as the prevention of HIV infection in a meaningful way. In taking up the HIV/AIDS challenge, I believe that emancipatory action research does provide the 
teacher in the classroom with a viable option that she cannot afford to ignore. However small the intervention, it is essential to believe that one's ongoing intellectual engagement will ultimately make a difference and that today's response will have an impact on tomorrow's outcry.

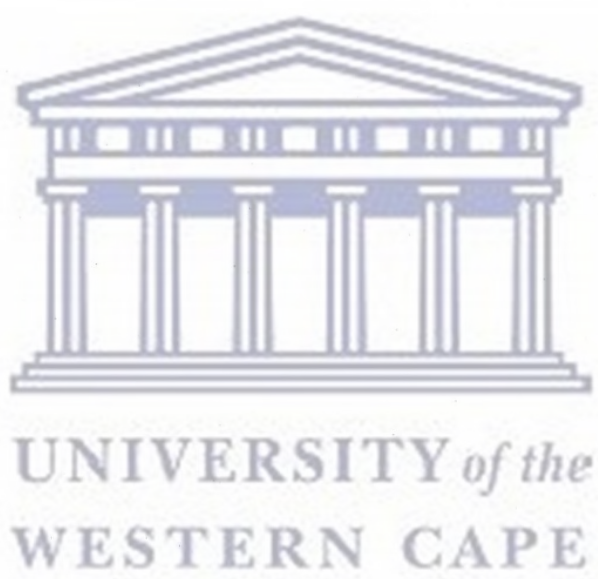




\section{BIBLIOGRAPHY}

African National Congress. 1994. A national health plan for South Africa. Johannesburg: ANC.

Althusser, L. 1972. Ideology and ideological state apparatuses. In B. Cosin, (ed.). Education: structure and society. Harmondsworth: Penguin.

Arendse, C. 2002. An evaluation of the effectiveness of a clinic-based HIV/AIDS counselling course on trainee functioning at their work sites. M Ed. thesis, Cape Town: University of the Western Cape.

Aronowitz, S. \& Giroux, H.A. 1987. Education under siege: The conservative, liberal and radical debate over schooling. London: Routledge \& Kegan Paul.

Asmal, K. 1999. Call to action: Mobilising citizens to build a South African education and training system for the $21^{\text {st }}$-century, 27.07.99. Available at http://education.pwv.gov.za/Media/Speeches1999/July.

Asmal, K. 2001. Opening address: Launch and briefing workshop: streamlining and strengthening C2005. Pretoria.

Asmal, K. 2002. Press statement by the Minister of Education, Professor Kader Asmal, on the Transformation añd Reconstrüction of the Higher Education System, 09.12.02. Pretoria.

\section{WESTERN CAPE}

Asmal, K. 2002. Science, Genomics and Education in South Africa. In W.James \& L. Wilson (Eds.). The Architect and the Scaffold - Evolution and Education in South Africa. Cape Town: HSRC Press.

Babbie, E. \& Mouton, J. 2001. The practice of social research. Cape Town: Oxford University Press.

Barnett, T. \& Whiteside, A. 2002. Aids in the Twenty-First Century: Disease and globalization. Hamshire: Palgrave Macmillan.

Beattie, C. 1989. Action Research: A Practice in Need of Theory. In J. Milburn, I. Goodson, G.A. Clark (eds.). Re-interpreting Curriculum Research: Images and Argument. London: The Falmer Press.

Becker, L. 2005. Working with Groups. Cape Town: Oxford University Press. 
Bell, J. 1993. Doing your Research Project. London: Open University Press.

Berdien, A. 1998. Interview. Cape Town.

Best, S. \& Kellner, D. 2001. Postmodern Theory: Critical Interrogations. London and New York: Macmillan and Guilford Press.

Best, S. \& Kellner, D. 1997. The Postmodern Turn. London and New York: Macmillan and Guilford Press.

Blanco, U. 1999. Teachers as Arbiters in School Chess. Venezuela: Graficas Linero.

Burgess J. 1996. 'Focusing on fear', Area 28 (2): 130-36.

Brown A. 1992. Groupwork ( $3^{\text {rd }}$ ed.). Aldershot: Arena.

Cape Argus: 19 October 2005.

Carr, W. \& Kemmis, S. 1986. Becoming critical: education, knowledge and action research. London: Falmer Press.

\section{TI}

Celone, J. 2001. The effects of a chess program on abstract reasoning and problemsolving in elementary school children. Yale University Master's Thesis. New Haven: Connecticut.

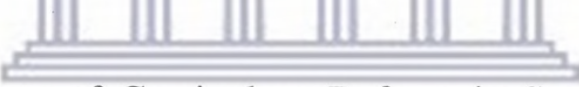

Chisholm, L. 2003. The State of Curriculum Reform in South Africa. In J. Daniel, A.Habib \& R.Southall (eds.). State of the Nation: South Africa 2003-2004. Cape Town: HSRC Press.

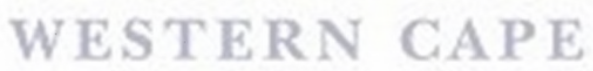

Chisholm, L. 2005. The State of South Africa's Schools. In J. Daniel, J. Lutchman \& R. Southall (eds.). State of the Nation: South Africa 2004-2005. Cape Town: HSRC Press.

Cohen, L. 1976. Educational Research in Classrooms and Schools: A Manual of Materials and Methods. London: Harper \& Row Press.

Cohen L. \& Manion, L.1989. Research Methods in Education, $3^{\text {rd }}$ edn. London: Routledge.

Cohen, L. Manion, L. \& Morrison, K. 2000. Research Methods in Education. $5^{\text {th }}$ edition. London: Routledge Falmer.

Commonwealth Secretariat, 2002. Gender Mainstreaming in HIV/AIDS: The Case for a Multisectoral Approach. Gender Dimensions in HIV/AIDS: A Commonwealth Approach, Paper 1. London: Commonwealth Secretariat. 
Coombe, C. 2000a. Keeping the Education System Healthy: Managing the Impact of HIV/AIDS on Education in South Africa. Current Issues in Comparative Education 3(1). Available at: www.tc.columbia.edu/cice/vol03nr1/ccart1.htm. [2006, May 5]

Coombe, C. 2000b. Managing the Impact of HIV/AIDS on the Education Sector. University of Pretoria, Centre for the Study of AIDS, Pretoria: Available at: www.csa.za.org/filemanager/list/6.

Coombe, C. \& M. Kelly. 2001. Education as a Vehicle for Combating HIV/AIDS. UNESCO Prospects XXX1(3): 435-45.

Cowan, G.M. 1990. Action research in the graphics classroom: reflections of educational change initiatives in two schools. Unpublished M.Ed. thesis, Cape Town: University of the Western Cape.

Cross, M., Mngadi, R. \& Rouhani, S. 2002. From policy to practice: Curriculum reform in South African Education, Comparative Education 38 (20). 171-187.

Cullingford, C. 1999. The Human Experience: The Early Years, Aldershot: Ashgate.

Da Costa, Y \& Davids, A. 1994. Pages from Cape Muslim History. Cape Town: Shuter \& Shooter.

Da Costa, Y. \& Meerkotter,D.A. 1994. Dug-up custems and implanted foreign crops: The [de] colonization of education in South Africa. In Y. Da Costa, C. Julie \& D.A. Meerkotter (eds.). Let the voices be heard: Process and practice in education. Cape Town: Wyvern Publications

Daniel, J., Habib, A. \& Southall, R. 2003. State of the Nation: South Africa 20032004. Cape Town: HSRC Press.

Darder , A. 2007. Critical Pedagogy in a Time of Uncertainty: Forging a New Movement -University of Illinois, Urbana Champaign. http://benhooks.

Memphis,edu/papers/darder_critical_pedagogy,pdf. [28 March 2007]

Datnow, A \& Castellano, M. 2000. Teachers' responses to success for all: how beliefs, experiences and adaptations shape implementation. American Educational Research Journal, 37(3):775-779.

Davidoff, S. \& van den Berg, O. 1990. Changing your Teaching - The Challenge of the Classroom. Pietermaritzburg: Centaur Publications (Pty)Ltd. 
Davids, M.N. 1991. Changing classroom practice: Reflections on two action research projects. Unpublished M Ed. Thesis, Cape Town: University of the Western Cape.

Department of Education. 2000a. Report of the Working Group on Values in Education: Values, Education and Democracy, Pretoria.

Department of Education. 2001. Education White Paper 6: Building an inclusive education and training system: Pretoria.

Department of Education. 2002a. Revised National Curriculum Statement Grades R-9 (Schools) Policy-Overview. Pretoria: Unpublished document.

Department of Education, 2002b. Strategic plan: Statement of policy and commitment by the Minister of Education. Pretoria: Department of Education.

Denzin, N.K. \& Lincoln, Y.S. 2000. Handbook of Qualitative Research. London: Sage.

Dewey, J. 1995. Democracy and Education. New York: The Free Press.

Doyal, L. Naidoo, J. \& Wilton, T. 1994. AlDS: Setting a feminist agenda. Bristol: University of the West of England.

Dube, M.W. 2003a. HIV/ADS and the Curriculum: Methods of Integrating HIV/AIDS in Theological Programmes. Geneva: WCC Publications.

Dube, M.W. 2003b. Africa Praying: A Handbook on HIV/AIDS sensitive sermon Guidelines and Liturgy, Geneva: WCC Publications.

Elliott, J. 1981. Action research: A framework for self-evaluation in schools. Schools Council Programme 2: Teacher-pupil interaction and the quality of learning, Working Paper No.1. London: Schools Council.

Elliott, J. 1984. Improving the Quality of Teaching through Action Research. Project TIQL - "Teacher Pupil Reaction and the Quality of Learning". School Council Project.

Elliott, J. 1985. Educational Theory, Practical Philosophy and Case Study. Centre for Applied Research in Education. United Kingdom: University of East Anglia.

Elliott, J. 1988. Studying the school curriculum through insider research: Some dilemmas. Paper presented at the International Conference on School-based innovations: looking forward to the 1990's, Hong Kong. 
Elliott, J. 1989. Educational Theory and Professional Learning of Teachers: an overview. Cambridge, Journal of Education, 19 (1): 81-101.

Elliott, J. 1991. Action Research for Educational Change. Milton Keynes: Open University Press.

Elmore, R. 1996. Getting to scale with good educational practice. Harvard Educational Review, 66(1), 1-26.

Enslin, P. 1984. The role of fundamental pedagogics in the formulation of educational policy in South Africa. In P. Kallaway (ed.). Apartheid and education (pp.139-147). Johannesburg: Raven Press.

Fals-Borda, O. 1992. Evolution and Convergence in Participatory Action-Research. in Frideres J. (ed.) A World of Communities: Participatory Research Perspectives. Toronto: Caputus University Publications.

Fataar, M.A. 1992. The role of education in generating a democratic culture in a post-protest phase. Unpublished M.Phil. thesis. Cape Town: University of the Western Cape.

Fataar, M.A. 2003. Comparative Study of Muslim Schools in the Cape. Unpublished article. Cape Town: University of the Western Cape.

Fawole, I.O., Asuzu, M.C., Oduntan, S.O., \& Brieger, W.R. 1999. A School-based AIDS Education Programme for Secondary School Students in Nigeria: A Review of Effectiveness.Health Education Research - Theory \& Practice 14:675-83.

Fay, B. 1975. Social Theory and Political Practice. London: George Allen and Unwin.

Fenton, P. 2004. HIV/AIDS - Life Skills in the Western Cape Schools. Unpublished article. Cape Town.

Fine, D., Heywood, M., \& Strode, A. 1997. HIV/AIDS \& The Law. Aids Law Project and Lawyers for Human Rights. South Africa: University of the Witwatersrand.

Flanagan, W. 1991. Towards a critical pedagogy: an action research investigation into democratic practices in a primary school classroom. Cape Town: University of the Western Cape (D. Ed thesis).

Flanagan, W. Breen, C. \& Walker, M. (eds). 1984. Action Research: justified optimism or wishful thinking? Cape Town: University of Cape Town.

Fleisch, B. 2002. Managing educational change: The state and school reform in South Africa. Cape Town: Heinemann. 
Frank, A \& D'Hondt, W. 1979. Chess and Aptitude., Doctoral Thesis of high school chess-aptitudes experiment, Zaire.

Freire, P. 1972. Pedogogy of the oppressed. Harmondsworth: Penguin.

Freire, P. 1982. The politics of culture, power and liberation. London: Macmillan.

Freire, P. 1985. The politics of education. London: Macmillan.

Freire. P. 1994. Pedagogy of the oppressed. (Revised edition). New York: The Continuum Publishing Company.

Freire, P. \& Shor, I. 1987. A pedagogy for liberation: dialogues on transforming education. London: Macmillan.

Frideras, J. S. 1992. Participatory Research: An Illusionary Perspective in Frideres J.S., (ed.) A World of Communities: Participatory Research Perspectives. Ontario: Caputus University Publications.

Fullan, M. 1991. The new meaning of educational change. London: Cassell.

Fullan, M. 2001. Leading a culture of change. San Francisco, CA: Jossey-Bass.

Fullan, M. 2003. The moral imperative of school leadership. Thousand Oaks, CA: Corwan.

Fullan, M. 2005. Leadership and sustainability. Thousand Oaks. CA: Corwan.

Furman, G.C. 1994. Outcome-based education and accountability, education and urban society, 26(4), 417-37.

Foster, G. \& Williamson. J. 2001. A Review of Current Literature on the Impact of HIV/AIDS on Children in sub-Saharan Africa. AIDS 2000 14(suppl 3): S275-S284.

Foucault, M. 1980. Power/Knowledge. New York: Pantheon Books.

Gilligan, R. 1998. The importance of schools and teachers in child welfare - Child \& Family Social Work 3 (1), 13-15.

Gilmore, T., Krantz, J., \& Ramirez, R. 1986. Action Based Modes of Inquiry and the Host-Researcher Relationship. Consultation 5.3: 160-76. 
Giroux, H.A. 1981. Ideology, culture and the process of schooling. London: Falmer Press.

Giroux, H.A. 1988. Schooling and the struggle for public life. Minneapolis: University of Minnesota Press.

Giroux, H.A. 1988. Teachers as Intellectuals. Massachussetts: Bergin \& Garvey.

Giroux, H.A. 1989. Schooling for democracy: critical pedagogy in the modern age. Minneapolis: University of Minnesota Press.

Giroux, H.A. 1991. Postmodernism, Feminism, and Cultural Politics. Albany: State University of New York Press.

Giroux, H.A. 1992. Border crossings: cultural workers and the politics of education. London: Routledge.

Giroux, H.A. \& Simon, R. 1989. Popular culture, schooling and everyday life. New York: Bergin \& Garvey.

Gramsci, A. 1971. Selections from prison notebooks. INew York: International Publishers.

Greenstein, R. 1998. New policies and the challenges of budgetry constraints, EPU Quarterly Review of Education and Training in South Africa 4(4):1-17.

Grundy, S. 1987. Curriculum: Product or praxis. London: Falmer Press.

Goss J.D. \& Leinbach T.R. 1996. Shopping around: focus group research in North London, Area 28 (2): 136-42.

Habermas, J. 1972. Knowledge and human interest. London: Heineman.

Hardiker, P. 1989. The Organisation and Management of Postgraduate Research Projects. University of Leicester, Faculty of the Social Sciences PhD Programme, Mimeo.

Hargreaves, A. 1994. Changing Teachers, Changing Times, Teachers Work and Culture in the Postmodern Age. London: The Falmer Press.

Hartshone, K. 1992. Crisis and challenge: Black education 1910-1990. Cape Town: Oxford University Press.

Hindle, D. 1996. A review of curriculum development structures and processes in South Africa, 1994-1995. EPU Working Paper No. 6, Education Policy Unit, University of Natal, Durban. 
Hitchcock, G. Hughes, D. 1995. Research and the Teacher. A Qualitative Introduction to School Based research. $2^{\text {nd }}$ edition. New York: Harper.

Holden, S. 2004. AIDS on the Agenda. London: Action Aid, Oxfam GB, and Save the Children UK.

Holter, I.M. \& Schwartz-Barcott, D. 1993. Action Research! What is it? How has it been used, and how can it be used in nursing? Journal of Advanced Nursing 18, 296-304.

Homan R. 1991. Ethics in Social Research. Harlow: Longman. Open University.

Hooks, B. 1994. Teaching to Transgress: Education as the Practice of Freedom. New York: Routledge.

Hoppe, M.J. Wells, E.A. Morrison, D.M. Gilmore, M.R. \& Wilsdon, A. 1995. 'Using focus groups to discuss sensitive topics with children' Evaluation Review 19 (1): 102-114.

Hopkins, D. 1985. A Teacher's Guide to Classroom Research, Milton Keyes: The Open University.

Hopkins, D. 2003. A Teacher's Guide to Classroom Research. Maidenhead: Open University Press.

Hubley, J. 2000. "Interventions Targeted at Youth Aimed at Influencing Sexual Behavior and AIDS/STDs." Leeds Health Education Database, April 2000, Leeds: United Kingdom.

Hyppolite, J. 1974. Genesis and Structure of Hegel's Phenomenology of Spirit Evanston, Illinois: Northwestern University Press.

Jackson, H. 2002. Aids Africa - Continent in crisis. Harare, Zimbabwe: SAFAIDS.

Jansen, J. 1997. 'Essential alterations?' A critical analysis of the states syllabus revision process, Perspectives in Education 17 (2): 1-11.

Jansen, J. 1998. Curriculum reform in South Africa: A critical assessment of outcomes-based education, Cambridge Journal of Education 28 (3):321-331.

Jansen, J. 1999. 'A very noise OBE': The implementation of OBE in Grade 1 classrooms. In J.Jansen \& P.Christie (Eds.). Changing the curriculum: Studies on outcomes- based education in South Africa. Cape Town: Juta. 
Jansen, J. 2001a. Rethinking education policy: Symbols of change, signals of conflict. In A. Kraak \& M. Young (Eds.). Education policy implementation in South Africa. Pretoria: HSRC.

Jansen, J. 2001b. The race for education policy after apartheid. In Y. Sayed \& J.Jansen (Eds.). Implementing education policies: The South African experience. Cape Town: UCT Press.

Jansen, JD \& Christie, P. 1999. Changing curriculum: Studies on outcomes-based education in South Africa. Cape Town: Juta.

James-Traore, T.A., Finger, W., Ruland, C.D. \& Savariaud, S. 2004. Teacher training: essential for school-based reproductive health and HIV/AIDS educationFocus on Sub-Saharan Africa. Youth Issues Paper 3, 2-7.

Jedaar, M.R. 1992. Muhammadeyah: 1929-1992. Unpublished paper. Cape Town.

Jewkes, R. 2001. Public Health and Epidemiology in the Era of South Africa's VD Pandemic of the 1930's and 1940s. Paper presented at the AIDS in Context Conference, 4-7 April, University of the Witwatersrand, Johannesburg.

Jewkes, R. \& Abrahams, N. 2002. The epidemiology of rape and sexual coercion in South Africa: An overview. Social Science \& Medicine, 55(7):1 231-44.

Johnson, L. \& Dorrington, R. 2002. The demographic and epidemiological impact of HIV/AIDS treatment and preventiō progrämmes: an evaluation based on the ASSA2000 model. Paper presented at the 2002 conference of the Demographic Association of Southern Africa, Cape Town.

Jonathan, R. 2001. The role of schooling in social transformation: high hopes and reasonable expectations. In D. Meerkotter, A. Fataar, O. L. Fuglestad \& S.Lillejord (Eds.). Learning from each other: school development and transformation in South Africa. Cape Town: Wyvern.

Kallaway, P. 1984. Apartheid and education. Johannesburg: Ravan Press.

Kaiser Daily HIV/AIDS Report: 8 August 2006.

Kaisernetwork.org - Daily HIV/AIDS Report - Kaiser Health Disparities Report: A Week Look At Race, Ethnicity And Health - Global Challenges / Social Stigma Complicating HIV/AIDS Awareness, Prevention Efforts in Saudi Arabia - 29 Nov 2006.

Khathide, A.G. 2000. Bone of My Bones: Building Functional Marriages in Africa, Auckland Park, AFM Theological Seminary. 
Kellner, D. 1989. Critical Theory, Marxism, and Modernity, Cambridge, UK and Baltimore, Md.: Polity Press and John Hopkins University Press.

Kellner, D. 2000. "New Technologies/New Literacies: reconstructing education for the new millennium," Teaching Education, Vol.11, No. 3: 245-265.

Kellner, D. 2003. Towards a Critical Theory of Education. [Online]. Available: http://www.gseis.ucla.edu/faculty/kellner/papers.html [2006, March 1]

Kelly, M.J. 1999. The Impact of HIV/AIDS on Schooling in Zambia. Paper presented at the XIth International Conference on AIDS and STDs in Africa, Lusaka, Zambia.

Kelly, M.J. 2000a. Planning for education in the context of HIV/AIDS. Paris: UNESCO: Education, Scientific and Cultural Organisation.

Kelly, MJ. 2000b. HIV/AIDS and Education in Eastern and Southern Africa. The Leadership Challenge and the Way Forward. Report for the African Development Forum.

Kemmis, S. \& McTaggart, R. 1982. The action research planner. Victoria: Deakin University Press.

Khumalo, L.P., Papo, W.D., Mabitla, A.M. \& Jansen, J.D. 1999. A baseline survey of $O B E$ in Grade 1 classrooms in the Northern Province. Centre for Education Research Evaluation and Policy, University of Durban-Westville.

Kincheloe, J.L. 1991. Teachers as researchers: Qualitative inquiry as a path to empowerment. New York: Falmer Press.

Kincheloe, J.L. 1993. Toward a Critical Politics of Teacher Thinking: Mapping the Postmodern. Granby, Mass.

Kitzinger, J. 1995. Introducing focus groups, British Medical Journal 311:299-302.

Kondrat, M.E. \& Julia, M. 1997. Participatory action research: self-reliant research strategies for human social development. Social Development Issues, 19(1): 32-39.

Kraak, A. 2001. Policy ambiguity and slippage: Higher education under the new state, 1994-2001. In A. Kraak \& M. Young (Eds.). Education policy implementation in South Africa, Pretoria: HSRC Press. 
Kraak, A. 2002. Discursive shifts and structural continuities in South African vocational education and training: 1981-1999. In P. Kallaway (Ed.). The history of education under apartheid, 1948-1994: The doors of learning and culture shall be opened. Cape Town: Maskew Miller Longman.

Kreuger, R.A. 1988. Focus groups: a practical guide for applied research, London: Sage.

Lather, P. 1986. 'Research as praxis', Harvard Educational Review, vol. 56 no 3.

Lankshear, A.J. 1993. 'The use of focus in a study of attitudes to student nurse assessment', Journal of Advanced Nursing 18: 1986-89.

Le Loux R \& Cornelius S. 2003. Sport: The Right to Participate and Other Legal Issues. Selected papers from the Sports Law Conference held at the University of Cape Town 6-7 February 2003.

Lewin, K. 1948. Resolving Social Conflicts. New York: Harper.

Liptrap, J. 1997. Chess and standard test scores, Chess Life Magazine.

LoveLife Games. 2002. Provincial Training Manual. Cape Town.

Lubisi, C. Wedekind, V. Parker, B. \& Gultig, J. (Eds.) 1997. Understanding, outcomes-based education: Knowledge, curriculum and assessment in South Africa: South African Institute of Distance Education (SAIDE) \& DoE.

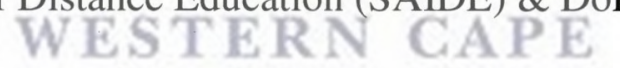

MacIntosh, J. 1993. Focus groups in distance nursing education, Journal of Advanced Nursing 18: 1981-85.

MacEnulty, D. 2007. First Steps to Understanding Chess. Unpublished paper. Cape Town.

Malcolm, C. 1999. Outcomes-based education has different forms. In J. Jansen \& P. Christie (Eds.). Changing curriculum: Studies on outcomes-based education in South Africa. Cape Town: Juta.

Management Help Organisation (2006). Retrieved 23 June, 2006, from http: www. managementhelp.org/evaluatn/interview.htm. 
Manie M.F. 1992. Towards participatory teaching and learning process in the English language classroom. Unpublished M Ed. Thesis. Cape Town: University of the Western Cape.

Marnewieck, L \& Spreen, C.A. 1999. Dancing with the monster: Mastering the steps of OBE in the Northern Province. Mimeo.

Martin, H.G. 2003. A Comparative analysis of the financing of HIV/AIDS programmes in Botswana, Lesotho, Mozambique, South Africa, Swaziland and Zimbabwe. Cape Town: Human Sciences Research Council.

Maseko, J. 1993. A crisis long in the making. Unpublished article. Cape Town.

Masters, J. 2000. The History of Action Research, Action Research e-Reports, 3, http://www.fhs.usyd.edu.au/arow/arer/003.htm.

Mbeki, T. 2000. Speech of the President of South Africa at the Opening Session of the $13^{\text {th }}$ International AIDSA Conference, Durban.

Mbeki, T. 2006. 'State of the Nation', Address by the President of South Africa, Thobo Mbeki, to the joint sitting of Parliament, Cape Town: 03.02.06.

Mathison, S. Ross, E.W. \& Cornett, J.W.(Eds.).71993. Considering Ethical Issues in Fieldwork in Ethical issues in Qualitative Research. Qualitative Research SIG, AERA.

Mbiti, S.J. 1969. African Religions and Philosophy. Kampala, African Traditional Publishers.

McCutcheon, G., \& Jurg, B. 1990. Alternative Perspectives on Action Research. Theory into Practice Volume 24, Number 3 Summer.

McKernan, J. 1991. Curriculum action research: a handbook of methods and resources for the reflective practitioner. London: Castlefield Press.

McKernan, J. 2000. Curriculum Action Research. $2^{\text {nd }}$ edition. London: Kogan Page.

McLaren, P. 1988. Schooling the Postmodern Body: Critical Pedagogy and the Politics of Enfleshment. Boston Journal of Education 170, no.3:53-83. 
McLaren, P. 1989. Life in schools. New York: Longman.

McLaren, P. 1991. Field Relations and the Discourse of the Other. In W.B. Shaffir \& R.A. Stebbins (Eds.). Experiencing Fieldwork. Newbury Park, CA: Sage.

McLaren, P. 2006. Rage \& Hope: Interviews with Peter McLaren on War, Imperialism, \& Critical Pedagogy. New York: Peter Lang Publishing.

McLaren, P. \& Leonard, P. 1993. Paulo Freire: a critical encounter. New York: Routledge.

McNicoll, P. 1999. Issues in Teaching Participatory Action Research. Journal of Social Work Education, 35(1): 51-62.

McNiff, J. 1988. Action research: Principles and Practice. Basingstoke: Macmillan.

McNiff, J. 2002. Action research for Professional Development Concise advice for new Action Researchers. London: Sage.

McNiff, J. 2006. Beyond alterity: creating my post-critical living theory of transformational identity. A paper presented at the British Educational Research Association annual meeting, University of Warwick, September. Retrieved 2 May 2007 from http://www.jeanmoniff.com/BERA06\%20Beyond\%20alterity.htm.

McNiff, J. 2007. 'My story is my living edueational theory', in D.J. Clandinin (Ed.) Handbook of Narrative Inquiry: Mapping a Methodology. Thousand Oaks, Sage, pages 308-329.

McNiff, J. 2007. Where the action Tis. Health Information and Libraries Journal, September. Retrieved 2 October 2007 from http://www.jeanmcniff@mac.com

McNiff, J. \& Whitehead, J. (2000) Action Research in Organisations. London: Routledge.

McNiff, J. \& Whitehead, J. (2005) Action Research for Teachers. London: David Fulton.

McNiff, J. \& Whitehead, J. (2006) All You Need to Know about Action Research. London: Sage.

McTaggert, R. 1992. Action Research: Issues in Theory and Practice Keynote address to the Methodological Issues in Qualitative Health Research Conference, Friday November $27^{\text {th }}$, 1992, Geelong: Deakin University.

Meerkotter, D.A. 1993. 'The NECC, People's Education and emancipatory action research at the University of the Western Cape'. In S. Davidoff, C. Julie, D. Meerkotter \& M. Robinson (Eds.). Emancipatory Education and Action Research. Pretoria: HSRC. 
Meerkotter, D.A. 1994. 'Teachers as agents of change'. In F. Sonn (Ed.). DSA in Depth: Reconstructing Education. Cape Town: IDASA, p.29).

Meerkotter, D.A. 1998. 'The state of schooling in South Africa and the introduction of Curriculum 2005'. In W. Morrow \& K. King (Eds) Vision and Reality: Changing Education and Training in South Africa. Cape Town: Cape Town University Press.

Meerkotter, D.A. 2000. 'Politicians! Don't blame our teachers!' in Making OBE Work? Proceedings of Western Cape Education Department Conference held in December 1999.

Meerkotter, D.A. 2002. The education and care of AIDS orphans and the need for informed action and participatory research. U.W.C. Papers in Education. Vol. 2.

Meerkotter, D.A. \& van den Berg, O.C. 1994. Technicism, schooling and power: Towards a recontextualization of education. In Y. Da Costa, C. Julie, \& D.Meerkotter (Eds.). Let the voices be heard: Process and practice in education. Cape Town: Wyvern Publications.

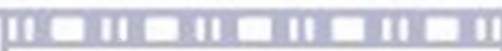

Micah - Towards a Christ Centred theology of HIV AIDS (2007). Retrieved 7

October, 2007, from http://en.micahnetwork.org/home/content/download/1458/ 16343/file/

Mohamed, H. 1998. The implementation of OBET in South Africa: Pathway to success or recipe for failure, Education Practice 1: 3-16.

\section{WFSTFRN CAPF}

Morgan, D.L. 1988. Focus groups as qualitative research. London: Sage.

Morgan, D. L. 1997. $2^{\text {nd }}$ Edition. Focus groups as qualitative research. London: Sage.

Morgan, D.L. \& Spanish M.T. 1984. 'Focus groups: a new tool for qualitative research', Qualitative Sociology 7: 253 - 70.

Motala, S \& Vally, S. 2002. People's education: From people's power to Tirisano. In P. Kallaway (Ed.). The history of education under apartheid: The doors of learning and culture shall be opened. Cape Town: Maskew Miller Longman.

Muller, J. 1998. NQF and outcomes-based education: Pedagogic models and hard choices, in Centre for Education Policy Development (Eds.). Reconstruction, development and the National Qualifications Framework: Conference proceedings. Johannesburg: CEPD. 
Muller, J. 2001. Progressivism redux: Ethos, policy, pathos. In A. Kraak \& M.Young (Eds.). Education in retrospect: Policy and implementation since 1990. HSRC \& Institute of Education, University of London.

Muller, J \& Taylor, N. 1995. Schooling and everyday life: Knowledges sacred and profane, Social Epistemology 9: 257-275.

New York Times: 22 October 1989.

Nasr A, 2006. AP/Houston Chronicle: 27 November 2006.

Nasson, B. 1983. Education: From poverty to liberty. Unpublished paper. Cape Town.

O'Brien, R. 1998. An overview of the methodological approach of action research. [Online]. Available: http://www.web.nrt-robien/papers/arfinal.html [2007, January 26].

Odora-Hoppers, C. 2002. Higher education, sustainable development and the imperative of social responsiveness. Mimeo, University of Pretoria.

Oja, S.N., \& Smulyan, L. 1989. Collaborative action research: A developmental approach. Philadelphia: The Falmer Press.

Papier, J. C. 1990. Using activity based resources in primary school history: an action research study. Belville: University of the Western Cape (M. Ed. thesis).

Powell, R.A. \& Single, H.M. 1996. 'Focus Groups', International Journal of Quality in Health Care 8 (5): 499-504.

\section{UNIVERSITY of the}

Powell R.A., Single H.M. \& Lloyd K.R. 1996. "Focūs groups in mental health research: enhancing the validity of user and provider questionnaires', International Journal of Social Psychology (42 (3): 193-206.

Pretorius, F. 1998. Outcomes-based education in South Africa. Johannesburg: Hodder \& Stoughton.

Proudfoot Consulting, 1999. Interim Report on the Provision of Learner Support Materials: Business Reviews. Prepared for the Department of Education.

Quinlan,T. \& Willan, S. 2005. HIV/AIDS: finding ways to contain the pandemic. In J. Daniel, J. Lutchman \& R. Southall (Eds.). State of the Nation: South Africa 20042005. Cape Town: HSRC Press.

Race K.E., Hotch D.F. \& Parker T. 1994. 'Rehabilitation program evaluation: use of focus groups to empower clients', Evaluation Review 18 (6): 730-40. 
Reason, P.,\& Bradbury, H. 2001. Introduction: Inquiry and participation in search of a world worthy of human aspiration. In P. Reason \& H. Bradbury (Eds.). Handbook for Action Research: Participative Inquiry and Practice (pp. 1-14). London: Sage.

Richter, L., Dawes, A \& Higson-Smith, C. 2004. Sexual abuse of young children in Southern Africa. Cape Town: HSRC Press.

Rifner, PJ. 1993. Playing chess: A study of the transfer of problem-solving skills in students with average and above average intelligence. Dissertation Abstracts International, 54(3-A), 871.

Robinson, M. 1989. Interactive teaching and learning in teacher education: an action research study. Bellville: The University of the Western Cape (M. Ed. thesis).

Robinson, M. 1993. Some challenges facing emancipatory action research in South Africa today. Unpublished Paper. Bellville: The University of the Western Cape.

Robinson, M. 2000. Mentoring and teacher development: a case study. Belville: The University of the Western Cape (D. Ed.thesis).

Roy, S.; Shibani, H. \& Rizvi, M. 1998. Sexuality: meaning, myth and practice. Delhi: B.R. Publishing Corporation

Sagor, R. 2000. Guiding School Improvement with Action Research, Alexandria: VA: ACD.

Sarason, S. 1991. The predictable failure of educational reform. San Francisco: JosseyBass Publishers.

Schaefer, C.E. \& Reid, S.E. 1986. Game Play: Therapeutic Use of Childhood Games. New York: John Wiley \& Sons.

Schoeman, J.P. \& Van der Merwe, M. 1996. The Art of the Relationship with Children: A Gestalt Approach, in Entering the Child's World: A Play Therapy Approach.Pretoria: Kagiso Publishers.

Schroeder, R. 2005. Interview. Cape Town.

Seleti, Y. 1997. From history and human and social sciences: The new curriculum framework and the end of history for the General Education and Training level. EPU Working Paper No.14, Education Policy Unit, University of Natal, Durban.

Shisana, O. \& Simbayi, L. 2002. The Nelson Mandela and HSRC Study of HIV/AIDS - South African National HIV Prevalence, Behavioural Risks and Mass Media Household Survey, Cape Town: HSRC. 
Shisana, O. 2004. Social aspects of access to care and treatment. Unpublished Paper. $2^{\text {nd }}$ African conference on social aspects of HIV/AIDS research. Cape Town.

Skweyiya, TL. 2002. Fighting the Scourge of HIV/AIDS. Unpublished manuscript.

Soul City, 2004. Aids in our community. Gauteng: Jacuna DFID.

Spady, W. \& Marshall, K. 1994. Light, not heat, on OBE. The American School Board Journal, 181 (November), 29-33.

Smart, R. 2003. Aids Brief - Education Sector. Durban: The Write Stuff. www.ukzn.ac.za/heard/publications/Aids Briefs/sec/Education.pdf. [Online 2007 June 2].

Smith, JP. \& Cage, BN. 2000. The effects of chess instruction on the mathematics achievement of southern, rural, Black secondary students. Research in the Schools, 7(1), 19-26.

Smith, J. \& Sullivan, M. 1997. The effects of chess instruction on students' level of field dependence/independence. Paper presented at the Annual Meeting of the MidSouth Educational Research Association, Nov. 12-14, 1997, Memphis, TN.

Stenhouse, L. 1975. Introduction to Curriculum Research and Development.

London: Heinemann.

Sunday Times: 23 September 2000. VERS ITY of the

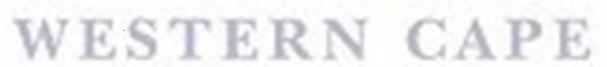

Sunday Times: 29 July 2001.

Taylor Committee, 2002. Transforming the present-Protecting the future. Report of the Committee of Inquiry into a Comprehensive System of Social Security for South Africa, Pretoria.

Taylor, N. \& Vinjevold, P. 1999. Getting learning right: Report of the President's Education Initiative, Johannesburg: Joint Education Trust.

Torino Commitments, 2003, http://multimedia.olympic.org/pdf/en-report-1001.pdf.

Toseland, R.W. \& Rivas, R.F. 2001. An introduction to group work practice $\left(4^{\text {th }}\right.$ ed.), Boston: Allyn \& Bacon. 
Towers, J.M. 1996. An elementary school principal's experience with implementing an outcome-based curriculum. In R.Winter (Ed.). Catalyst for Change. (pp.19-23). London: Falmer Press.

UNAIDS (United Nations Programme on HIV/AIDS). 1999a. UNAIDS Best Practices: School AIDS Education Category. The Kenya Youth Initiatives Project. UNAIDS Best-Practice Collection. Geneva.

UNAIDS (United Nations Programme on HIV/AIDS). 1999b. Sexual Behavioral Change for HIV: Where Have all the Theories taken Us? Geneva.

UNAIDS (United Nations Programme on HIV/AIDS). 2000a. Report on the Global HIV/AIDS Epidemic. Geneva.

UNAIDS (United Nations Programme on HIV/AIDS). 2000b. AIDS Epidemic Update: December 2000. Geneva.

UNAIDS (United Nations Programme on HIV/AIDS). 2000c. AIDS in Africa, Country by Country. UNAIDS and ECA. Geneva.

UNAIDS (United Nations Programme on HIV/AIDS). 2000d. Innovative Approaches to HIV Prevention: Selected Case Studies. Geneva.

UNAIDS (United Nations Programme on HIV/AIDS). 2002. Report on the Global HIV/AIDS Epidemic, XIV International Conference on AIDS, Barcelona, 7-12 July 2002, Geneva: UNAIDS, www.unaids.org.

UNAIDS (United Nations Programme on HIV/AIDS). 2004. AIDS Epidemic Update: December 2004. Geneva.

UNAIDS \& IOC, 2004. http://www.unaids. org/en/events Fampaigns/ iocunaids\%2 Bpartnership.asp.

UNAIDS (United Nations Programme on HIV/AIDS), UNICEF (United Nations Children's Fund), and National Black Leadership Commission on AIDs, Inc. (BLCA). 1999. Call to Action for Children Left Behind by Aids. Washington, D.C.

UNDPI \& UNAIDS, 2001. Fact Sheets: Global Crisis ... Global Action. New York: UNDPI and UNAIDS.

UNESCO, 2004. UNESCO's Strategy for HIV/AIDS Prevention Education. Paris: International Institute for Educational Planning (http;//unescodoc.unesco.org/ images/0013/001345/134572e.pdf 07/11/2005).

Unterhalter, E. 1998a. Citizenship, difference and education: Reflection on the South African transition. In P. Werbner \& N. Yuval-Davis (Eds.). Women, citizenship and difference. London: Zed. 
Unterhalter, E. 1998b. Economic rationality or social justice? Gender, the National Qualifications Framework and educational reform, in South Africa 1989-1996, Cambridge Journal of Education 28(3).

Vally, S. 2001. Fundamentalism and the Fundamentals of Education. Quarterly Review of Education and Training Vol.8 no.4.

Van den Berg, O. \& Meerkotter, D. 1996. 'Emancipatory action research in South Africa: from critical opposition to critical support'. In B.Boog, H. Coenen, L. Keune, and R. Lammerts (Eds.). Theory and Practice of Action Research: With Special Reference to the Netherlands. Tilburg: Tilburg University Press.

Van Zyl, ASAJ. 1991. The significance of playing chess in improving a child's intellectual actualization. (Afrikaans text) Dissertation Abstracts International, 52/06, 2083.

Verwoerd, H.F. 1954: House of Assembly. Hansard, Senate.

Vinjevold, P. \& Roberts, J. 1999. External evaluation report: Provision of learning materials Grade 7 pilot project. Johannesburg: Joint Education Trust.

Vygotsky, L. 1978. Mind in Society. Cambridge, Mass., Harvard University Press.

Walker, L., Reid, G. \& Cornell, M. 2004.Waiting to Happen HIV/AIDS in South Africa. Cape Town: Creda Communications.

Walker, M. 1987. Action Research in South African ${ }^{\text {Schools: Gilding Gutter }}$ Education or Transforming Teaching? Perspectives in Edueation II.

Walker, M. 1988. 'Reflection on learning to facilitate teachers' critical understanding of their classroom practice in the context of primary education'. In S.Abrahams (Ed.). Education in the Eighties. Proceedings of the Kenton Conference 1988. Cape Town: University of Cape Town. pp 186-206.

Walker, M. 1989. Action research in South African schools - gilding gutter education or transforming teaching. Paper presented at RESA Conference, Essex.

Walker, M. 1990. Action research as a project. Cape Town: Primary Education Project, University of Cape Town.

Wallace, M.J. 2002. Action Research for Language Teachers. $5^{\text {th }}$ printing. Cambridge: Cambridge University Press.

Wirth, A.G. 1983. Productive Work. Lanham, Md, University Press of America. 
Weekend Argus: 2 December 2006.

Western Cape Education Department. 2004. WCED. HIV/AIDS Life Skills Programme. Cape Town.

WHO (World Health Organisation) 2000. Health systems: Improving performance. The World Health Report 2000. Geneva: WHO.

Wieder, A. 2003. Voices from Cape Town Classrooms Oral Histories of Teachers who fought Apartheid. New York: Peter Lang Publishing.

Williams, C. 2002. The suitability of critical action research as a methodology for ensuring democratic deliberation. UWC Papers in Education - Vol.2, 61.

Wilson, F. \& Ramphele, M. 1989. Uprooting Poverty, The South African Challenge. Cape Town: David Philip, Publishing.

Winter, R. 1987. Action Research and the Nature of Social Enquiry: Professional Innovation and Educational work. Gower Publishing Company. Aldershot: Avebury.

Winter, R. 1989: Learning from experience: principles and practice in action research. London: Falmer Press.

Wiseman, J.P. \& Aron, M.S. 1972. Fietd Reports in Sociology, London, Transworld Publishers.

Wolfensohn, J.D 2000: Address to the United Nations Security Council, January 2000 .

World Bank. 1999. Confronting AIDS: Public Priorities in a Global Epidemic. A World Bank Policy Research Report. New York: Oxford University Press.

World Bank. 2002. Education and HIV/AIDS A Window of Hope. Washington, DC 20433.

Wood, E. \& Bennett, N. 2000. Changing theories, changing practice: exploring early childhood teachers' professional learning. Teacher and Teacher Education, 16(1): 635-647. 


\section{APPENDIX 1}

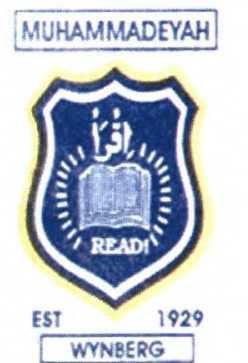

\section{MUHAMMADEYAH PRIMARY SCHOOL}

TEL: (021) 7978047

FAX: (021) 7622487

103 BATTS ROAD WYNBERG 7800

PRINCIPAL: E. ISMAIL

Dear Mr O Esau

\section{Research Project: Checkmating HIV/AIDS}

On behalf of the Governing Body of Muhammadeyah Primary School I am hereby notifying you that your application to do the HIV/AIDS research project with our senior pupils has been given the go-ahead.

\section{IID}

We have no problem if you use the name of the school - Muhammadeyah Primary School as we believe that AIDS prevention is a necessity in our country. AIDS kills and making communities aware of its dangers has become an imperative. If you find any teacher or learner confiding in you and revealing to you that s/he is IIIV-Positive or have AIDS then we urge you not to identify the person or mention the person in you research document.

We would however want a copy of the research once you have completed.

We wish you well in your pursuit of knowledge.

Yours sincerely

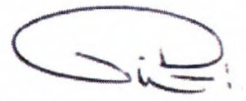

Chairperson of the Governing Body

Dated 31 August 2006 


\section{APPENDIX 2}

103 Batts Road

Wynberg

7800

10 September 2003

The Principal/Governing Body

Dear Madam/Sir

Re: Research at School

I am reading towards my Doctorate in Education at the University of the Western Cape. My research aims to make Grade 6's and Grade 7's aware of the HIV/AIDS pandemic.

This research will encompass the following:

a.) the use of the school premises.

b.) the use of the learners, specifically grade six (6) learners in 2004 and the same grade seven (7) learners in 2005.

The questionnaires will be within the parameters of ethics as described by the Department of Education and the University. ITY of the

My promoter for this research is Prof. Dirk Meerkotter (Dean of the Faculty of Education) at the University of the Western Cape.

I would like, if possible to obtain permission to do this action research study at the school. A copy of my research proposal is attached to this letter.

Hope my request will meet your approval.

Yours faithfully

Omar Esau

P.S. For further information contact Omar Esau at oesau@mweb.co.za or 0834074355 . 


\section{APPENDIX 3}

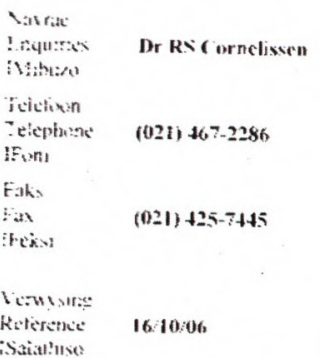

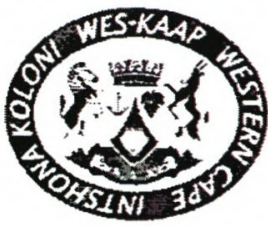

Wes-Kaap Onderwysdepartement

Western Cape Education Department

SSebe le.Mfundo teitshona Koloni

istiat!luse:

\section{Dear Mr O Esau}

Before research can be approved the following must be provided:

1. Concise description of the research project/proposal.

2. If questionnaires/interviews tests are to be used in the investigation. copies of such questionnaires/struetured questions/test questions to be provided.

3. A letter from your supervisor/project head must accompany the application stating that you are registered at a tertiary institution (for students only).

4. The names of the departmental institutions (schools) where the research will be conducted.

5. Who are the Respondents (i.e. learners, parents, educaters. elc.)?

6. The period during which the researeh wil! be conducted.

7. No research can be conducted during the fourth term (October-December) as schools are preparing and finalising syllabi for examinations.

8. Complete the Rescarch Application Form (attached with letter).

The above information can be faxed or e-mailcd. If further assistance is needed. please e-mail (rcornelissen apgwe.gov.7a).

Yours in I:ducation

Signed: Ronald S. Curnclissen

for: HEAD: EDLCATION

DATE: $16^{\text {th }}$ October 2006

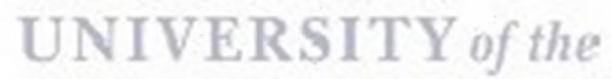

WESTERN CAPE

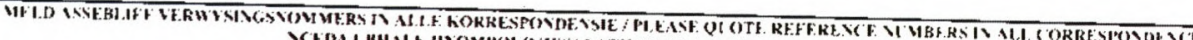

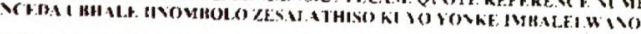

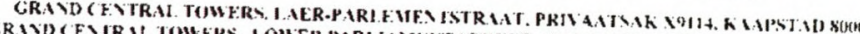

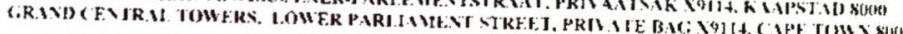

WF.B: http://wced.wcape.gov.za

INBELSF.YTRLYM/CALI. CENTRE.

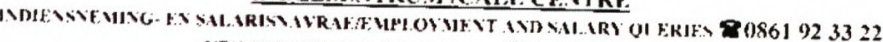

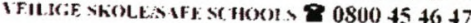




\section{APPENDIX 4}

\begin{tabular}{|c|c|}
\hline 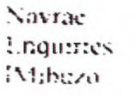 & Dr RS Cornelissen \\
\hline 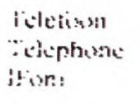 & $(021) 467-2256$ \\
\hline $\begin{array}{l}\text { Fajis } \\
\text { Fax } \\
\text { ificks }\end{array}$ & $(021)+25-7+45$ \\
\hline $\begin{array}{l}\text { Vumping } \\
\text { kitertsice }\end{array}$ & $20061023-0020$ \\
\hline
\end{tabular}

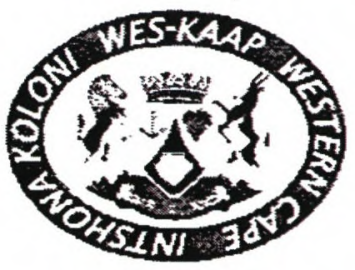

Wes-Katp Onderwysdepartement

Western Cape Education Department

ISebe le.Mfundo le.vitsiona Kuloni

Mr Omar Esau

9 Scout Road

LANSDOWNE

7800

Dear Mr O. Esau RESEARCH PROPOSAL: ADDRESSING THE "CULTURE OF SILENCE" IN CHECKMATING HIVIAIDS AS
A TEACHER - RESEARCHER. Your application to conduct the above-mentioned research in schools in the Western, Cape has been approved
subject to the following conditions:

1. Principals. educators and learners are under no obitgation to assist you in your irvestigation.

2. Principals, educators, learners and schools should not be identifiable in any way from the resuits of the

3. You make all the arrangements concerning your investigation

4. Educators' programmes are not to be interupted.

5. The Study was conducted from $1^{\text {st }}$ February 2005 to 23 September 2006.

6. No research can be conducted during the fourth term as schools are preparing and finalizing syllabi for 7. Should you wish to extend the period of your survey, please contact Dr R. Cornelissen at the contact
numbers above quoting the reference number.

8. A photocopy of this letter is submitted to the Principal where the intended research is to be conducted.

Department.
De limited to the list of schools as submitted to the Western Cape Education:

10. A brief summary of the content, findings and recommendations is provided to the Director: Education

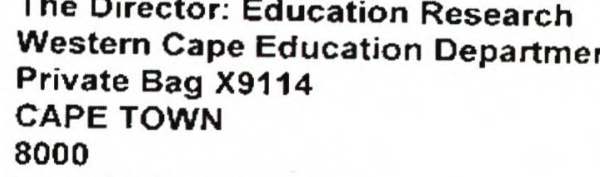

We wish you success in your research

Kind regards.

Signed: Ronald S. Cornelissen

for HEAD: EDUCATION

DATE: 16th November 2006

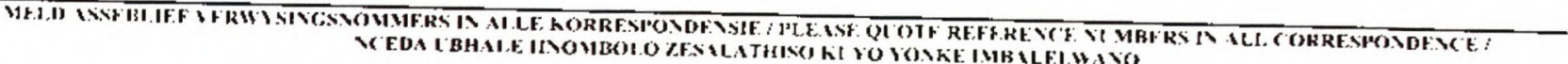

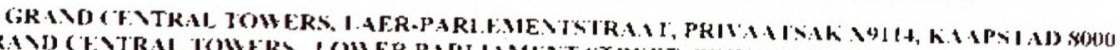

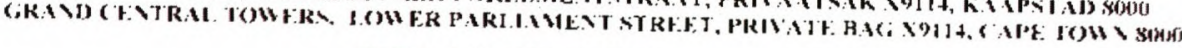

WF.B: http://wced.wcape.gov.za

INBF.LSE.YIRI M/CALLCWNTRE

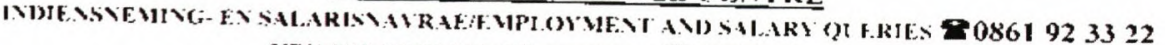

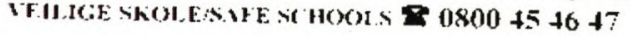




\section{APPENDIX 4}

Mr Omar Esau

9 Scout Road

LANSDOWNE

7800

Dear Mr O. Esau

RESEARCH PROPOSAL: ADDRESSING THE "CULTURE OF SILENCE" IN CHECKMATING HIVIAIDS AS A TEACHER - RESEARCHER.

Your application to conduct the above-mentioned research in schools in the Western Cape has been approved subject to the following conditions:

1. Principals, educators and learners are under no obligation to assist you in your investigation.

2. Principals, educators, learners and schools should not be identifiable in any way from the results of the investigation.

3. You make all the arrangements concerning your investigation.

4. Educators' programmes are not to be interrupted.

5. The Study was conducted from $1^{\text {st }}$ February 2005 to 23 September 2006.

6. No research can be conducted during the fourth term as schools are preparing and finalizing syllabi for examinations (October to December)

7. Should you wish to extend the period of your survey, please contact $\mathrm{Dr} R$. Cornelissen at the contact numbers above quoting the reference number.

8. A photocopy of this letter is submitted to the Principal where the intended research is to be conducted.

9. Your research will be limited to the list of schools as submitted to the Western Cape Education Department.

10. A brief summary of the content, findings and recommendations is provided to the Director: Education Research.

11. The Department receives a copy of the completed report/dissertation/thesis addressed to:

The Director: Education Research

Western Cape Education Department

Private Bag X9114

CAPE TOWN

8000

We wish you success in your research.

Kind regards.

Signed: Ronald S. Cornelissen

for: HEAD: EDUCATION

DATE: 16th November 2006 


\section{APPENDIX 5}

SURVEY OF GRADE 6 LEARNERS:

\section{MUHAMMADEYAH PRIMARY SCHOOL:}

FEBRUARY 2005

MARK THE APPROPRIATE NUMBER WITH A CROSS (X):

a. GENDER

Male

Female

\section{b. HOME LANGUAGE}

English

Afrikaans

English \& Afrikaans

Other

c. WHERE ARE YOU LIVING THIS YEAR WHILE YOU ARE STUDYING?

With my parents

With another family

I board with people

Other

\section{d. ARE YOUR PARENTS STILL ALIVE?}

Both Alive

Father Deceased

Mother Deceased

Both Deceased 
e. WHAT IS THE APPROXIMATE MONTHLY INCOME OF YOUR

\section{PARENTS?}

Unemployed

Less than R1000

R1000 - R2000

R2000 - R3000

R3000 - R4000

R4000 - and more

I do not know

\section{f. EDUCATIONAL LEVEL OF FATHER/STEPFATHER/GUARDIAN}

Grade 8 or lower

Grade 9 to Grade 11

Grade 12

Further than Grade 12

I do not know

g. EDUCATIONAL LEVEL OF MOTHER/STEPMOTHER/GUARDIAN

Grade 8 or lower

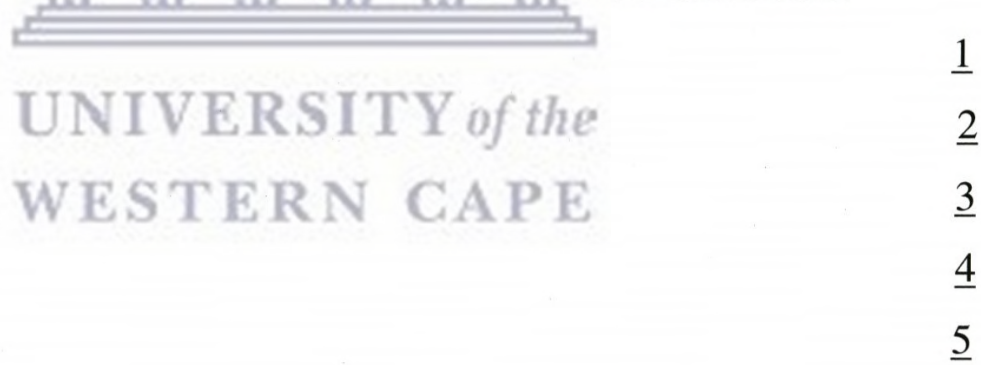

Grade 9 to Grade 11

Grade 12

Further than Grade 12

I do not know

h. HOW MANY CHILDREN (LIVING CHILDREN, YOURSELF INCLUDED) ARE THERE IN YOUR FAMILY?

One (self)

Two

Three $\underline{3}$

Four

Five $\underline{5}$

Six $\underline{6}$

Seven or more 
i. HOW MANY ADDITIONAL FAMILY MEMBERS CURRENTLY LIVE IN YOUR HOUSEHOLD (EG., GRANDPARENTS, AUNTS UNCLES, COUSINS)?

One

Two $\underline{2}$

Three $\underline{3}$

Four $\underline{4}$

Five and more $\underline{5}$

None

j. INDICATE YOUR POSITION IN THE BIRTH-ORDER OF YOUR FAMILY Eldest child

Second eldest

Third eldest

Fourth eldest

Youngest

Only child

Other

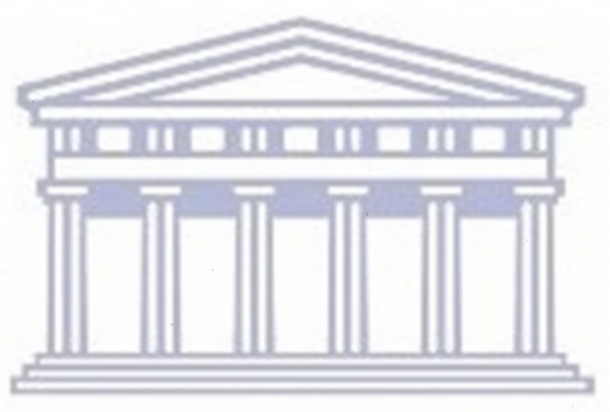




\section{APPENDIX 6}

\section{UNSTRUCTURED INTERVIEW}

\section{AUGUST 2005}

\section{The Unstructured Interview concentrated on the following questions:}

1. What is the difference between someone who has HIV and someone who has AIDS?

2. When and where was the first time you heard of HIV/AIDS?

3. Do you think we need to be concerned about this pandemic? Why do you say so?

4. How can we go about educating people about HIV/AIDS?

5. What do you understand by the terms sex and sexuality?

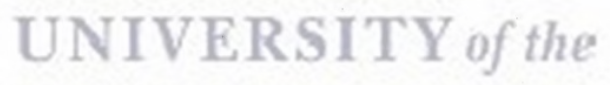

6. How are drugs and drug abuseirelated to HIV/AIDS?

7. Draw up an exciting "Holiday Programme" to make people aware of HIV/AIDS. 


\section{APPENDIX 7}

\section{HIV AND AIDS EDUCATION}

\section{SEPTEMBER 2005}

\section{GRADE 6}

Please read the following questions carefully and answer them to the best of your ability:

1) Describe in your own words how you went about acting and planning your play about HIV/AIDS?

2) What was the moral of the play?

3) In the media, or in your own experience, what have you learnt about HIV and AIDS?

4) What can our school do to make the HIV/AIDS awareness lessons more exciting or interesting?

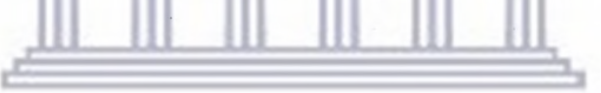

5) How can we infuse or link HIV HAIS awareness into our school sports programme/s?

6) How can drugs and drug abuse influence the HIV/AIDS pandemic?

7) What has the knowledge of sex and sexuality got to do with HIV and AIDS education?

8) Draw up an Agenda for HIV/AIDS public meeting. Also indicate who your guest speakers will be and why you specifically chose these guest speakers? 


\section{$\underline{\text { APPENDIX } 8}$}

\section{PROJECT: CHECKMATING HIV/AIDS!}

\section{a) Introduction}

Sport has indeed contributed in rallying the masses to voice their opposition to the Apartheid government in the past and has also been a rallying point in our country's Transformation and Nation Building agenda. It was also used as a motivating factor to fight crime as the famous cliché of the late Minister of Sport, Steve Tshwete is often quoted, "... A child in sport is a child out of court." Recently, sport has also been widely integrated as part of Youth Wellness and Development programmes such as that advocated by loveLife and by some ad hoc government programmes to 'Get the Nation to Play'.

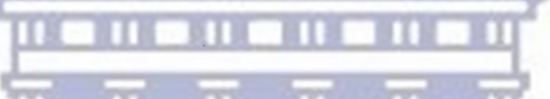

In this paper I focus specifically on one code of sport, Chess and I set out to discuss the potential of using this code of sport to take up the HIV/AIDS challenge. I am almost sure that we can also use other codes of sport in similar or more creative ways to take up the daily challenges and risks our youth are faced with.

\section{b) Motivation for Project}

The impact of HIV/AIDS remains a major health threat and continues to have a devastating impact on the socio-political and economic well-being of the global population. No where has the impact been more devastating than in sub-Saharan Africa. During 2003 an estimated 2,2 million people died of AIDS in sub-Saharan Africa (UNAIDS 2004). According to Holden, (2004:5), 
...[m]ore than 90 per cent of HIV-positive people live in developing nations, and sub-Saharan Africa alone is thought to account for about two thirds of the global total of cases. The worst affected region in the world, Southern Africa, is home to about two per cent of the world's population - but thirty per cent of all the people in the world who are living with HIV/AIDS live in Southern Africa.

It is clear that the response to HIV/AIDS cannot be sectoral but should be multisectoral. There is still no cure for HIV/AIDS. Nothing can prevent infection except our own behaviour. Our behaviour is mostly controlled by our mindset. In order to have a responsible and open mind we need to think logically. Chess, being a mind game encourages deep logical thinking which lends itself to responsible action.

Promoting the play of Chess is a creative and strategic way in taking up the HIV/AIDS challenge.

"As partners against HIV/ADS, together we pledge to pool our resources and to commit our brain power" (Thabo Mbeki: 1999)

\section{c) Vision}

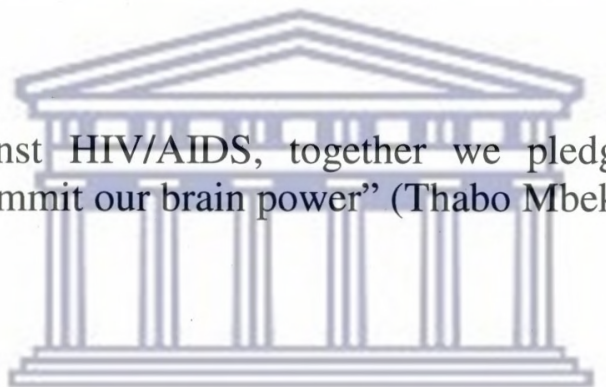

To empower all schools and communities in South Africa to develop thinking skills by playing Chess and to utilise the strategy applied in the game to combat the HIV/AIDS pandemic.

\section{d) Mission}

To promote Chess as a Code of Sport in South Africa and to be involved in HIV/AIDS awareness in the School Enrichment and Wellness Programme.

\section{e) Objectives}

1) To use Chess as a vehicle to promote a "positive lifestyle" and to make pupils in schools and communities aware of the HIV/AIDS pandemic. 
2) To train teachers and learners in playing, coaching and administering Chess activity.

3) To increase cognitive skills and to improve learners' ability to think rationally.

4) To instil in young players a sense of self-confidence and self-worth.

5) To promote gender equity as chess allows girls to compete with boys on a non-threatening, socially acceptable plane.

6) To promote healthy competition and socialisation in a safe environment.

7) To teach children to try their best to win, while accepting defeat with grace.

8) Ensure a bias towards the target group most at risk and where there is a greater threat of HIV infection.

9) To promote the brand awareness, "Checkmating HIV/AIDS" and to promote and market other HIV preventative strategies.

10) To encourage inter-class, inter-school, inter-regional, inter-provincial and international Chess activity.

\section{UNIVERSITY of the}

\section{f) Basic requirements to stage the project}

1) The target group is all school-going children with specific focus on the $12-17$ years old age group.

2) The project will initially focus on young people from disadvantaged and poverty-stricken areas.

3) The project is developmental and will therefore emphasise training and skills enhancement of players, participants, officials, administrators, educators and organisers. 
4) The programme must lead to greater participation at inter-school level and school leagues must be the natural starting point to identify schools that will progress to the Zonal, Regional, Provincial and National Chess competitions.

5) The theme for the project is "Checkmating HIV/AIDS!"

\section{g) How will the programme be organised?}

1) A school will be identified, In a primary school Grade $6 \mathrm{~s}$ and Grade $7 \mathrm{~s}$ will be targeted and in a secondary school all grades will be targeted.

2) The game of Chess will be introduced by a trainer or administrator.

3) Participants will be seated in pairs with a Chess board, Chess pieces, pens, notation book (includes HIVIAIDS information and particulars of Chess)

4) Trainers will introduce learners to the basics of Chess.

5) Once the learners are Chess competent, they will be given a Chess board and pieces and a Chess competency certificate with symbols emphasising "Checkmating HIV/AWS!" VERSITY of the

6) All participants including the administrators and trainers will be wearing sweaters with the logo "Checkmating HIV/AIDS!"

\section{h) Concluding Remarks}

This project, together with other sport code projects with similar aims and objectives will definitely contribute towards making our youth aware and skillful enough to deal amicably with the HIV/AIDS pandemic. 


\section{APPENDIX 9}

\section{HIV/AIDS ACTION PLAN FOR MUHAMMADEYAH PRIMARY:}

Priority One:

Prevention

\section{Date:}

February 2006 - October 2006.

\section{Participants:}

SGB, SMT, UWC, School Based Support Team.

\section{Action:}

Checkmating HIV/AIDS! - Pupils are taught to play chess and are made aware of HIV/AIDS.

\section{Activities:}

1) Planning of campaign

2) Contact role players and stakeholders

3) Discuss with staff how to use HIV/AIDS as a teaching theme

4) Fundraising

5) Invite guests

6) Carry out campaign as planned.

\section{Resources needed:}

1) Chess Demonstration Board,

2) Chess boards,

3) Chess pieces,

4) Pens,

5) Notation book (includes HIV/AIDS information and particulars of Chess),

6) Trainers, 
7) Certificates,

8) T-Shirts,

9) Catering

\section{Indicators of Success:}

1) There is a program of activities in place

2) Comments by speakers

3) Learners, educators and the community around the school become aware of the spread of HIV/AIDS and start to speak about it.

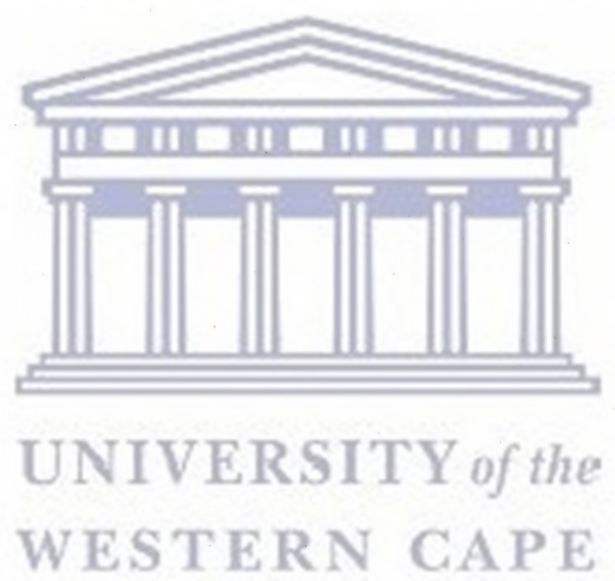




\section{APPENDIX 10}

\section{WRITTEN CONSENT OF PARTICIPANTS WHO PARTICIPATED IN THE}

\section{PROJECT:}

These are the names of the persons who participated in the "Checkmating HIV/AIDS Project" and have given me their consent to mention them by name in the thesis. I acknowledge their participation and remain indebted to them for their input, constructive criticism and motivation in the project.

I hereby give my consent to the researcher, Omar Esau to mention my name in the thesis - "Breaking the Culture of Silence in Checkmating HIV/AIDS as a TeacherResearcher".

\section{Name:}

\section{Signature:}

Adams Aneesa

Emmert Anne

Hamdulay Samsodien

Hanekar Mariam

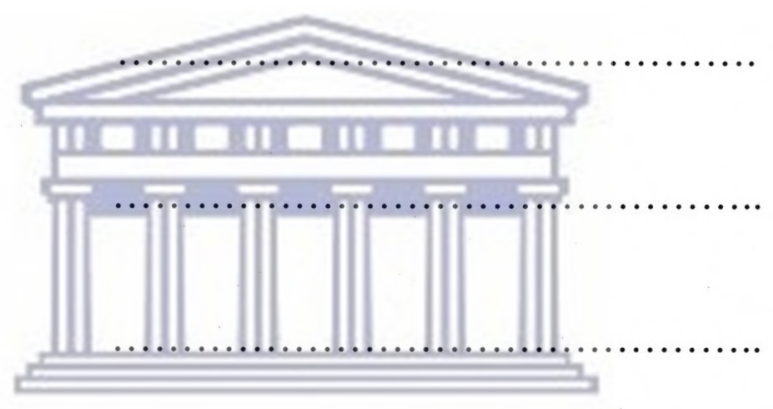

Ebrahim Ismail

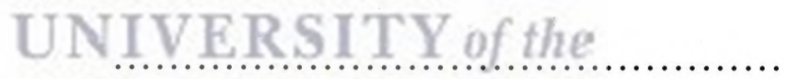
WESTERN CAPE

Jacobs Abdurakiep

James Jackie

Karbelkar-Pheiffer Nabeel

Schroeder Rashard

Willenberg Athon 


\section{APPENDIX 11}

\section{UNSTRUCTURED INTERVIEW}

\section{CHECKMATING HIV/AIDS!}

The Unstructured Interview concentrated on the following questions:

a. What do you understand by the term - Checkmating HIV/AIDS?

b. How can Chess help you to fight HIV/AIDS?

c. How can the playing of Chess assist your everyday life?

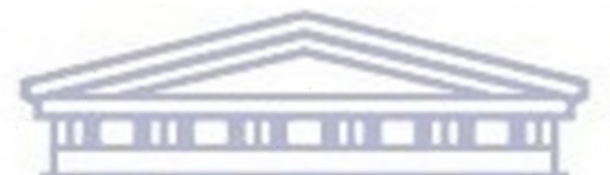

d. What do you understand by making the Right Move in life?

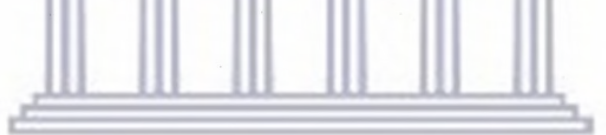

e. What do you understand by Touch is a Move in life?

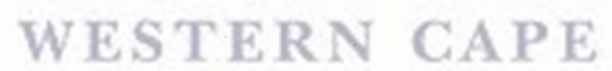

f. What do you think makes the playing of Chess different from other codes of sport? 


\section{APPENDIX 12}

\section{MUHAMMADEYAH PRIMARY SCHOOL'S HIV/AIDS POLICY}

\section{PREAMBLE:}

Acquired Immune Deficiency Syndrome (AIDS) is a communicable disease that is caused by the Human Immunodeficiency Virus (HIV).

HIV/AIDS is one of the major challenges to all South Africans. According to UNAIDS (2001), since the epidemic began, more than 60 million people have been infected with the virus. Sub-Saharan Africa continues to bear the brunt of HIV and AIDS with close to $70 \%$ of the global total of HIV positive people (UNAIDS, 1999). Botswana, Lesotho, Mozambique, Swaziland, Zimbabwe and South Africa comprise 1.3 per cent of the world's population and account for 23.3 per cent of the total HIV/AIDS burden globally. Similarly, 12.1 per cent of the sub-Saharan Africa population reside in these countries, yet they account for 32.5 per cent of the people living with HIV/AIDS on the sub-continent (Martin,2003).AIDS is clearly a if not the key obstacle to achieving sustainable development on our continent (Shisana, 2004).

\section{OBJECTIVES:}

\section{UNIVERSITY of the}

- To increase awareness of the HIV/AIDS pandemic amongst our learners, parents, teachers and community and to provide accurate information to assist in preventing the disease.

- To promote a cross-curricular approach to HIV/AIDS education in our school.

- To provide an opportunity for educators and learners to develop the interpersonal skills required to deal with HIV/AIDS - such as communication, decision-making, assertiveness and peer-leadership.

\section{LEARNERS:}

\section{ADMISSION POLICY:}

- No learner will be refused admission to the school based on her/his status.

\section{TREATMENT OF LEARNER/S WITH HIV/AIDS:}

- Learners with HIV/AIDS will not be discriminated against in anyway. 
- Their needs will be accommodated as far as is reasonably possible within the school environment.

- Any special measures taken, will be fair, medically justifiable and taken in consultation with the learner and parent.

\section{HIV/AIDS STATUS OF LEARNERS:}

- All medical information will be treated confidentially unless voluntarily disclosed.

\section{PREVENTION OF HIVIAIDS TRANSMISSION IN THE SCHOOL SETTING:}

- Accurate information must be provided to learners, educators and parents. This should be followed up with counselling, if necessary. The situation should be resolved by the HIV/AIDS co-ordinator, the principal with the assistance by the governing body if necessary.

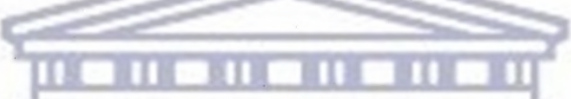

\section{PREVENTION OF HIVIAIDS DURING CONTACT SPORT:}

- An injured player that bleeds must be taken off the field and be treated with gloves. The player may resume play once the wound has been securely covered and soiled clothes changed. Learners and coaches with HIV should receive medical counselling before participating in contact sport.

\section{ISSUING OF CONDOMS:}

- Due to our belief in abstinence we will not issue condoms to learners.

\section{EDUCATORS AND OTHER STAFF:}

No staff in an educational setting may be:

- $\quad$ Tested for HIV without their consent.

- Tested for HIV as a prerequisite for appointment or continued service.

- Forced to disclose their HIV status.

- Dismissed or demoted because of their HIV status.

- Discriminated in any way because of their HIV status.

\section{CONTACTS FOR COUNSELLING:}

- Health services connected to the school. 
APPENDIX 13

NEWSPAPER CLIPPINGS \& PHOTOS OF CHECKMATING HIV/AIDS PROJECT
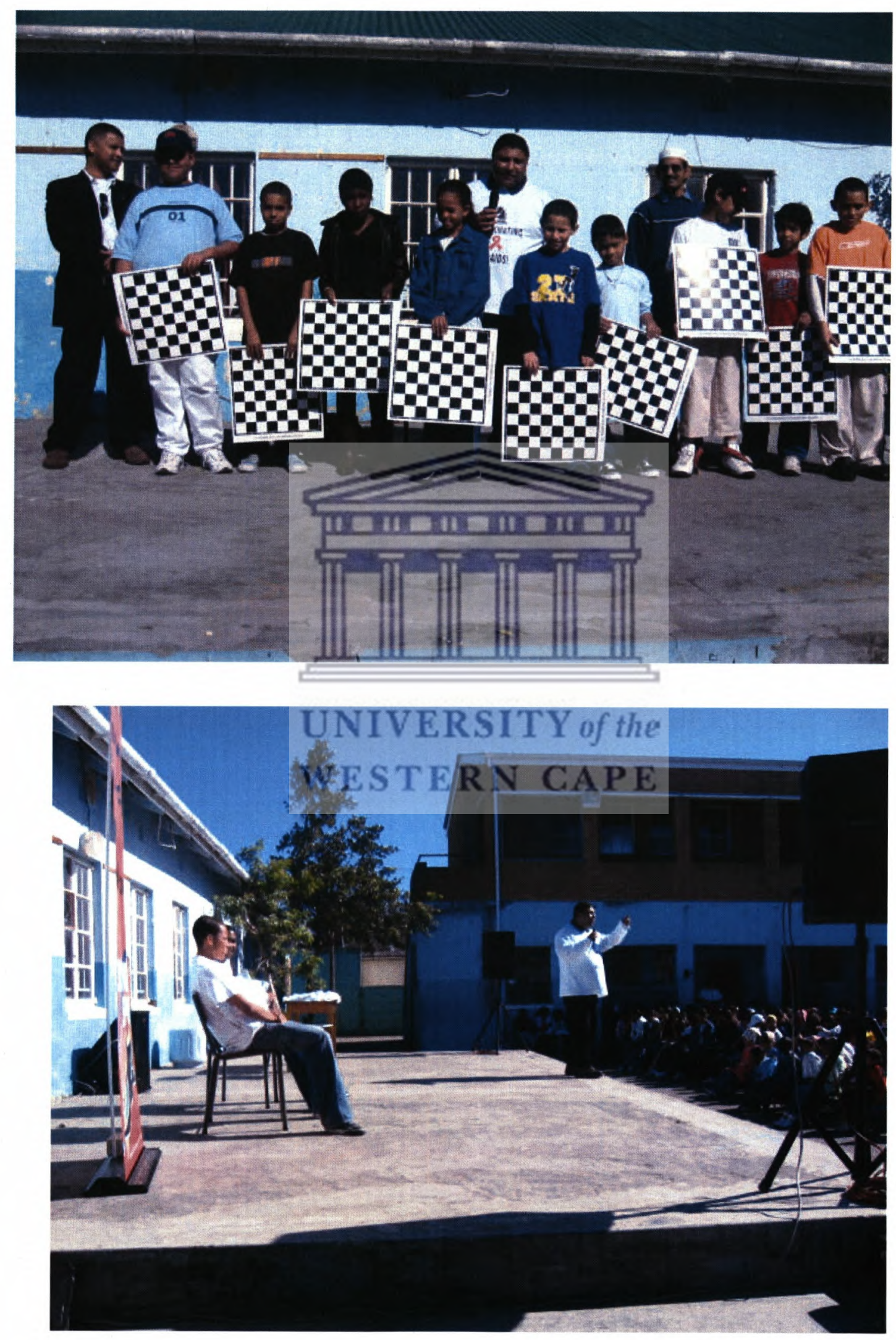

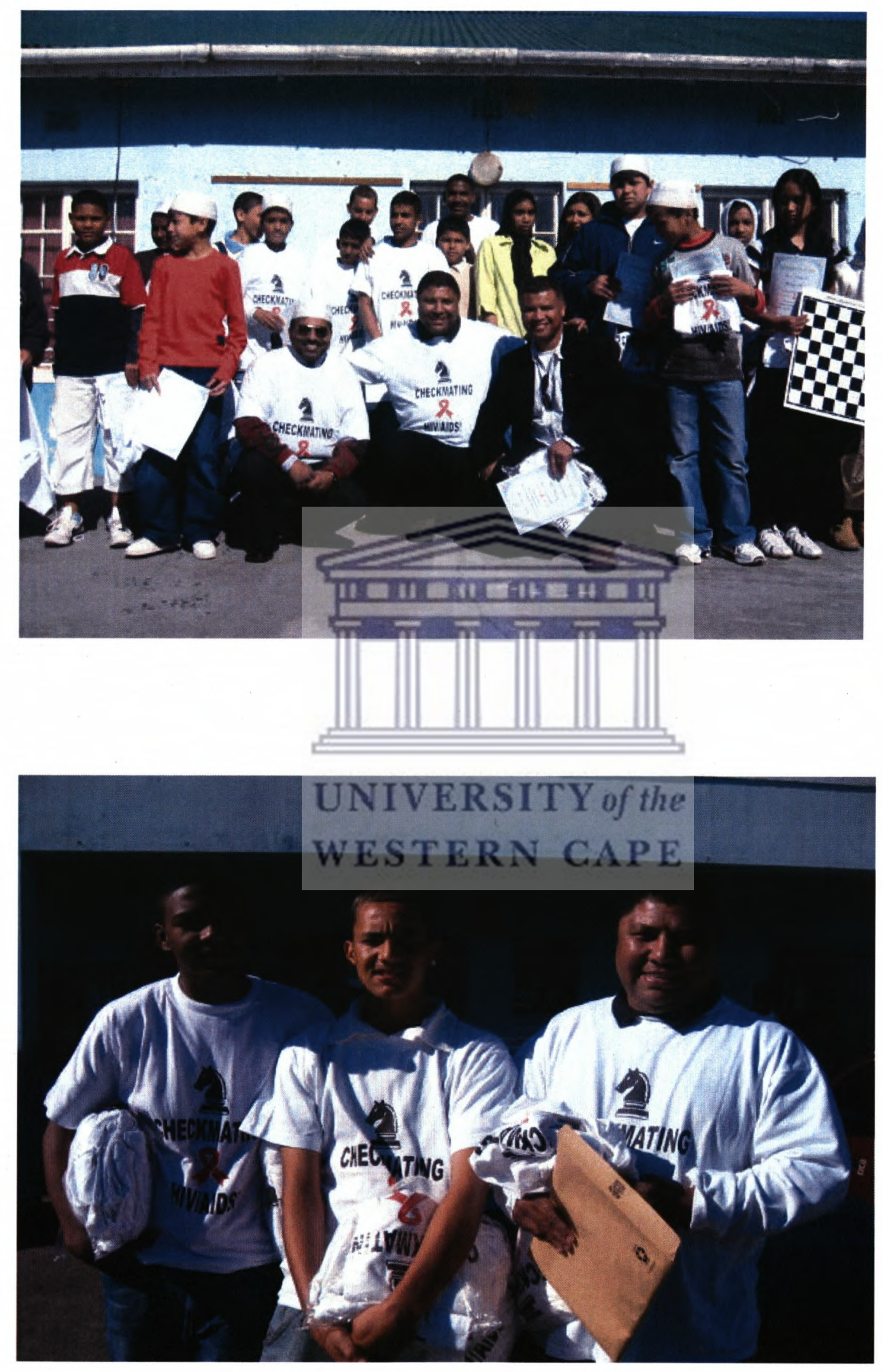


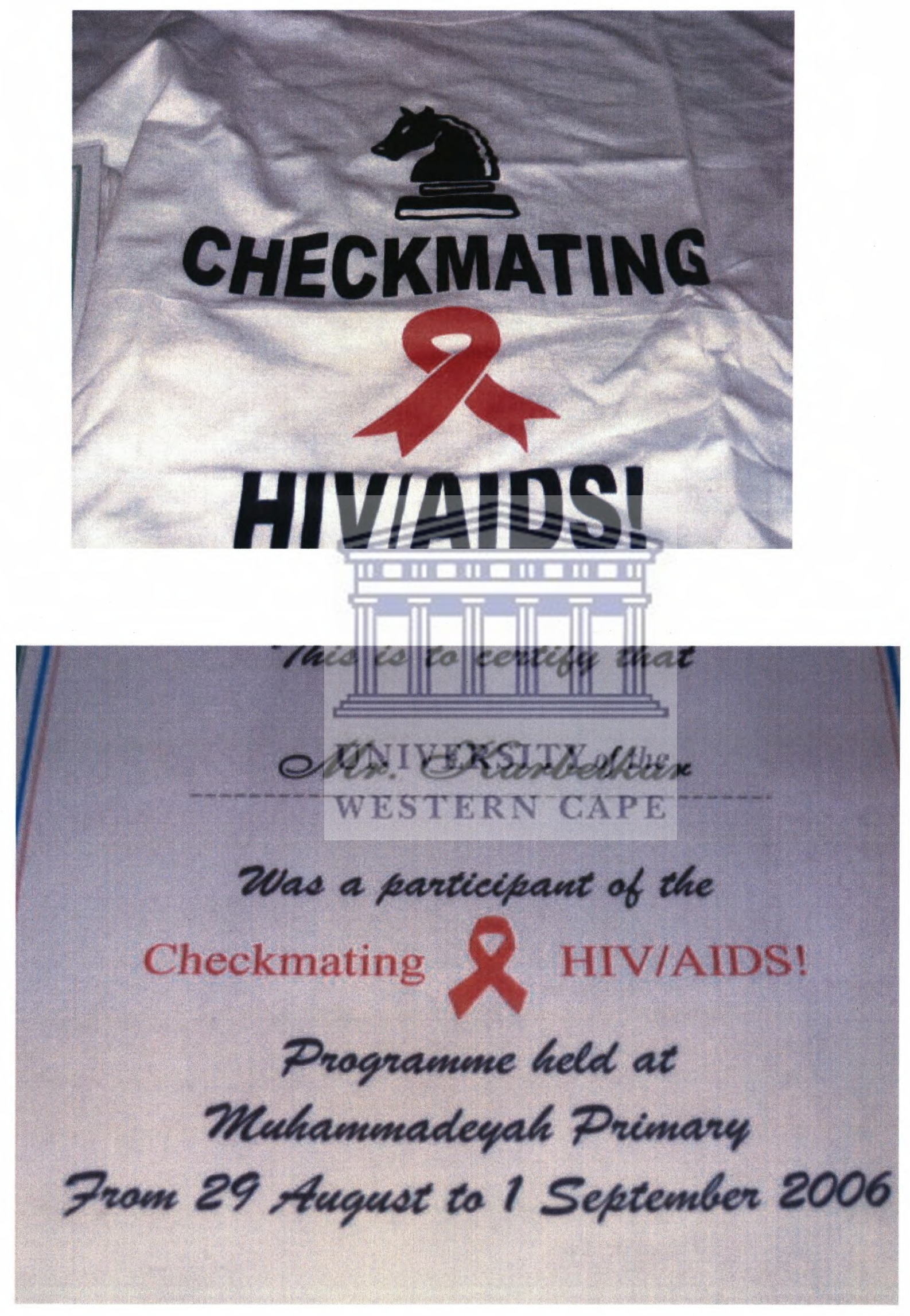




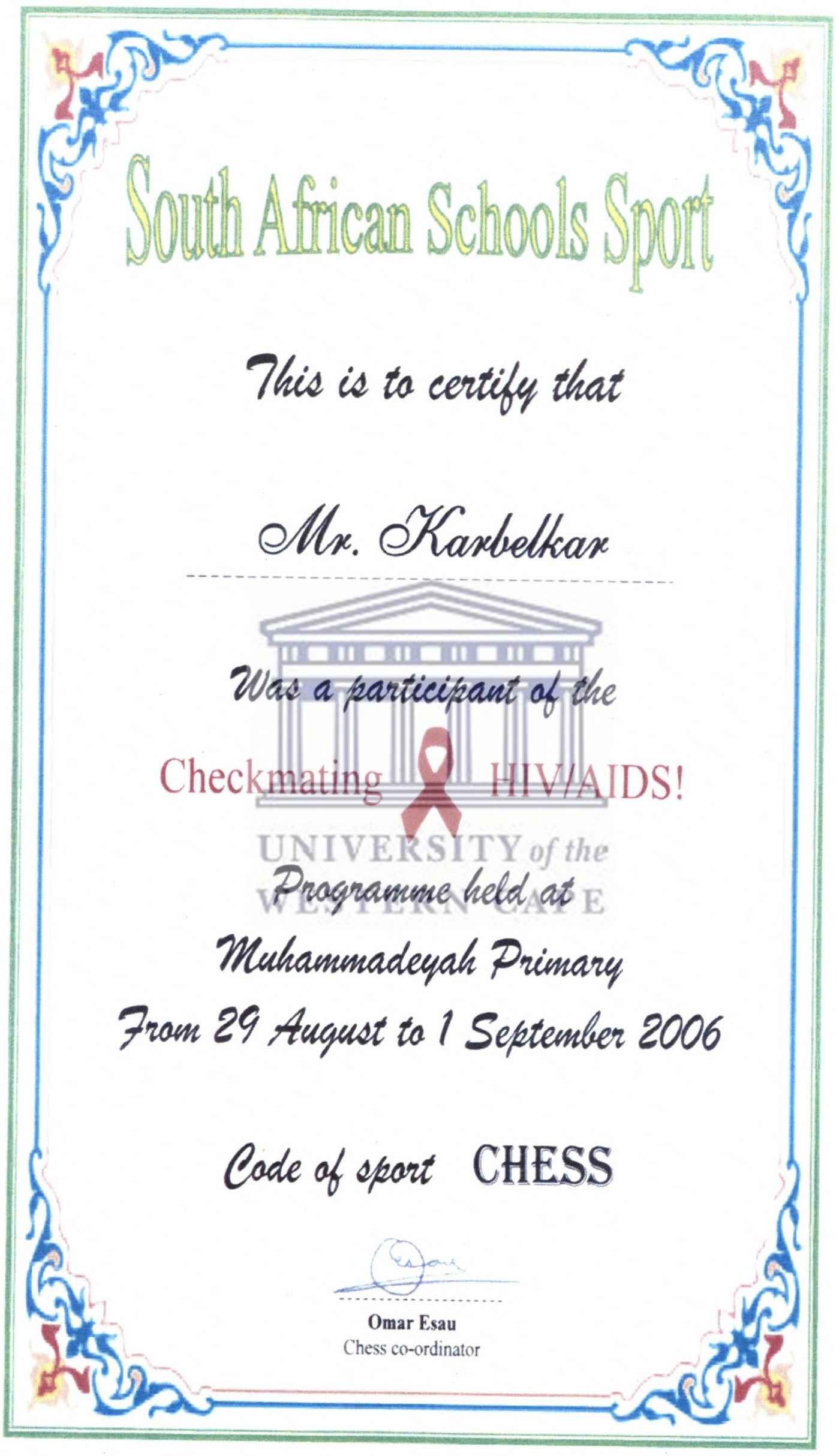




\section{Chess makes its move in Vrygrond}

Micix

Barnetr

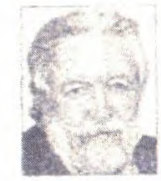

Cith

VRYGROND Librarv last Sat urday hosted its first chess tournament.

As part of a community efurt to encourage young people to advance their talents, Chess SA development officer Omar Esaut coached the enthu siastic players and also taught them the rrale of the game.

Esau was supported by Lil van Ryneveld. who not only contributed trophies for the winners. but also raised funds towards the estabhishment of an outdoor chess board and pieces.

The \#ryigrond Chess Competition was won by Sebastian Garcia. Sydwill Mjonono was runner-up in the open section, while Veronica Maryj won the giris' section.

Inder the gaidance of Eliz abeth Everson, the group of young adults knower as "Generation for Change" helped to organise a celebratory after. noon to acknowledge the progress made, and to give thanks for the contributions.

Chess WP is promoting chess as an activity under the slogan "Checkmating HIV. Aids" in order to encourage young people to think about their next move both on and of the chess boerd, and the consequences of making choices in life

- The Comamonwealth Champlonsbip which ended in

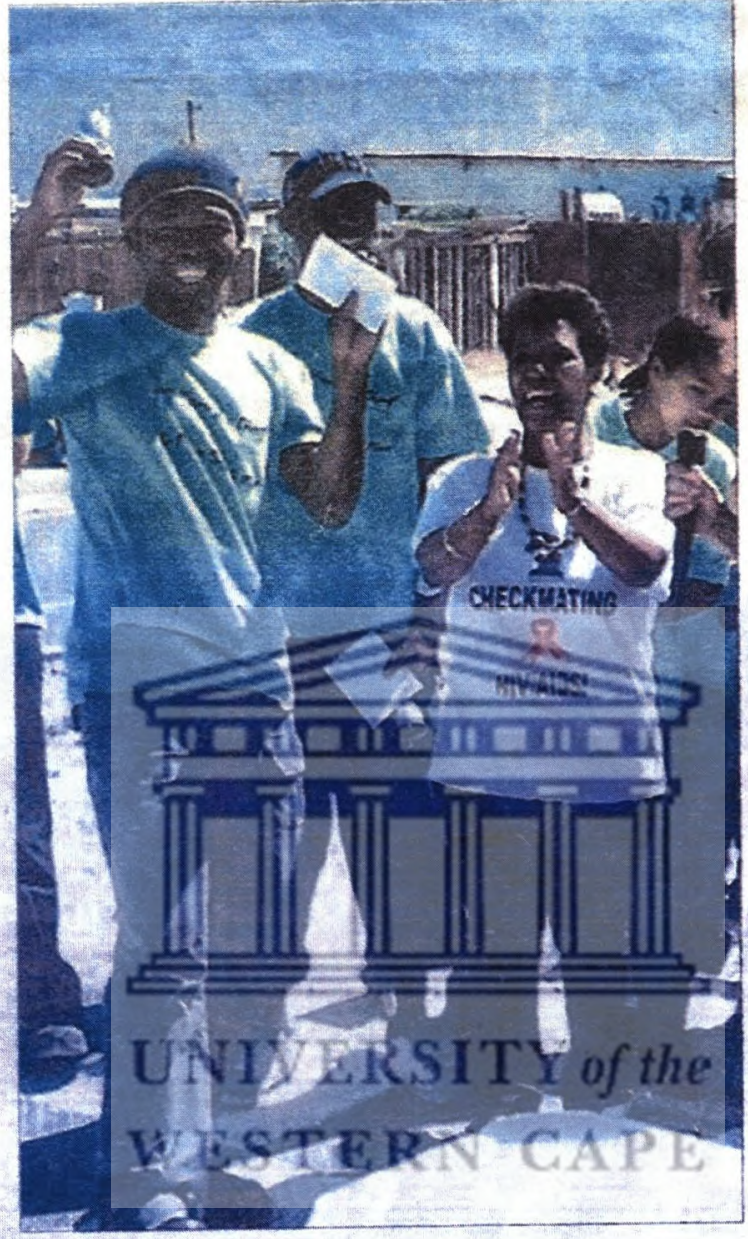

Celebrating his chess triumph is Sydwil Mjonono with, from left to right, Sebastian Garcia, Elzzabeth Everson and Lit van Ryneveld.

Mumbai on Wednesday was easily won by defending cham pion GM Nigel Short (Eng. land).

Short scored nine out of 10

but incal interest centred on and Melissa Greeff

Donovan finished on 5.5 and Melissa on 4.5-which earned a tournament performance of over 2000 and a medal.

the number of e-mails I received is anything to go by they had thousands of fans cheering them on

Melissa's mum, Janet, charmpioned the cause of South African chess, and it is now almost certain that the next Commonwealth Championship will be held in Cape Town in 2007.

- There was a sencation in the Man vs Machine duel Vladimir Kramnik vs Deep Fritz - being staged from November 25 until December 5 in the National Art Gallery in Bonn, Germany

After drawing in game one of the $\$ 500000$ match - when he missed a winning ending Kramnik ignored the machine's mate in one threat in machine's

Deep Fritz leads by two points to one after three games. If Kramnik beats the machine he will collect an additional $\$ 500000$.

The match, with a huge internet audience, is sponsored by the RAG $A G$, one of Europe's largest energy companies.

Kramnik played 1.... Bxc and after 2. Nxf8 sought to exchange queens into a winning ending 2... Qe3, but was shocked by 3 . Qh7 check mate.

E A double-round match between Helderberg Chess Club and Worcester Braille was held last weekend. The Worces ter Braille team won both $31 / 2-1 \frac{1}{2}$

Petor Micklem drew with Fredcrich Liebenberg but lost to Floris Brown; Louis Heyl lost to Stanley Knutzen and drew with Frederich Liebenberg. E Moses beat Heinrich Richte and Stanley $\mathrm{K}$ while Floris Brown beat E Moses twice. D Murray lost to Floris B The two Capetonian chess and Hein R. Piet Bok twice lost to Abey Conradie. 

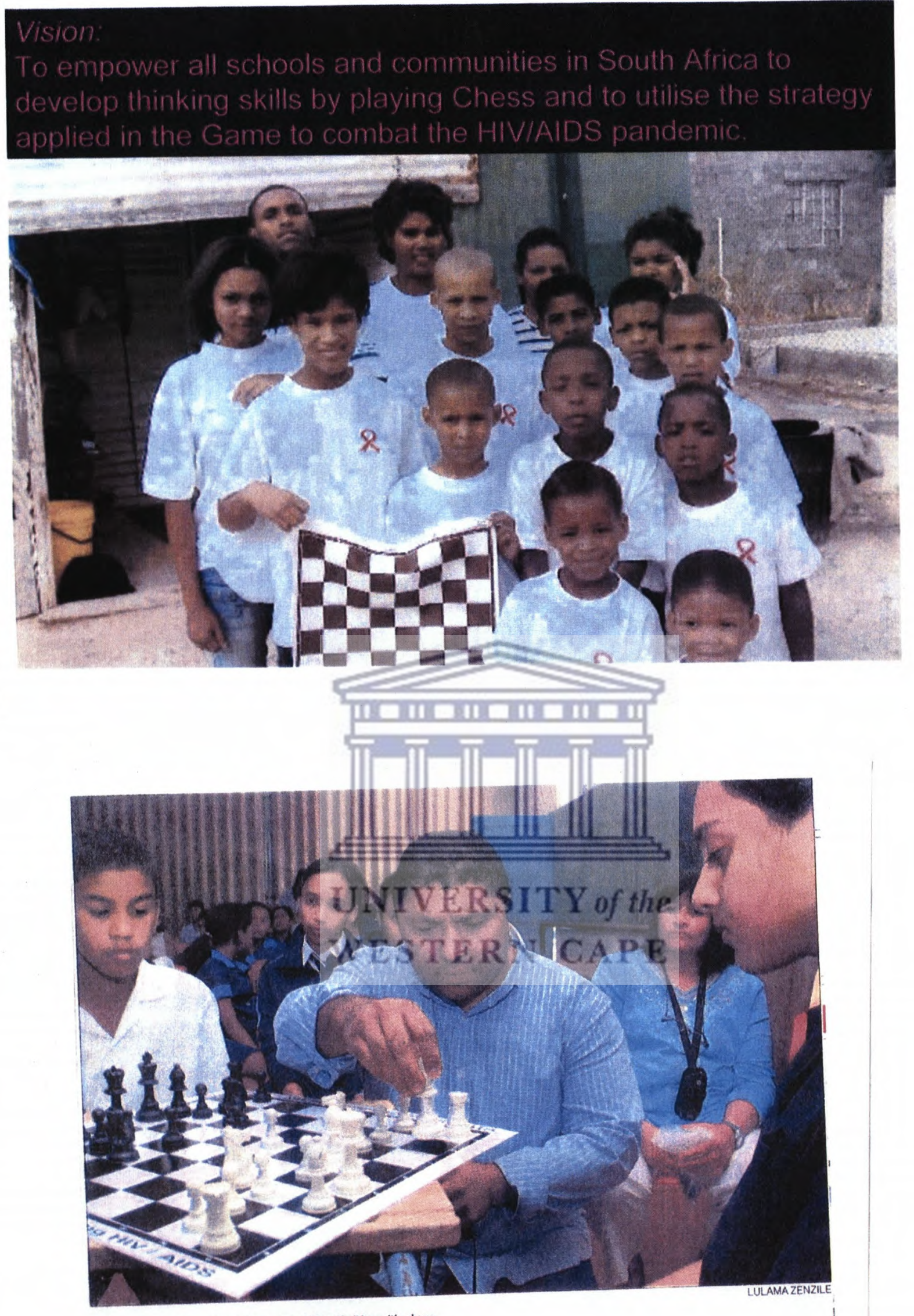

mar Esau shows Grant Davids and Zara Bell how it's done. 


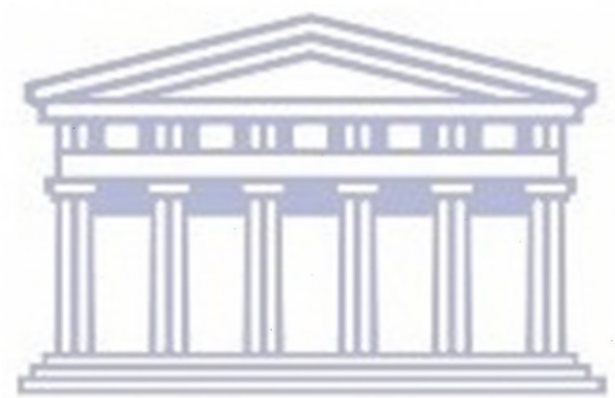

UNIVERSITY of the

WESTERN CAPE 


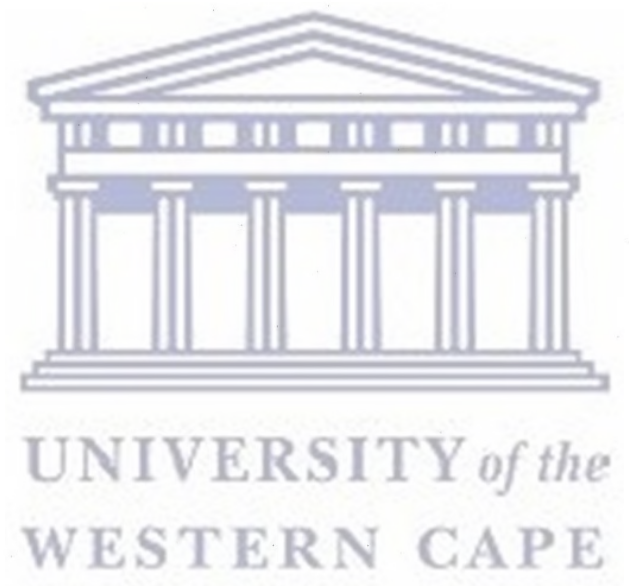

